\title{
EXPLORATORY STUDY OF BURN TIME, DUTY FACTOR, AND FLUENCE ON ITER ACTIVATION HAZARDS
}

\author{
Steven J. Piet
}

August, 1992

EGG-FSP-10396

Fusion Safety Program

IDAHO NATIONAL ENGINEERING LABORATORY

EG\&G IDAHO, INC.

IDAHO FALLS, IDAHO 83415

Prepared for the

U.S. Department of Energy, Office of Energy Research

Under DOE Idaho Field Office

Contract DE-AC07-76ID01570 


\section{TABLE OF CONTENTS}

ABSTRACT AND SUMMARY ..................... . . Page 3 ACKNOWLEDGMENTS . . . . . . . . . . . . . . . . . . Page 5

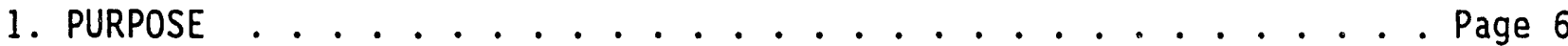

1.1 Parameters ................... . Page 7

1.2 ITER mission . . . . . . . . . . . . . . . . . Page 8

1.3 Consequence measures . . . . . . . . . . . . . Page 8

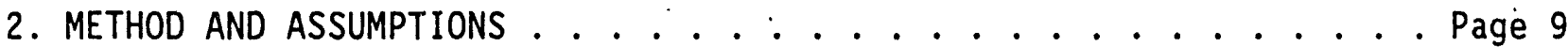

2.1 Key analytical equations ............ Page 9

2.2 Isotopes where parent/progeny assumption failed... . Page 10

3. IMPACT OF COMPOSITION ON VOLATILITY . . . . . . . . . . Page 11

4. RESULTS AND DISCUSSION . . . . . . . . . . . . . . Page 13

5. CONCLUSIONS ........................ Page 19

6. REFERENCES ................... . . . Page 22

APPENDIX A. EQUATIONS FOR CONTINUOUS AND PULSED IRRADIATION . . . . Page 23

APPENDIX B. APPROXIMATIONS . . . . . . . . . . . . . Page 25

APPENDIX C. STEEL DETAILS . . . . . . . . . . . . . . . Page 31

APPENDIX D. COPPER DETAILS . . . . . . . . . . . . Page 37

APPENDIX E. TUNGSTEN - FIRST WALL DETAILS . . . . . . . . . . Page 48

APPENDIX F. TUNGSTEN - DIVERTOR DETAILS . . . . . . . . . . Page 54

APPENDIX G. NIOBIUM - DIVERTOR DETAILS . . . . . . . . . . Page 64

DISTRIBUTION LIST . . . . . . . . . . . . . . . Page 70 


\section{ABSTRACT AND SUMMARY}

The safety analyses for the Conceptual Design Activity (CDA) of the International Thermonuclear Experimental Reactor (ITER) ${ }^{7}$ were based on the simplifying assumption that the activation of materials occurs continuously. Since the analyses showed a significant hazard, it is appropriate to examine how much hazard reduction might occur if this conservative assumption were relaxed. This report explores how much reduction might be gained by considering noncontinuous operation, that is, by considering plasma burn time, duty factor, and integrated fluence. Other factors impacting activation hazards - material choice, flux, and size - are not considered here.

The analysis combines analytical expressions with detailed activation calculations performed by $H$. Attaya (ANL) during the ITER Conceptual Design Activity (CDA) in 1989 and 1990. Attaya's activation calculations generally assumed $100 \%$ duty factor, that is, continuous irradiation. Pulsed operation allows some decay of isotopes between pulses. Reduction factors are defined as the ratio of the continuous activation hazard to the discontinuous hazard as a function of burn time, duty factor, and total integrated fluence, and consequence measure. I studied five cases: austenitic steel, tungsten, and copper as first wall/side wall materials, and tungsten and niobium as divertor materials.

These analyses assume $1.0 \mathrm{MW} / \mathrm{m}^{2}$ and $800 \mathrm{~m}^{2}$ area for first wall and $0.4 \mathrm{MW} / \mathrm{m}^{2}$ and $200 \mathrm{~m}^{2}$ for divertor; the reduction factors are not sensitive to these values.

Several issues exist when quantifying activation hazards, including dose from mobilized activation products, decay heat, and waste disposal. I performed all dose calculations, consisient with the CDA. The two major mechanisms for mobilizing activation products are tokamak erosion dust and volatility in high temperature air and steam transients. The contribution of isotopes to total mobilized hazard is stoichiometric for dust but varies for air/steam volatility by temperature, gas, and alloy composition. Thus, we must consider which chemical elements' isotopes dominate particular hazards for each material. The two major consequence measures are specific early public dose $(\mathrm{mSv} / \mathrm{kg})$ and specific activity ( $\mathrm{Ci} / \mathrm{cc}$ ). For dose (mSv/kg), I identified which elements' isotopes dominate either tokamak dust or air/steam volatility.

One key parameter is the length of test campaigns, pulses linked together for some test, especially technology tests. For present purposes, a high duty factor campaign of pulses is effectively a single longer pulse. For example, a 2 -week near-continuous ( $>90 \%$ ?) test campaign is effectively one pulse. The effective burn time is defined as the larger of the actual burn time or the duration of near-continuous test campaign.

For safety hazards, the most important parameters are effective burn time and duty factor; lower fluence gains little since shorter-lived isotopes dominate. (Lower fluence does reduce buildup of long-lived isotopes for waste disposal, but the volume and qualitative problems for ITER do not change.) Considering effective burn times (test campaigns) of 1-14 days and $20-30 \%$ duty factors, the reduction factors for specific dose vary from 1.2 to 4.4 . For individual elements, the reduction factor goes as high as 14 . 
If the ITER mission is reduced to only physics, then the effective burn time, fluence, and duty factor would presumably be lowered. Then, the reduction factors for specific dose vary from 4.5 to 7.1 , increasing for some individual elements.

Probabilistic risk reduction would combine these consequence factors with frequency reduction, (duty factor) ${ }^{-1}$, for that portion of total risk arising from tokamak operation instead of shut down periods and maintenance. These reduction factors would be offset by increases in size and neutron flux.

To take credit for these factors in formal ITER safety assessments, detailed activation calculations would be required. The approximations here are sufficient to indicate the magnitude of the effect, but not sufficient for formal, quantitative safety assessments. Also, the maximum allowable operational parameters (burn time, duty factor, integrated fluence) would have to be established and made part of the "safety basis" regulatory case.

Finally, note that this report does not include the impact of any increases in size, wall loading, or total fusion power as are being currently discussed within the ITEP community. Those changes would increase activation inventories. 


\section{ACKNOWLEDGMENTS}

I especially thank $H$. Attaya (ANL) for his calculations during the CDA and, in particular, for sharing with me the raw activation results. I have no good reference for these in this report, instead the interested reader should either contact $H$. Attaya directly or the various ITER CDA reports. I appreciate his taking the time to review a draft of this report.

Also, I thank INEL Fusion Safety Program co-workers, Steve Herring, Kathy McCarthy, and Doug Holland for reviewing the manuscript. 


\section{EXPLORATORY STUDY OF BURN TIME, DUTY FACTOR, AND FLUENCE ON ITER ACTIVATION HAZARDS}

\section{PURPOSE}

The safety analyses for the ITER CDA $^{1}$ were based on the simplifying assumption that the activation of materials occurs continuously. Since the analyses show a significant hazard, it is appropriate to examine how much hazard reduction might occur if this conservative assumption were relaxed. Since much of ITER operation will be pulsed, there will be time for some decay of activation products between pulses. This report explores how much reduction might be gained by considering non-continuous operation, that is, by considering plasma burn time, duty factor, and integrated fluence.

The report is not meant to be fully rigorous. Indeed, some neutronics experts are working on more detailed, rigorous treatments. Such a rigorous treatment would be required for actual ITER safety assessments. That would require combining detailed, exact activation calculations with formally restricting ITER operation parameters: Instead, here the intent is to scope out how much reduction in activation hazards might ensue from such a detailed assessment. I combined analytical expressions and H. Attaya calculations for the ITER CDA, see Sec. 2. The key simplifying assumptions are that single parent isotopes produce only single radioactive progeny and (for a given case) the pulse length and duty factor are constant over the machine lifetime. These assumptions are adequate for the present scoping purpose. The single parent/progeny assumption fails for many key isotopes but that is where I make use of Attaya's CDA activation calculations. More specifically, the assumption typically holds for isotopes produced by 1 -step reactions, like $(n, 2 n)$ and $(n, \gamma)$. It does not hold for isotopes produced by multi-step reactions, but these are generally unimportant to accident safety analyses. (They are more likely important for waste management evaluations.)

Because of the availability of activation calculations and the potential interest for ITER, I studied five material cases:

- Austenitic steel, at first wall, $1.0 \mathrm{MW} / \mathrm{m}^{2}$ flux

- Copper, at first wall (or side wajl) for plasma stabilization, $1.0 \mathrm{MW} / \mathrm{m}^{2}$

- Tungsten, at first wall, $1.0 \mathrm{MW} / \mathrm{m}^{2}$

- $\quad$ Tungsten, at divertor, $0.4 \mathrm{MW} / \mathrm{m}^{2}$

- Niobium, at divertor (candidate substrate), $0.4 \mathrm{MW} / \mathrm{m}^{2}$

The copper and tungsten were initially pure before irradiation. The compositions for the steel and niobium alloy are given in Appendix $C$ and Appendix $G$. There were no ITER activation calculations for other candidate materials like molybdenum as a divertor substrate. In principle, other materials could show varying results. However, the present results show relatively little variation among these cases, so there is little reason to think there would be major differences.

The rest of this Section describes the key parameters impacting activation hazards, the ITER mission, and measures of consequence. Following Sections describe the method ( $\mathrm{Sec} .2$ ), how alloy composition impacts hazards ( $\mathrm{Sec} .3$ ), 
results (Sec. 4), conclusions (Sec. 5), and references (Sec. 6). Appendices A through $G$ contain details.

\subsection{Parameters}

The study considers three of the parameters that impact activation hazards - plasma burn time, duty factor, and integrated fluence - described below. Other factors are not considered. They include the following

- size; volume impacts waste problems and total decay heat; plasma surface area impacts accident mobilization

- neutron flux

- material choice

- whether or not breeding occurs. In the CDA, about $90 \%$ of the neutrons make tritium. If breeding is eliminated, those neutrons will go somewhere else. If that "somewhere" is absorption by steels or the materials considered here, the decay heat and activation inventory will increase roughly an order of magnitude.

In particular, increases in neutron flux and surface area will increase hazards compared to the CDA values.

Here, I consider the effective plasma burn time rather than the actual physics burn time. From a plasma physics standpoint, the burn time is the actual time during a pulse that a plasma is burning. For a machine used for various tests, pulses would be grouped into test campaigns. I define a test campaign as a group of pulses with the same burn time and dwell time, such that the duty factor is high. Especially for technology tests, the duty factor during a test campaign would have to be high, perhaps $90 \%$. Thus, during the test campaign, there would be little time for isotope decay. Then, the effective plasma burn time is the test campaign duration. Possible burn times in this study therefore range from isolated $100-s$ pulses up to 2 -week test campaigns for blanket test modules per the CDA. ${ }^{2}$

The duty factor is defined as the burn time divided by the sum of burn time and dwell time. During a test campaign, the duty factor would be high, as noted above. We care about the duty factor between isolated pulses or campaigns. The CDA goal was up to $25 \%$. Here, I consider a range of $10-30 \%$.

For a given case, the burn time and duty factor are kept constant throughout the ITER lifetime. Thus, for example, the "physics" mission cases do not refer to only a portion of the ITER lifetime. Rather, the physics mission cases mean that those burn time and duty factor values are kept constant over the entire machine life. Thus, the number of pulses is more than the number in the limited 0.05-year fluence of the ITER CDA physics phase.

The integrated fluence primarily cintrols the buildup of long-lived isotopes. The CDA goal was up to $3.0 \mathrm{MW}-\mathrm{yr} / \mathrm{m}^{2}$, from about $1 \mathrm{MW} / \mathrm{m}^{2}$ fiux for 3 years. Here, I consider a range of 0.1 to $3.0 \mathrm{MW}-\mathrm{yr} / \mathrm{m}^{2}$ for the first wall, up to only $1.0 \mathrm{MW}-\mathrm{yr} / \mathrm{m}^{2}$ for the divertor. I. used CDA analyses (scaled if needed) to a first wall flux of $1.0 \mathrm{MW} / \mathrm{m}^{2}$ and divertor flux of $0.4 \mathrm{MW} / \mathrm{m}^{2}$. The integrated burn time therefore ranges from 0.1 to 3.0 years for the first wall, up to only 1 year for the divertor. 
There are other parameters I used; these do not impact the calculated reduction factors only the absolute values in the calculations in the Appendices. These are all consistent with the CDA. The neutron flux is kept constant at $1.0 \mathrm{MW} / \mathrm{m}^{2}$ for the first wall and $0.4 \mathrm{MW} / \mathrm{m}^{2}$ for the divertor. The wall surface areas are $800 \mathrm{~m}^{2}$ for the first wall and $200 \mathrm{~m}^{2}$ for the divertor.

\subsection{ITER mission}

To simplify the analyses, I considered discrete combinations of parameters roughly according to the ITER mission, see Table 1. The first case, "sub-mininum physics," corresponds to early physics operation and would not be adequate for most of the ITER 7 ifetime; it represents an extreme case with maximum reduction factors. The next two cases "minimum physics" and "maximum physics" are meant to reflect the types of parameters mentioned currently the physics mission of ITER. The next two cases "minimum technology" and "maximum technology" reflect the range of parameters to implement the technology mission. The final case is simply the CDA case of continuous operation.

\section{Table 1. ITER MISSION PARAMETERS ASSUMED IN THIS STUDY}

\begin{tabular}{||l||c|c|c|c|c|c||}
\hline Parameter & $\begin{array}{l}\text { Sub-minimum } \\
\text { physics }\end{array}$ & $\begin{array}{l}\text { Minimum } \\
\text { physics }\end{array}$ & $\begin{array}{l}\text { Maximum } \\
\text { physics }\end{array}$ & $\begin{array}{l}\text { Minimum } \\
\text { technology }\end{array}$ & $\begin{array}{l}\text { Maximum } \\
\text { technology }\end{array}$ & $\begin{array}{l}\text { CDA } \\
\text { Analyses }\end{array}$ \\
\hline \hline Burn time & $100 \mathrm{~s}$ & $1000 \mathrm{~s}$ & 1 hour & 1 day & 2 weeks & \\
\hline Duty factor & $10 \%$ & $20 \%$ & $20 \%$ & $20 \%$ & $30 \%$ & $100 \%$ \\
\hline Fluence (yr) & 0.1 & 0.3 & 0.7 & 1.0 & $3.0^{\mathrm{a}}$ & $3.0^{\mathrm{a}}$ \\
\hline Number of pulses & 31600 & 9500 & 6100 & 365 & 78 & 1 \\
\hline Calendar time $(y \mathrm{r})$ & 1.0 & 1.5 & 3.5 & 5.0 & 10.0 & 3.0 \\
\hline \hline
\end{tabular}

\subsection{Consequence measures}

There is no single unique way to quantify activation hazards. Issues include dose from mobilized activation products, decay heat, and waste disposal. The two major mechanisms for mobilizing activation products are tokamak erosion dust and volatility in high temperature air and steam transients. The contribution of isotopes to total mobilized hazard is stoichiometric for dust but varies for air/steam volatility by temperature, gas, and alloy composition. Thus, we must consider which chemical element's isotopes dominate particular hazards for each material. Here, the two primary consequence measures are specific early dose to the public (mSv/ kg) and specific activity $(\mathrm{Ci} / \mathrm{cc})$. For early dose $(\mathrm{mSv} / \mathrm{kg})$, I identified which elements' isotopes dominate either tokamak dust or air/steam volatility.

"Dose" means the early dose to the maximum exposed individual of the public. I used the dose factors, $D F_{i}$, for individual isotopes that were used in the CDA safety analyses. These factors (mSV/ $\mathrm{C}$-released) implicitly assume that all isotopes accidentally mobilized are in fact released to the environment. 
Release assumptions include $1-\mathrm{km}$ site boundary, class $F$ atmospheric stability, $1-\mathrm{m} / \mathrm{s}$ wind speed, 7-days exposure, and no ingestion.

The specific dose $(\mathrm{mSv} / \mathrm{kg}$ ) for isotopes of a given element is given by

$$
I_{i}=\sum_{j=\text { isotopes }} \frac{D F_{j} A_{j, i} 10^{6}}{\rho}
$$

where

$$
\begin{aligned}
& I_{j_{1}}=\text { specific dose }(\mathrm{mSv} / \mathrm{kg}) \text { of } i \text { sotopes of the } i^{\text {th }} \text { element } \\
& D_{j}=\text { dose factor }(\mathrm{mSv} / \mathrm{C} i) \text { of the } j^{\text {th }} \text { isotope } \\
& A_{j, i}=\text { activity }(\mathrm{C} / \mathrm{cc}) \text { of the } j^{\text {th }} \text { isotope of the } i^{\text {th }} \text { element } \\
& \rho^{\prime}=\text { alloy density }\left(\mathrm{kg} / \mathrm{m}^{3}\right) \\
& 10^{6}=\text { correction for } \mathrm{cc} / \mathrm{m}^{3} .
\end{aligned}
$$

I al so report the reduction factors for specific activity $(\mathrm{Ci} / \mathrm{CC}$ ) for their relevance to waste disposal and as a clue to decay heat.

\section{METHOD AND ASSUMPTIONS}

As noted in Sec. 1, the intent is to scope the magnitude of the possible credit from considering isotope decay in-between pulses. Thus, exact calculations were not warranted nor needed. Instead, I combined simple analytical expressions with ITER CDA activation calculations by $H$. Attaya (ANL).

The analytical expressions (see Appendix $A$ and below) are based on a key assumption that single parent isotopes produce single radioactive progeny isotopes. Also, burn time and duty factor are constant throughout the ITER lifetime.

The parent/progeny assumption will generally fail for isotopes produced by multiple-step reaction chains. However, such isotopes generally do not dominate accident safety concerns. For each material, I compared the analytical expressions with regard to fluence with Attaya's calculation, see Sec. 2.2. (see Appendix $B$ and Appendices $C$ through $G$ for specific materials). For the present materials and purposes, the major isotope where the parent/progeny assumption fails is Re-186, which is produced by 2 -step reactions from tungsten isotopes. See below.

The interested reader can consult more exact treatments. ${ }^{3,4}$ In particular, the approach by Attaya, et al., ${ }^{3}$ is similar to that here.

\subsection{Key analytical equations}

With the assumptions, the total inventory of a progeny isotopes at the end of $n$ uniform pulses is given by 


$$
N(t)=\frac{C}{\lambda}\left(1-e^{-\lambda t_{b}}\right) \sum_{i=1}^{n} e^{-\lambda(n-i) t_{b} / d}
$$

where

$$
\begin{array}{ll}
N(t) & =\text { inventory of progeny at time } t \\
C & =\text { constant including flux and parent-progeny cross section } \\
\lambda & =\text { progeny decay constant } \\
t_{b} & =\text { effective burn time } \\
d & =\text { duty factor }
\end{array}
$$

For continuous operation (only one pulse), this simplifies appropriately to

$$
N(t)=\frac{C}{\lambda}\left(1-e^{-\lambda t_{b}}\right)
$$

For very short-lived isotopes $\left(T_{1 / 2} \ll t_{b}\right)$, Eqn. (2) simplifies to

$$
N=\frac{c}{\lambda}(1-0)(0+0+\ldots+1)=\frac{C}{\lambda}
$$

which is independent of $d, t_{b}, n$, or $T$ (fluence). ( $T$ is simply $t_{b}$ times $n$.) That is, very short-lived isotopes build to their saturation value, $c / \lambda$, each pulse.

For very long-lived isotopes $\left(T_{1 / 2} \gg t_{b} n=T\right)$, Eqn. (2) simplifies to

$$
\left.N=\frac{C}{\lambda}\left(\lambda t_{b}\right) \text { (n terms of } 1\right)=C\left(t_{b} n\right)=C \text { (fluence) }=C T
$$

which is independent of $d$. That is, very long-lived isotopes build to a value only depending on integrated fluence.

The ratio of the inventory of a progeny isotope for pulsed versus continuous comes is the ratio of eqn. (2) to eqn. (3).

$$
\text { Ratio }=\frac{\left(1-e^{-\lambda t_{b}}\right)}{\left(1-e^{-\lambda T}\right)} \sum_{i=1}^{n} e^{-\lambda(n-i) t_{b} / d}
$$

The constant, C, drops out. For very long or very short-lived isotopes, the ratio goes to 1 .

\subsection{Isotopes where parent/progeny assumption failed}

As expected when using such a simplifying assumption, the parent/progeny assumption fails for several important isotopes. Remember that we really do not 
care about individual isotopes per se, but rather only for the dose for $_{i}$ all isotopes from a given element. Even then, that element may or may not be an important contributor to the total dose from that alloy class. For each material studied, I compared the analytical expressions with regard to fluence with Attaya's calculation; see Appendices C through $G$ for specific materials. Perhaps surprisingly, the assumption worked well for steel and niobium and fairly well for key copper isotopes. The assumption fails for tungsten, since the key isotope, Re-186, is produced by several steps along two different pathways.

Normally, when the assumption works, the method is to use eqns. (2), (3), and $(6)$ and the CDA/Attaya values ${ }^{1,3}$ for the activation inventory at the maximum fluence values. Attaya's raw activation results provide values at some intermediate fluences. This allowed a partial check of eqn. (2) with regard to fluence, a key variable regarding the parent/progeny assumption.

I developed an approximate method to adjust for those important cases where the parent/progeny assumption failed. Instead of using the maximum-CDA fluence inventory values, I used whatever intermediate fluence value from Attaya's CDA calculation was the closest. In such cases, I was no longer adjusting for fluence with eqn. (2) but only burn time and duty factor, thereby reducing the potential for error arising from the parent/progeny assumption.

When calculating the dose from air or steam volatility, more than the activation inventory is needed. One al so needs the irradiated composition, which itself changes with time. This complication is described in the next Section.

\section{IMPACT OF COMPOSITION ON VOLATILITY}

When calculating specific activity $(\mathrm{Ci} / \mathrm{cc}$ ) or specific dose (mSv/ $\mathrm{kg}$ ), one uses the activation results directly. Any activation calculation is based on a specific initial unirradiated composition. The irradiated composition is calculated automatically. Subtleties arise when going further and calculating the volatility.

Volatility means release of chemical species from hot walls in an oxidizing environment. The basic scenario involves a combination of abnormally hot walls (such as ciuring a loss of coolant) and air or steam in the plasma chamber. This causes rapid oxidation; some species are volatile. The INEL Fusion Safety Program has an experimental program $5,6,7$ to measure this volatility.

The mobilized, volatilized mass of each element is given by

$$
m_{i}=\Gamma_{i} \text { a } t
$$

where

$$
\begin{aligned}
& m_{i}=\text { mass }(g) \text { of the } i^{\text {th }} \text { element in the allo, } \\
& \Gamma_{i}=\text { volatility flux }\left(\mathrm{g} / \mathrm{m}^{2}-\mathrm{hr}\right) \text { of the } i^{\text {th }} \text { element in the alloy } \\
& a=\operatorname{area}\left(\mathrm{m}^{2}\right) \\
& t=\text { time }(h r) \text {. }
\end{aligned}
$$

Page 11 
Then the mobilized dose (mSv) for isotopes of a given element is given by

$$
\text { Dose }_{i}=\frac{I_{i} m_{i}}{10^{3} c_{i}}=\frac{I_{i} \Gamma_{i} a t}{10^{3} c_{i}}
$$

where

$$
\begin{aligned}
& c_{i}=\text { composition (weight \%) of the } i^{\text {th }} \text { element in the alloy } \\
& 10^{3}=\text { correction for } \mathrm{g} / \mathrm{kg} .
\end{aligned}
$$

Alternatively, eqn. (8) can be written as

$$
\text { Dose }_{\mathrm{i}}=I_{\mathrm{i}} R F_{\mathrm{i}} \text { (alloy mass) }=I_{\mathrm{i}} R F_{\mathrm{i}} \rho \delta \text { a }
$$

where

$$
\begin{aligned}
\mathrm{RF}_{i} & =\text { release fraction of the } i^{\text {th }} \text { element from the alloy } \\
& =\text { wall thickness }(\mathrm{m}) .
\end{aligned}
$$

Thus, RF is given by

$$
R F_{i}=\frac{m_{i}}{(\text { mass present })_{i}}=\frac{\Gamma_{i} a t}{10^{3} c_{i} \rho a \delta}=\frac{\Gamma_{i} t}{10^{3} c_{i} \rho \delta}
$$

The spreadsheets appearing in the Appendices follow eqn. (9) and (10). Whether given by eqn. (8) or eqn. (9), the dose varies as $\Gamma_{i} / c_{i}$. The complication arises from the fact that there are values of $\Gamma$ for only specific test sample compositions (only one scoping test series for each alloy class). The volatility flux, $\Gamma$, likely varies with composition as follows:

$$
\Gamma_{i}=\Gamma_{i, 0}\left(\frac{c_{i}}{c_{i, 0}}\right)^{D}
$$

where

$\Gamma_{i, 0}=$ volatility $\left(\mathrm{g} / \mathrm{m}^{2}-\mathrm{hr}\right)$ measured in test using sample with $c_{i, 0}$

$c_{i, 0}=$ composition (weight $\%$ ) of the $i^{\text {th }}$ element in the sample

$D_{i}, 0$ composition scaling exponent for the $i^{\text {th }}$ element.

The $D_{i}$ are believed to fall in the range 0 to 1.5 If volatility follows behavior for a dilute solution of an element in the alloy, $D=1$ would be expected. If volatility saturates as composition increases, $D=0$ would be expected.

Thus, the dose or release fraction scales as $\Gamma_{i} / c_{i}$ or $c_{i}^{D-1}$. For a dilute solution $(D=1)$, the dose and release fraction are independent of the changing composition, although the volatility flux does change. For saturated conditions $(D=0)$, the dose and release fraction vary inversely with $c_{i}$ and the volatility flux is constant. 
To really know how the air or steam volatility dose varies with burn time, duty factor, and fluence, we therefore need to know

- activation, $A_{i}$, of each isotope over time $\left(t_{b}, d, T\right)$

- composition, $c_{i}$, of each element over time $\left(t_{b}, d, T\right)$

- composition exponent, $D_{i}$, of each element

Given the present lack of knowledge of the third and the difficulties of the first two, this problem was deemed generally outside the scope of this exploratory study. The potential reduction factors were studied by three methods.

1. For all five cases, I separately calculated the reduction factors for the specific activity $(\mathrm{mSv} / \mathrm{kg})$ for the isotopes of the dominant chemical elements. See Sec. 4.

2. For several cases (See Appendices), I calculated the air and/or steam volati?ity as a function of fluence only, using Attaya's activation and composition results, ignoring my analytica? expressions. In some instances I did this two ways - (a) fixing the release fractions at the CDA values and (b) using best guesses for composition exponents. This provided additional evidence for which chemical elements actually would dominate in each case.

3. For some cases (See Appendices), I attempted to calcuiate the actual reduction factors for various ITER "missions" in spite of the uncertainties.

\section{RESULTS AND DISCUSSION}

At the level of specific isotopes, the key numerical result is the ratio of the inventory for the pulsed case versus inventory for continuous irradiation. One can calculate the ratio in eqn. (6) two different ways, with the reference fluence either kept the same (pulsed or continuous) or fixed at the CDA value of 3.0 years. The results as a function of halflife are shown in Figures 1 and 2 .

As noted in Sec. 2, the ratio is 1.0 for very short-1ived isotopes, they always reach saturation during each pulse. For short-lived isotopes, the baseline fluence is not relevant, thus the left-hand portions of Figures 1 and 2 are the same. In this regime, the main issue is how much inventory builds up during each pulse.

At intermediate halflife, the ratio approaches (duty factor) ${ }^{-1}$. From the isotope's point of view, it is seeing an effective neutron flux of (duty factor) ${ }^{-1}$, that is, the neutron flux is effectively diluted by the amount of time the plasma is off.

At longer halflife, Figures 1 and 2 diverge, since the total fluence become important. In Figure I (total fluence kept constant), the ratios for very longlived isotopes approach 1 . That is, for the same constant fluence, it does not matter if the plasma is off part of the time because there is insufficient time for isotopes to decay. In Figure 2 (baseline fluence fixed at CDA value of 3.0), the ratios for very long-lived isotopes approach the ratio of the fluence for that "ITER mission" divided by 3.0. For example, for the "minimum technology" mission with 1.0-yr fluence, the ratio approaches $1.0 / 3.0=0.33$. 


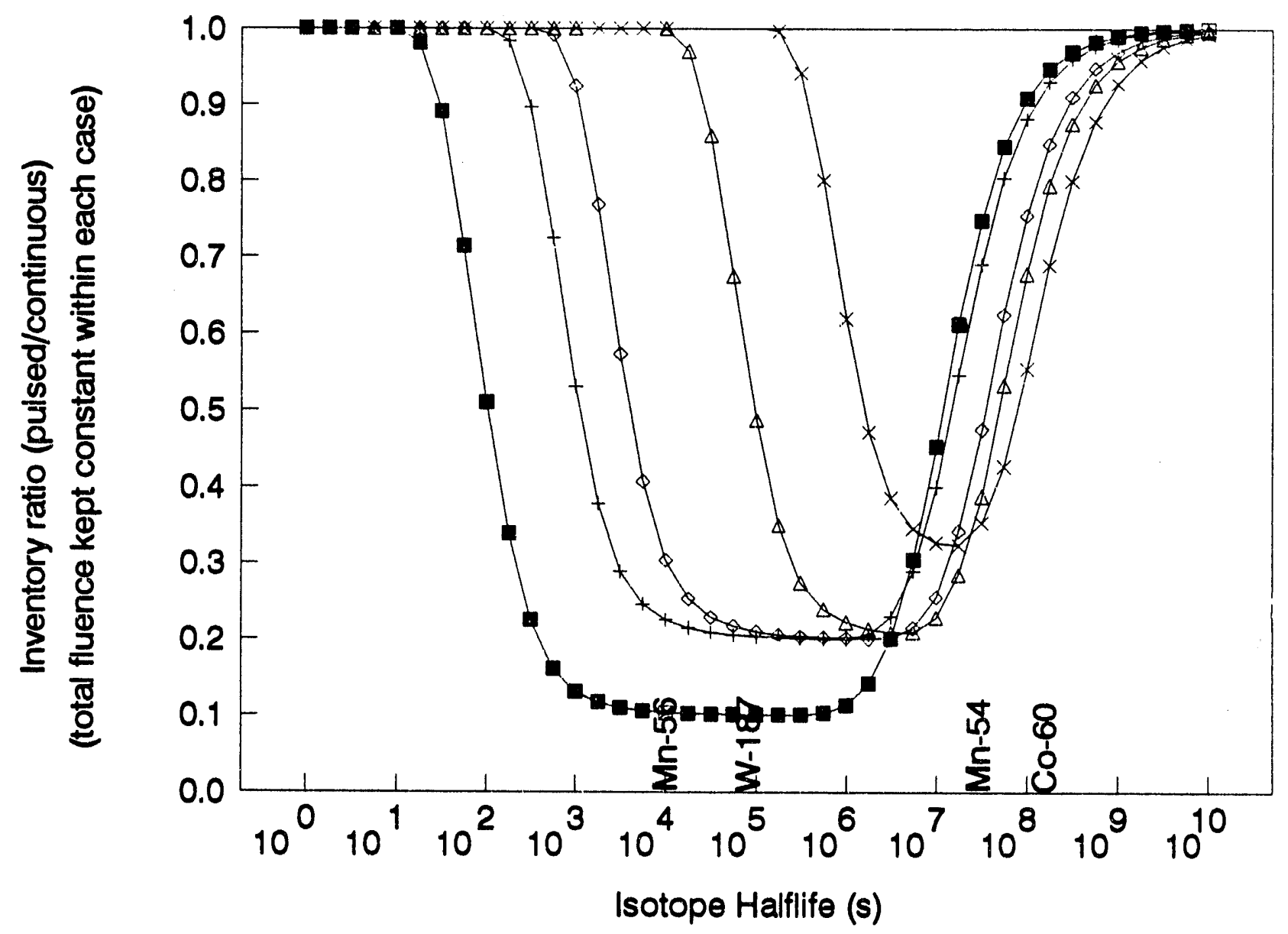

$\begin{array}{cccc} & \text { burn time } & \text { duty factor } & \text { fluence (yr) } \\ \text { - } & 100 \mathrm{~s} & 10 \% & 0.1 \\ + & 1000 \mathrm{~s} & 20 \% & 0.3 \\ - & 1 \text { hour } & 20 \% & 0.7 \\ \Delta & 1 \text { day } & 20 \% & 1.0 \\ \times & 2 \text { weeks } & 30 \% & 3.0\end{array}$

Figure 1. Effect of isotope halflife, burn time, duty factor, and fluence on inventory ratio (pulsed/continuous)

- for total fluence kept constant within each case 


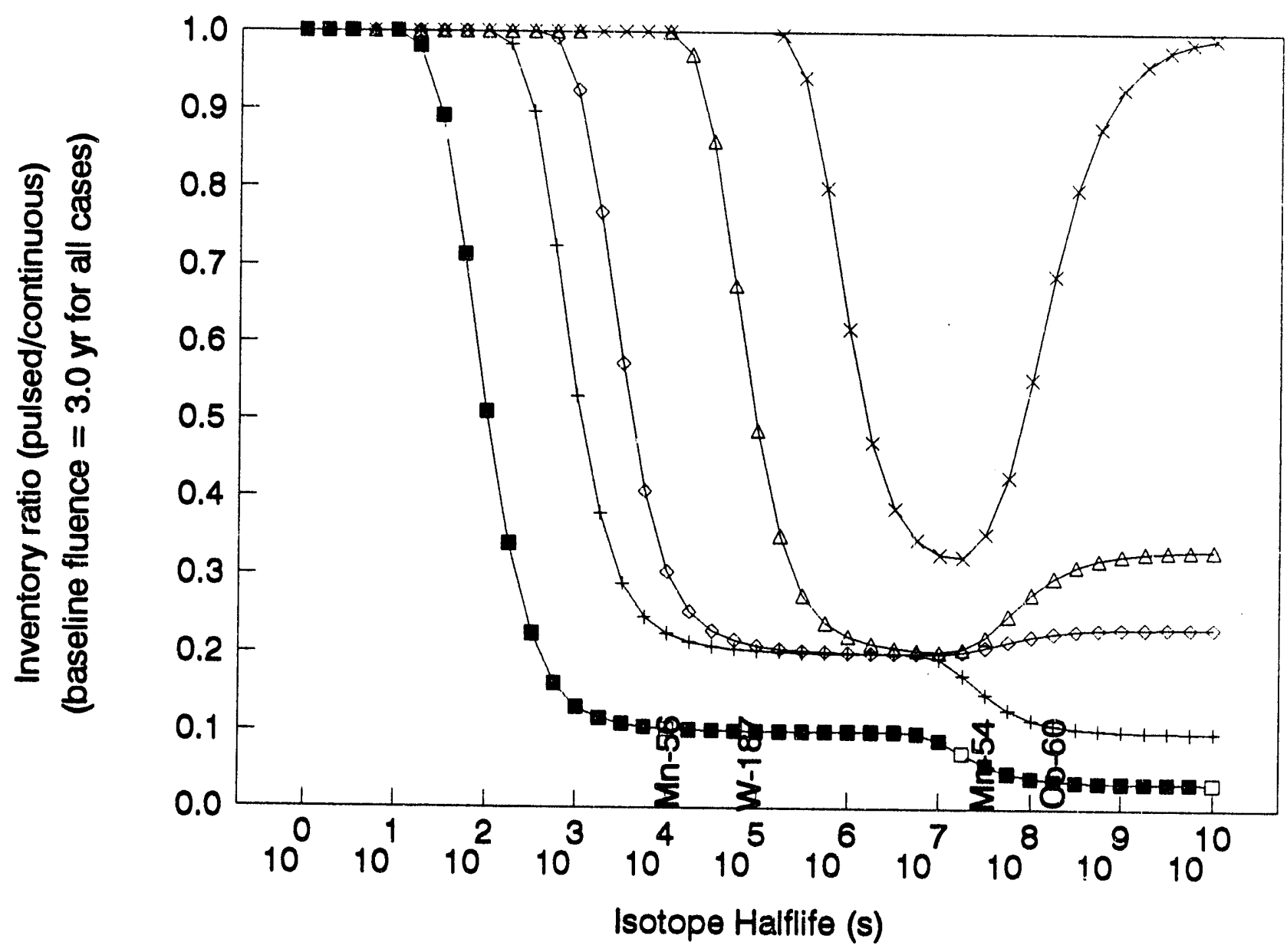

$\begin{array}{cccc} & \text { burn time } & \text { duty factor } & \text { fluence (yr) } \\ + & 100 \mathrm{~s} & 10 \% & 0.1 \\ + & 1000 \mathrm{~s} & 20 \% & 0.3 \\ - & 1 \text { hour } & 20 \% & 0.7 \\ \Delta & 1 \text { day } & 20 \% & 1.0 \\ \times & 2 \text { weeks } & 30 \% & 3.0\end{array}$

Figure 2. Effect of isotope halflife, burn time, duty factor, and fluence on inventory ratio (inventory for pulsed cases with varying fluence / inventory for continuous 3-yr fluence) 
Table 2 shows the ratio of the inventory for specific key isotopes relative to $100 \%$ duty factor and 3.0-yr fluence, that is, the same values as in Figure 2 graphically. Consider bounding cases of short and long-lived isotopes.

Consider Cu-66 as fairly short-7ived. For burn times over 1 hour, its 5.1minute halflife is sufficiently short that the ratio is 1.0 , that is, the inventory reaches saturation during each pulse. At 1000-s burn time, it reaches $90 \%$ of saturation. Even at $100 \mathrm{~s}$ ( 1.67 minutes), it reaches $23 \%$ of saturation.

Consider tritium as fairly long-lived. Its ratio at $0.1-y$ r fluence is 0.035 ; approaching the actual fluence ratio of $0.1 / 3.0=0.033$. That is, its 12.3-yr halflife is sufficiently long that its inventory ratio approaches the simple ratio of fluences. Similarly, the tritium ratio for the other ITER missions also approaches the simple ratio of fluences.

Table 3 summaries the main results, the reduction factors for specific dose, $\mathrm{mSv} / \mathrm{kg}$, for various materials - relative to the CDA case. Naturally, as the burn time, duty factor, and fluence move away from CDA values, the reduction factors increase. However, even for the most extreme case (100 s, 10\%, 0.1-yr), the factors range from 10 to 15, only one order of magnitude. (I say "only" because drastically changing the ITER mission to exclude most technology testing buys one order of magnitude reduction in consequence.) Assuming ITER keeps a technology mission, the reduction factors range from a low of 1.2 (copper at 2week pulse, $30 \%$ duty factor, 3.0-yr fluence) to a high of 4.4 (niobium at 1-day pulse, $20 \%$ duty factor, 1.0-yr fluence.)

Table 3 also shows the specific dose for some key elements for the various materials. Here, the ranges are somewhat higher. The highest reduction factors occur for rhenium isotopes in the tungsten cases because Re-186 increases nonlinearly with fluence since it is formed by multiple step reactions. The "tungsten-divertor/DP" case probably better approximates the Re-186 case because it is based on Attaya raw results with more values of fluence, specifically down to 0.1 year. There were fewer fluence values in the Attaya calculation for "tungsten-first wall", thus more of the values had to be scaled down from higher fluences, thus understating the reduction for Re-186.

As discussed in Sec. 3, depending on alloy, air versus steam, composition, and composition exponent, ( ne or another element may dominate volatility hazards. For example, rhenium isotopes dominate tungsten-air volatility; tungsten isotopes dominate tungsten-steam.

Table 4 is similar to Table 3 , except it shows the reduction factors for specific activity, $\mathrm{Ci} / \mathrm{cc}$, instead of specific dose. The values are generally similar and follow the same trends. Reduction factors for decay heat are likely to be similar to the values in Table 3 and Table 4. 
TabIe 2. RATIO OF KEY ISOTOPES' INVENTORIES FOR PULSED VERSUS CONTINUOUS IRRADIATION

\begin{tabular}{|c|c|c|c|c|c|c|}
\hline \multicolumn{2}{|l|}{ ITER Mission } & $\begin{array}{l}\text { Sub-min, mum } \\
\text { physics }\end{array}$ & $\begin{array}{l}\text { Minimum } \\
\text { physics }\end{array}$ & $\begin{array}{l}\text { Maximum } \\
\text { physics }\end{array}$ & $\begin{array}{l}\text { Minimum } \\
\text { technology }\end{array}$ & $\begin{array}{l}\text { Maximum } \\
\text { technology }\end{array}$ \\
\hline \multicolumn{2}{|l|}{ Burn time } & $100 \mathrm{~s}$ & $1000 \mathrm{~s}$ & $1 \mathrm{hr}$ & 1 day & 2 Heeks \\
\hline \multicolumn{2}{|l|}{ Duty factor } & 0.10 & 0.20 & 0.20 & 0.20 & 0.30 \\
\hline \multicolumn{2}{|l|}{ Fluence $(y r)$} & 0.10 & 0.30 & 0.70 & 1.00 & 3.00 \\
\hline \multicolumn{2}{|c|}{ Fraction of CDA fluence } & 0.03 & 0.10 & 0.23 & 0.33 & 1.00 \\
\hline Isotope & $T_{1 R}$ & \multicolumn{5}{|c|}{ Ratio of inventory relative to $3.0 \mathrm{yr}$ at $100 \%$ duty factor } \\
\hline $\mathrm{Cu} \cdot 66$ & $5.1 \mathrm{~m}$ & 0.229 & 0.904 & 1.000 & 1.000 & 1.000 \\
\hline $2 n-63$ & $38.1 \mathrm{~m}$ & 0.113 & 0.332 & 0.683 & 1.000 & 1.000 \\
\hline $\mathrm{Ni} \cdot 65$ & $2.52 \mathrm{~h}$ & 0.103 & 0.228 & 0.317 & 1.000 & 1.000 \\
\hline Mn-56 & $2.579 \mathrm{~h}$ & 0.103 & 0.227 & 0.314 & 1.000 & 1.000 \\
\hline $\mathrm{Cu} \cdot 64$ & $12.7 \mathrm{~h}$ & 0.101 & 0.206 & 0.220 & 0.745 & 1.000 \\
\hline$W \cdot 187$ & $23.9 n$ & 0.100 & 0.203 & 0.211 & 0.532 & 1.000 \\
\hline $\mathrm{Ni}-57$ & $36.1 \mathrm{~h}$ & 0.100 & 0.202 & 0.207 & 0.416 & 1.000 \\
\hline$Y \cdot 90$ & $64.0 \mathrm{~h}$ & 0.100 & 0.201 & 0.204 & 0.309 & 0.981 \\
\hline Mo. 99 & $65.94 \mathrm{~h}$ & 0.100 & 0.201 & 0.204 & 0.305 & 0.979 \\
\hline $2 r-89$ & $78.4 \mathrm{~h}$ & 0.100 & 0.201 & 0.203 & 0.285 & 0.959 \\
\hline $\mathrm{Re}-186$ & $90.7 \mathrm{~h}$ & 0.100 & 0.201 & 0.203 & 0.271 & 0.935 \\
\hline $\mathrm{Nb} \cdot 92 \mathrm{~m}$ & $10.13 d$ & 0.100 & 0.200 & 0.201 & 0.225 & 0.660 \\
\hline $\mathrm{Nb}-95$ & $34.98 \mathrm{~d}$ & 0.100 & 0.200 & 0.200 & 0.208 & 0.390 \\
\hline $\mathrm{Fe} \cdot 59$ & $44.51 \mathrm{~d}$ & 0.100 & 0.200 & 0.200 & 0.206 & 0.369 \\
\hline Co.58 & $70.91 \mathrm{~d}$ & 0.097 & 0.199 & 0.200 & 0.204 & 0.342 \\
\hline $\mathrm{Ta}-182$ & $114.5 \mathrm{~d}$ & 0.089 & 0.193 & 0.200 & 0.203 & 0.327 \\
\hline$W \cdot 181$ & $121.0 \mathrm{~d}$ & 0.088 & 0.192 & 0.200 & 0.203 & 0.325 \\
\hline $2 n \cdot 65$ & $243.8 d$ & 0.068 & 0.165 & 0.204 & 0.210 & 0.327 \\
\hline Co. 57 & $271.8 \mathrm{~d}$ & 0.065 & 0.160 & 0.205 & 0.214 & 0.332 \\
\hline $\mathrm{Mn} \cdot 54$ & $312.2 d$ & 0.061 & 0.154 & 0.206 & 0.220 & 0.340 \\
\hline $\mathrm{Fe} \cdot 55$ & $2.68 y$ & 0.042 & 0.119 & 0.221 & 0.269 & 0.520 \\
\hline $\mathrm{Co} .60$ & $5.272 y$ & 0.038 & 0.110 & 0.226 & 0.296 & 0.676 \\
\hline $\mathrm{H} \cdot 3$ & $12.3 y$ & 0.035 & 0.104 & 0.230 & 0.316 & 0.831 \\
\hline Minimm rotio & & 0.035 & 0.104 & 0.200 & 0.203 & 0.325 \\
\hline Maximum ratio & & 0.229 & 0.904 & 1.000 & 1.000 & 1.000 \\
\hline
\end{tabular}


Table 3. SUMMARY OF CONSEQUENCE REDUCTION FACTORS FOR VARIOUS MATERIALS

\begin{tabular}{|c|c|c|c|c|c|}
\hline & $\begin{array}{l}\text { Sub- } \\
\text { minimum } \\
\text { physics }\end{array}$ & $\begin{array}{l}\text { Minimum } \\
\text { Physics }\end{array}$ & $\begin{array}{l}\text { Maximum } \\
\text { physics }\end{array}$ & $\begin{array}{l}\text { Minimum } \\
\text { technology }\end{array}$ & $\begin{array}{l}\text { Maxinum } \\
\text { technology }\end{array}$ \\
\hline Burn time & $100 s$ & $1000 \mathrm{~s}$ & $1 \mathrm{hr}$ & 1 day & 2 weeks \\
\hline Duty factor & $10 \%$ & $20 \%$ & $20 \%$ & $20 \%$ & $30 \%$ \\
\hline Fluence $(y r)$ & 0.1 & 0.3 & 0.7 & 1.0 & $3.0^{\mathrm{a}}$ \\
\hline \multicolumn{6}{|l|}{ Specific dose, mSv/kg } \\
\hline Austenitic steel & 14.3 & 6.2 & 4.7 & 3.7 & 2.1 \\
\hline Copper al loy & 14.6 & 6.4 & 4.5 & 2.0 & 1.2 \\
\hline Tungsten - first wall & 14.6 & 7.1 & 6.9 & 3.2 & 1.3 \\
\hline Tungsten - divertor & 10.7 & 5.1 & 4.7 & 2.3 & $1.2^{\mathrm{a}}$ \\
\hline Niobium & 10.0 & 5.0 & 4.9 & 4.4 & $1.6^{\mathrm{a}}$ \\
\hline MINIMU & 10.0 & 5.0 & 4.5 & 2.0 & 1.2 \\
\hline AVERAGE & 12.8 & 6.0 & 5.1 & 3.1 & 1.5 \\
\hline maximn & 14.6 & 7.1 & 6.9 & 4.4 & 2.1 \\
\hline \multicolumn{6}{|l|}{ Specific dose (alloy: element) } \\
\hline Steel: $\quad$ Manganese isotopes & 14.6 & 6.0 & 4.4 & 2.8 & 2.2 \\
\hline Copper: $\quad$ Cobalt isotopes & 26.5 & 9.1 & 4.4 & 3.4 & 1.5 \\
\hline Steel: $\quad$ Cobalt isotopes & 14.2 & 6.3 & 4.7 & 4.1 & 2.1 \\
\hline Copper isotopes & 9.9 & 4.8 & 4.5 & 1.3 & 1.0 \\
\hline Zinc isotopes & 14.8 & 6.1 & 4.9 & 4.8 & 3.1 \\
\hline Niobium: Niobium isotopes & 10.0 & 5.0 & 5.0 & 4.5 & 1.5 \\
\hline Tungsten-FW: Tungsten isotopes & 9.4 & 4.6 & 4.4 & 1.9 & 1.1 \\
\hline Tungsten-DP: Tungsten isotopes & 10.0 & 4.9 & 4.7 & 2.2 & $1.2^{\mathrm{a}}$ \\
\hline Tungsten-FW: Rhenium isotopes & 37.8 & 18.8 & 18.6 & 13.9 & 1.1 \\
\hline Tungsten-DP: Rhenium isotopes & 585.4 & 20.5 & 4.9 & 3.7 & $1.1^{\mathrm{a}}$ \\
\hline MINIMM & 9.4 & 4.6 & 4.4 & 1.3 & 1.0 \\
\hline AVERAGE & 73.3 & 8.6 & 6.1 & 4.3 & 1.6 \\
\hline maximun & 585.4 & 20.5 & 18.6 & 13.9 & 3.1 \\
\hline
\end{tabular}


Table 4. SUMMARY OF SPECIFIC ACTIVITY REDUCTION FACTORS FOR VARIOUS CASES AND ITER MISSIONS

\begin{tabular}{|c|c|c|c|c|c|}
\hline ITER Mission & $\begin{array}{l}\text { Sub- } \\
\text { minimum } \\
\text { physics }\end{array}$ & $\begin{array}{l}\text { Minimum } \\
\text { physics }\end{array}$ & $\begin{array}{l}\text { Maximum } \\
\text { phys ics }\end{array}$ & $\begin{array}{l}\text { Minimum } \\
\text { technology }\end{array}$ & $\begin{array}{l}\text { Maximum } \\
\text { technology }\end{array}$ \\
\hline Burn time & $100 \mathrm{~s}$ & $1000 \mathrm{~s}$ & 1 hour & 1 day & 2 weeks \\
\hline Duty factor & $10 \%$ & $20 \%$ & $20 \%$ & $20 \%$ & $30 \%$ \\
\hline Fluence $(y r)^{a}$ & 0.1 & 0.3 & 0.7 & 1.0 & $3.0^{\mathrm{a}}$ \\
\hline \multicolumn{6}{|c|}{ Specific activity, $\mathrm{Ci} / \mathrm{cc}$} \\
\hline Austenitic steel & 11.4 & 4.5 & 3.4 & 2.1 & 1.6 \\
\hline Copper alloy & 8.1 & 3.0 & 2.8 & 1.3 & 1.0 \\
\hline Tungsten - first wall & 11.0 & 5.4 & 5.2 & 2.6 & 1.3 \\
\hline Tungsten - divertor ${ }^{a}$ & 10.3 & 4.9 & 4.7 & 2.7 & 1.5 \\
\hline Niobium ${ }^{a}$ & 6.0 & 1.9 & 1.7 & 1.6 & 1.2 \\
\hline AVERAGE & 9.4 & 4.0 & 3.6 & 2.1 & 1.3 \\
\hline
\end{tabular}

\section{CONCLUSIONS}

Table 5 summaries the reduction factors for pulsed or intermittent irradiation versus continuous irradiation up to the CDA 3.0-yr fluence (1.0-yr fluence for divertor cases.) Remember that a reduction factor is the ratio of the activation hazard from continuous irradiation divided by the hazard from discontinuous irradiation. The reduction factors are probably large enough to warrant more detailed neutronic/activation analyses during the ITER Engineering Design Activity (EDA). However, it must be remembered that taking credit for these reductions in formal ITER safety assessments would also require establishing operational limits on burn time, duty factor, and/or fluence. It would not be appropriate to take credit for machine limitation on say burn time if in fact the machine was allowed to operate with a higher burn time.

Table 5 first shows the reduction factors for frequency, which is simply (duty factor) ${ }^{-1}$. That is, if the duty factor is only $20 \%$, then the frequency of events would decrease (reduction factor) by a factor of 5 versus continuous operation. There are two important caveats. First, the frequency reduction only applies to those events (and that portion of risk) occurring during tokamak 
Table 5. SUMMARY OF REDUCTION FACTORS FOR MATERIALS AND MISSIONS

\begin{tabular}{|c|c|c|c|c|c|}
\hline ITER Mission & $\begin{array}{c}\text { Sub-minimum } \\
\text { physics }\end{array}$ & $\begin{array}{l}\text { Minimum } \\
\text { physics }\end{array}$ & $\begin{array}{l}\text { Maximum } \\
\text { physics }\end{array}$ & $\begin{array}{c}\text { Minimum } \\
\text { technology }\end{array}$ & $\begin{array}{c}\text { Maximum } \\
\text { technology }\end{array}$ \\
\hline \multicolumn{6}{|c|}{ Reduction factors for frequency ( 1 /duty factor) ${ }^{a}$} \\
\hline & 10 & 5 & 5 & 5 & 3 \\
\hline \multicolumn{6}{|c|}{ Reduction factors for specific dose ${ }^{b}$} \\
\hline Minimum & $\begin{array}{r}9.4 \\
\end{array}$ & 4.6 & 4.4 & 1.3 & 1.0 \\
\hline Average & 12.8 & 6.0 & 5.1 & 3.1 & 1.5 \\
\hline Maximum & 585.4 & 20.5 & 18.6 & 13.9 & 3.1 \\
\hline \multicolumn{6}{|c|}{$\begin{array}{l}\text { Minimum and maximum come from specific alloy:element cases. } \\
\text { average of the alloy-averaged } \mathrm{mSv} / \mathrm{kg} \text {. }\end{array}$} \\
\hline \multicolumn{6}{|c|}{ Maximum theoretical reduction factors } \\
\hline $\begin{array}{l}\text { From reduced } \\
\text { duty factor }\end{array}$ & 10.0 & 5.0 & 5.0 & 5.0 & 3.3 \\
\hline $\begin{array}{l}\text { From reduced } \\
\text { fluence }\end{array}$ & 30.0 & 10.0 & 4.3 & 3.0 & 1.0 \\
\hline $\begin{array}{l}\text { Maximum } \\
\text { theoretical } \\
\text { credit }\end{array}$ & 30.0 & 10.0 & 5.0 & 5.0 & 3.3 \\
\hline \multicolumn{6}{|c|}{ Risk reduction factors (consequence times frequency) } \\
\hline Minimum & 3.8 & 23. & 22. & 6.7 & 3.3 \\
\hline Average & 128. & 30. & 26. & 15. & 4.9 \\
\hline Maximum & 5850. & 102. & 93. & 70. & 10. \\
\hline \multicolumn{6}{|c|}{$\begin{array}{l}\text { a. Caution, some accidents can happen during "off-time, " especially } \\
\text { during maintenance. } \\
\text { b. The niobium divertor substrate and tungsten divertor plate would } \\
\text { see a maximum of } 3.0 \mathrm{MW}-\mathrm{yr} / \mathrm{m} 2 \text {, so the comparisons for } \mathrm{Nb} \text { and } \mathrm{W}-\mathrm{DP} \\
\text { are made on that basis. }\end{array}$} \\
\hline
\end{tabular}


operation, it does not apply to events during maintenance and other shutdowns. Such events require more study during the EDA. Second, the frequency reduction: does not contain any penalty for the unavoidable increase in failure rates from cyclic operation.

Table 5 next shows the reduction factors for specific dose, the main focus of this report. The "minimum" and "maximum" values reflect the extreme values among specific elements, thereby showing the most or least credit that might occur, depending on material and accident (volatility, dust, etc.) The "average" values are the average for the alloy specific dose, $\mathrm{mSv} / \mathrm{kg}$.

Finally, Table 5 shows the risk reduction factors, combining frequency and specific dose. Neglecting accidents during maintenance and other shutdowns, and neglectirig failure rate increases from cyclic operation, ${ }^{9}$ the risk reductions can be significant.

Assuming that ITER keeps a tecnnology mission, the main factor to consider in reducing hazards and risk from the CDA values is the duty factor. A duty factor of $20-30 \%$ reduces the amount of time per year that ITER is at most risk by factors of 3-5 - if we neglect accidents during maintenance and penalties for cyclic operation. Such a duty factor also contributes to lowering the specific dose by factors of 1.0 to 14. The corresponding risk reduction factors might range from 3 to 70 in the most extreme cases.

In conclusion, assuming that ITER keeps a technology mission, accounting for burn time, duty factor, and fluence versus the CDA assumption of continuous irradiation toward 3.0-yr fluence probably lowers activation risk by about an order of magnitude at best. This reduction will be particularly useful in countering other trends that will worsen the risk picture - risk from maintenance and shutdowns (not included in the CDA), penalties from cyclic operation (not included in the (DA), and possibly larger size and higher neutron flux. 


\section{REFERENCES}

1. J. Raeder and S. Piet, ed, ITER Safety Analyses, IAEA ITER Documentation Series No. 36, November 1990.

2. ITER Test Programme, IAEA ITER Documentation Series No. 24, 1991.

3. H. Attaya, Y. Gohar, and D. Smith, "US-ITER Activation Analysis," Fusion Technology, 19, (3, part 2B), May, 1991, pp. 1837-1842.

4. J. E. Sisolak, S. E. jpangler, and D. L. Henderson, "Pulsed/Intermittent Activation in Fusion Energy Reactor Systems," Fusion Technology, 21, (3, part 2B), May 1992, pp. 2145-2151.

5. S. J. Piet, et al., Initial Experimental Investigation of the Elemental Volatility from Steel Alloys for Fusion Safety Application, EGG-FSP-8459, April 1989.

6. G. R. Smolik, R. M. Neilson, Jr, and S. J. Piet, "Volatility from Copper and Tungsten Alloys for Fusion Reactor Applications, "IEEE 13 Symposium on Fusion Engineering, Knoxville, Tennessee, October 2-6, 1989, pp. 670-673.

7. G. R. Smolik, S. J. Piet, and R. M. Neilson, Jr., "Predictions of Radioactive Tungsten Release from Hypothetical ITER Accidents, "Fusion Technology, 19, (3, part 2B), May 1991, pp. 1398-1402.

8. G. R. Smolik and K. A. McCarthy, Oxidation and Volatilization of a Niobium Alloy, EGG-FSP-10341, August 1992.

9. L. C. Cadwallader, Investigation of Component Failure Rates for Pulsed Versus Steady State Tokamak Operation, EGG-FSP-10262, July 1992. 


\section{APPENDIX A. EQUATIONS FOR CONTINUOUS AND PULSED IRRADIATION}

Make the following key assumptions:

- Parent isotope is stable, its composition does not change much

- Progeny is radioactive, decaying to a stable isotope

- Duty factor, $d$, is constant throughout machine life

- Neutron flux, $\Gamma$, is constant throughout machine life

- Effective burn time, $t_{b}$, is constant throughout machine life

- Dwell time, $t_{d}$, is constant throughout machine life

Define the following variables,

$\mathrm{N}_{p} \quad$ parent atom density

$N_{d}^{p} \quad$ progeny atom density, $N_{d}(t=0)=0$

$\sigma_{p} \quad$ cross section for parent - $->$ progeny

$\sigma_{d}^{p} \quad$ cross section for destruction of progeny

$\Gamma$ neutron flux

$T_{1 / 2}$ isntope halflife

$\lambda_{r} \quad$ radiological decay constant $=0.693 / T_{1 / 2}$

$\lambda^{r} \quad$ effective decay constant $=\lambda+\Gamma \sigma_{d}$

$t_{b}$ burn time

$t_{d} \quad$ dwell time

$d^{d} \quad$ duty factor $=t_{b} /\left(t_{b}+t_{d}\right)$

$n$ number of pulses

$T$ total integrated burn time $=$ fluence $=n t_{b}$

$\alpha \quad \lambda t_{b} / d$

$c$ constant involving $\Gamma, \sigma$, and $N_{p}$.

For continuous irradiation, and the parent isotope not being burned out,

$$
N_{d}(t)=\frac{C}{\lambda}\left(1-e^{-\lambda t}\right)
$$

Now turn to the case of pulsed operation. The inventory at the end of a single pulse is

$$
N_{d}=\frac{C}{\lambda}\left(1-e^{-\lambda t_{b}}\right)
$$

The inventory at some time, $t$, after that pulse is

$$
N_{d}=\frac{C}{\lambda}\left(1-e^{-\lambda t_{b}}\right) e^{-\lambda t}
$$

The inventory at the end of $n$ pulses $\left(t=(n-1) t_{b} / d+t_{b}\right)$ from the activation during the $i^{\text {th }}$ putse is 


$$
N_{d}=\frac{C}{\lambda}\left(1-e^{-\lambda t_{b}}\right) e^{-\lambda(n-i) t_{b} / d}
$$

since $(n-i) t_{b} / d$ is the time available for isotope decay after the $i^{\text {th }}$ pulse. Note that if $n=i$, there is no decay time for the last pulse.

The total inventory at the end of $n$ pulses is therefore

$$
N_{d}=\frac{C}{\lambda}\left(1-e^{-\lambda t_{b}}\right) \sum_{i=1}^{n} e^{-\lambda(n-i) t_{b} / d}
$$

If $n=1$, eqn. (E) simplifies to equal eqn. (B). For very short-lived isotopes, $T_{1 / 2} \ll \operatorname{tb}$ or $\lambda t_{b} \gg 1$, eqn. (E) simplifies to

$$
N_{d}=\frac{C}{\lambda}(1-0)(0+0+0+\ldots+1)=\frac{C}{\lambda}
$$

since only the last of $n$ terms is non-zero. For very short-lived isotopes, therefore, the inventory of the progeny builds to saturation each pulse, independent of $d, t_{b}, n$, or $T$.

For very long-lived isotopes, $T_{1 / 2} \gg t_{b} n=T$, we get $n \lambda t_{b} \ll 1$, and eqn. (E) simplifies to

$$
N_{d}=\frac{C}{\lambda}\left(\lambda t_{b}\right)(1+1+1+\ldots+1)=\frac{C}{\lambda}\left(\lambda t_{b}\right) n=C t_{b} n=C T
$$

which is independent of $d$ and $t_{b}$ and only depends on total fluence $\left(T=t_{b} n\right)$.

For an individual isotope, the ratio of the inventory from pulsed versus continuous irradiation is the ratio of eqn. (E) to eqn. (A),

$$
\text { Ratio }=\frac{\left(1-e^{-\lambda t_{b}}\right)}{\left(1-e^{-\lambda T}\right)} \sum_{i=1}^{n} e^{-\lambda(n-i) t_{b} / d}
$$

For very short-lived isotopes, eqn. (H) goes to 1. For very long-lived isotopes, eqn. (H) goes to $\left(t_{b} n\right)$ for the pulsed case divided by (T) for the continuous case. For the same fixed total fluence $\left(t_{b} n=T\right)$, this is 1 . 


\section{APPENDIX B. APPROXIMATIONS}

The equations in Appendix A are generally too complex for use in spreadsheets. Thus, I devised two approxinations - for relatively short lived isotopes and relatively long lived isotopes - discussed below. The end of this appendix discusses the validity of the single parent/progeny assumption.

\section{B.1 Approximation for short-lived isotopes}

The complexity in eqn. (H) in Appendix A comes from the summation term,

$$
\text { summation }=\sum_{i=1}^{n} e^{-\lambda(n-i) t_{b} / d}=\sum_{i=1}^{n} e^{-(n-i) \alpha}
$$

which is only a function of $n$ and $\alpha=\lambda t_{b} / d$.

For $\alpha$ large ( $T_{1 / 2}$ smal1), only the last term of the summation contributes and the sum approaches 1 . In this case, the summation is independent of $n$.

For $\alpha$ small ( $T_{1 / 2}$ large), the sum approaches $\alpha^{-1}$ is $n$ if large enough. I used a spreadsheet of actual values from eqn. $(H)$ to find a general approximation to the suri. The approximation,

$$
\text { summation } \approx \frac{\left(1+1.5 \alpha+0.155 \alpha^{2}+\alpha^{3}\right)^{1 / 3}}{\alpha}
$$

depends only on $\alpha$ and not on the number of pulses. Once the number of pulses, $n$, is high enough, the summation saturaies. The approximation gives a maximum error of $2.6 \%$ provided that $n$ is high enough that the summation saturates. For $\alpha=0.01$, the approximation starts to fail at $n=1000$ pulses. For alpha $=0.001$, the approximation starts to fail at $n=10,000$ pulses.

Figure B-1 shows the summation term as a function of $\alpha$, comparing the approximation in eqn. (J) to the exact summation.

As the halflife, $T_{1 / 2}$, gets larger ( $\alpha$ smaller), the approximation approaches $\alpha^{-1}$. At that point, the summation and therefore the ratio (pulsed/continuous) scales as d, as explained previously. The number of pulses to make the summation saturate grows also. Eventually, the approximation breaks down.

\section{B.2 Approximation for long-lived isotopes}

For a large number of pulses, the summation in eqn. $(H)$ or eqn. (E) should approximate an integral. Specifically, we assume $t_{b} \ll T_{1 / 2}$ or $\lambda t_{b} \ll 1$. If we set $d t=t_{b}=T / n$, eqn. (E) becomes, 


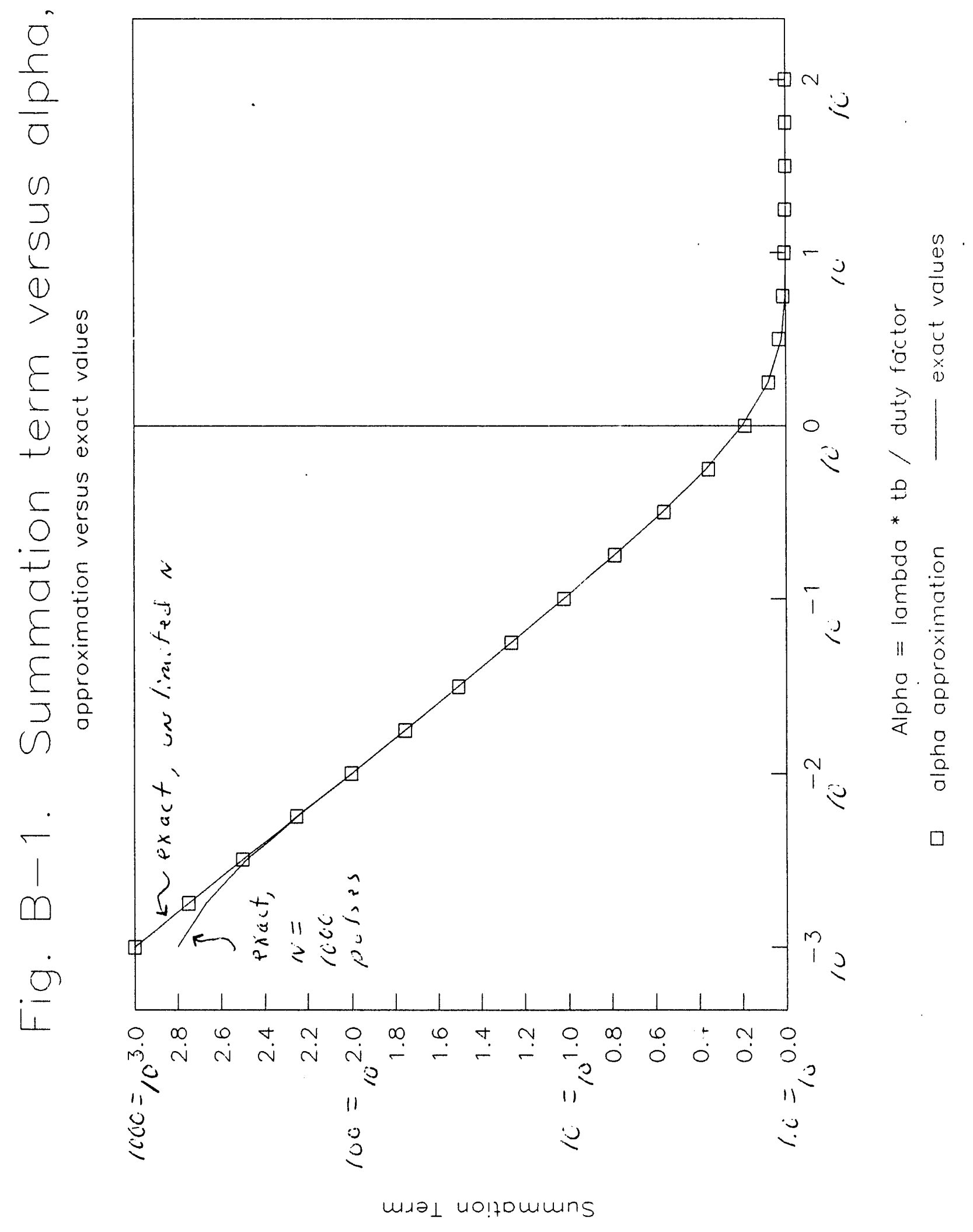

Page 26 


$$
N_{d}=\frac{C}{\lambda} \int_{0}^{T}(\lambda d t) e^{-\lambda t / d}=\frac{C}{\lambda} d\left(1-e^{-\lambda T / d}\right)
$$

Then, the ratio of the inventory for the pulsed case versus the continuous irradiation case becomes

$$
\text { Ratio }=d \frac{\left(1-e^{-\lambda T / d}\right)}{\left(1-e^{-\lambda T}\right)}
$$

If $d=1$, the ratio goes to 1 as expected. For relatively short halfifife, $\lambda T$ large, the ratio approaches $d$. In this regime the integral approximation and the $\alpha$ approximation of Sec. B.l match, that is, the ratio approaches $d$. For long halflife, $\lambda T$ small, the ratio approaches $d(\lambda T / d) /(\lambda T)=1$, as expected.

\section{B.3 Validity of approximations for use in spreadsheets}

Figures B-2 and B-3 compare the $\alpha$ and integral approximations versus the actual summation in eqn. (H) for two different cases. The $\alpha$ approximation is clearly good for shorter-lived isotopes. At high halflife, the a approximation errs high; the summation term does not saturate. The integral approximation is clearly good for long-lived isotopes. At short halflife, the integral approximation give a flat value of 1 /duty factor.

\section{B.4 Validity of single parent/progeny assumption}

As mentioned in Sec. 2.2, I examined the validity of the single parent/progeny assumption. For each material, H. Attaya's CDA activation calculations provide the specific activity ( $\mathrm{Ci} / \mathrm{Cc}$ ) for individual isotopes for particular times before shutdown. Using the single parent/progeny assumption and the activity for each isotope at shutdown, I calculated the inventory for each isotope at the same particular times before shutdown. The percent error in the my calculation is simply the difference in values divided by the true value (Attaya's value).

This method tests the validity of the parent/progeny assumption with regard to fluence, but not burn time or duty factor. It should, however, be a good indication of the validity of the simplifying assumptions.

Table B-1 summarizes the percent errors for key isotopes for the various cases. It also shows the maximum percent errors for the total specific activity. In essentially all cases, the maximum percent errors occur for the shortest time period in Attaya's CDA activation file, since that case is the biggest downward scaling from the end-of-life activation value. 


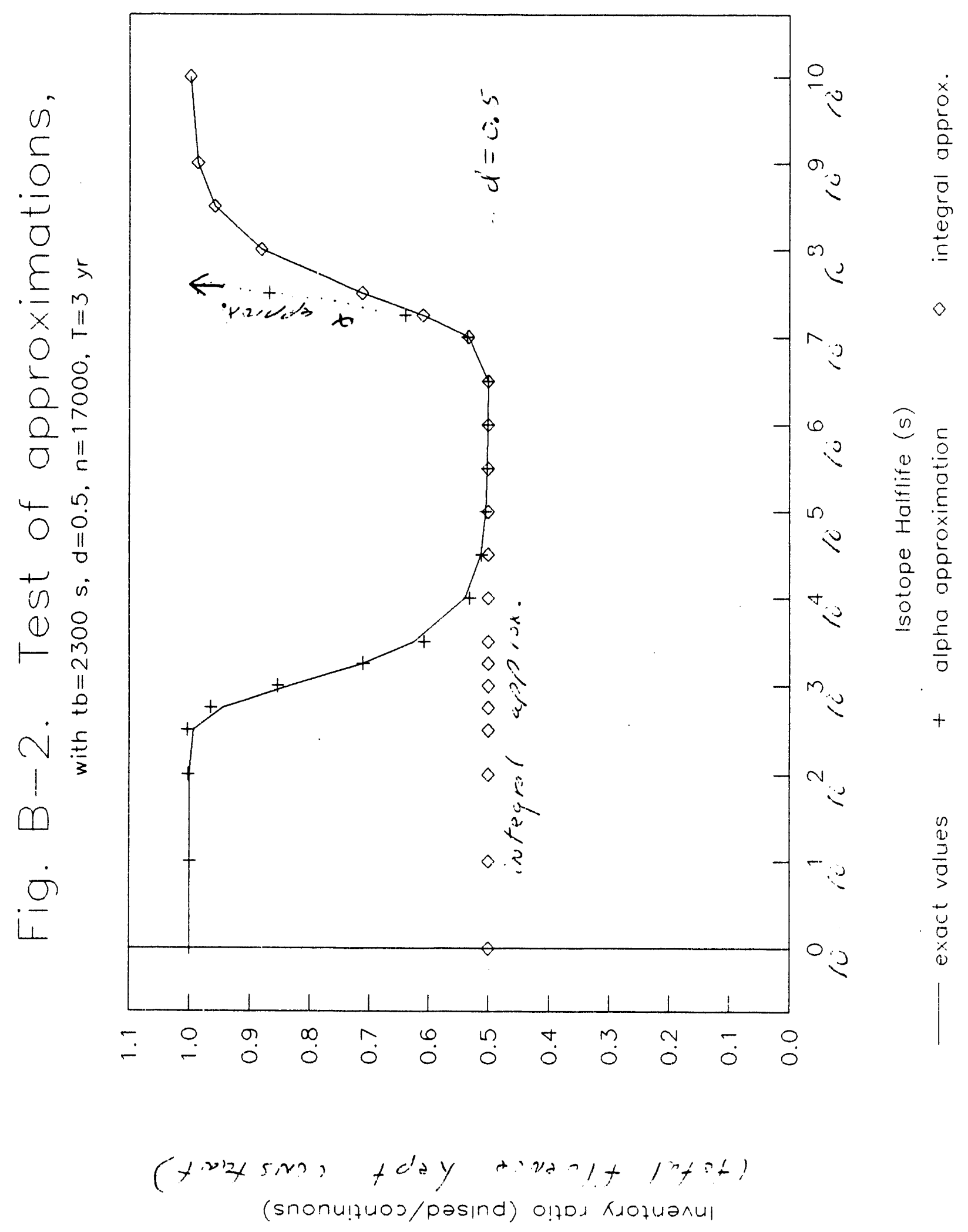

Page 28 


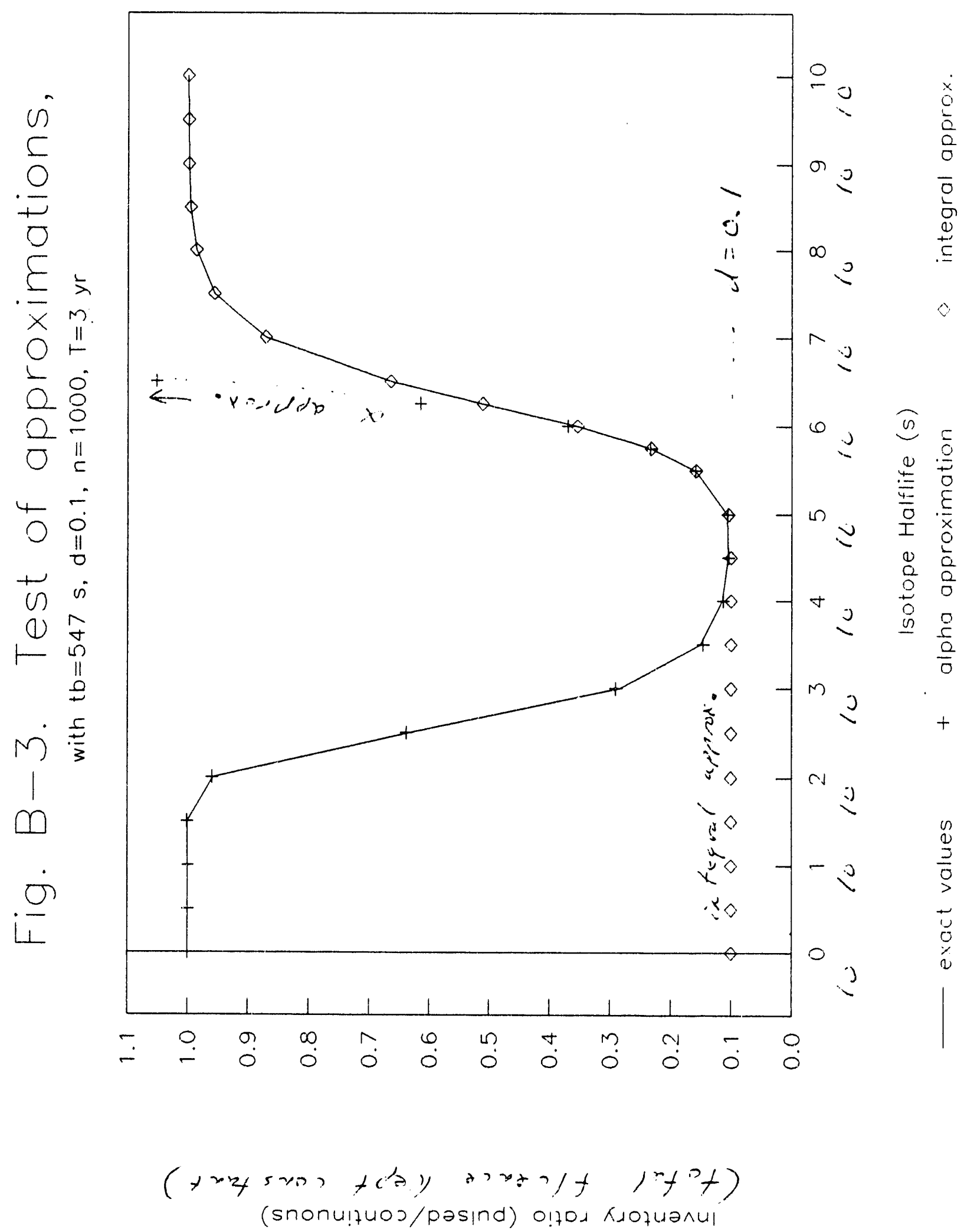

Page 29 
Table B-1. SUMMARY OF PERCENT ERRORS FOR KEY ISOTOPES FOR EACH CASE

\begin{tabular}{|c|c|c|c|c|}
\hline \multirow{2}{*}{$\begin{array}{l}\text { MATERIAL } \\
\text { CASE }\end{array}$} & \multicolumn{4}{|c|}{ Percent errors $=$ difference $/$ true yalue } \\
\hline & $<10 \%$ & $10-100 \%$ & $100-1000 \%$ & $>1000 \%$ \\
\hline \multirow[t]{2}{*}{$\begin{array}{l}\text { Austenitic } \\
\text { Steel at first } \\
\text { wall }\end{array}$} & $\begin{array}{l}V-52 \\
C r-51 \\
M n-54 \\
M n-56 \\
\mathrm{Fe}-55 \\
\mathrm{Co}-58\end{array}$ & $\begin{array}{ll}\text { Co-57 } & (20 \%) \\
\text { Co-60 } & (23 \%)\end{array}$ & & \\
\hline & \multicolumn{4}{|c|}{ Maximum specific activity error $=7 \%$} \\
\hline \multirow[t]{2}{*}{$\begin{array}{l}\text { Copper at } \\
\text { first wall }\end{array}$} & $\begin{array}{l}\mathrm{C} 0-60 \\
\mathrm{Cu}-64 \\
\mathrm{Cu}-66\end{array}$ & & & $\begin{array}{l}\mathrm{Fe}-59 \\
\mathrm{Ni}-65 \\
\mathrm{Zn}-63 \\
\mathrm{Zn}-65\end{array}$ \\
\hline & \multicolumn{4}{|c|}{ Maximum specific activity error $=4 \%$} \\
\hline \multirow[t]{2}{*}{$\begin{array}{l}\text { Tungsten at } \\
\text { first wali }\end{array}$} & $\begin{array}{l}W-181 \\
W-185 \\
\end{array}$ & $W-187(14 \%)$ & & $\begin{array}{l}\text { Ta-182 } \\
\operatorname{Re}-186\end{array}$ \\
\hline & \multicolumn{4}{|c|}{ Maximum specific activity error $=11 \%$} \\
\hline \multirow[t]{2}{*}{$\begin{array}{l}\text { Tungsten at } \\
\text { divertor }\end{array}$} & $\begin{array}{l}W-181 \\
W-185 \\
W-187\end{array}$ & & Ta-182 & $\operatorname{Re}-186$ \\
\hline & \multicolumn{4}{|c|}{ Maximum specific activity error $=4 \%$} \\
\hline \multirow[t]{2}{*}{$\begin{array}{l}\text { Niobium at } \\
\text { divertor }\end{array}$} & $\begin{array}{l}\mathrm{Y}-90 \\
\mathrm{Zr}-89 \\
\mathrm{Zr}-95 \\
\mathrm{Nb}-92 \mathrm{~m} \\
\mathrm{Ta}-182\end{array}$ & NB-92m $(20 \%)$ & & $\mathrm{Nb}-95$ \\
\hline & \multicolumn{4}{|c|}{ Maximum specific activity error $=7 \%$} \\
\hline
\end{tabular}

For all materials, the total specific activity is well predicted by my simplified equations since the maximum percent error is at worst $11 \%$ for the tungsten/first wall case. Remember that the intent of the study is to estimate the total reduction factors for non-continuous operation versus continuous irradiation.

Except for tungsten, the total specific dose $(\mathrm{mSv} / \mathrm{kg})$ is well predicted by my simplified equations. That is, the isotopes in the ?ast two columns (100$1000 \%,>1000 \%$ ) are not major contributors to total specific dose. See discussion in the following Appendices. 


\section{APPENDIX C. STEEL DETAILS}

Figure $C-1$ shows the specific activity as a function of fluence, based on H. Attaya's CDA activation calculation. The initial unirradiated composition is B $(0.001 \%), C(0.018 \%), N(0.07 \%), A 1(0.30 \%), \quad S i(0.46 \%), P(0.026 \%)$, $\mathrm{S}(0.011 \%), \mathrm{Ti}(0.04 \%), \mathrm{V}(0.004 \%), \mathrm{Cr}(17.1 \%), \operatorname{Mn}(1.7 \%), \mathrm{Fe}(64.6 \%)$, $\mathrm{Co}(0.03 \%)$, $\mathrm{Ni}(13.2 \%), \mathrm{Cu}(0.10 \%), \mathrm{Mo}(2.5 \%), \mathrm{W}(0.001 \%)$, and $\mathrm{Bi}(0.0008 \%)$. The domiriant isotopes all are well predicted by the parent/progeny assumptions. Figure $\mathrm{C}-2$ shows the steel specific activity for various ITER "missions." The reduction factors are only 1.6 to 2.1 for technology missions.

Figure $\mathrm{C}-3$ shows the specific dose as a function of fluence, based on Attaya's CDA activation calculation. That is, I used the specific activity, multiplied by appropriate dose values for each isotope. The parent/progeny assumptions predict the inventory of all important isotopes within $20 \%$ of Attaya's calculations, even when scaling down to only a total fluence of 38 minutes. Figure $\mathrm{C}-4$ shows the steel specific activity for various ITER missions. The reduction factors are only 2.1 to 3.7 for technology missions. Figure C-5 is the same as C-4, except it is grouped by chemical element instead of individual isotopes. The dominance of manganese and cobalt isotopes is apparent.

I examined the impact on air and steam volatility. The first issue is how does the composition change with irradiation. Perhaps surprisingly, with the exception of cobalt, no other element's composition (weight \%) changes more than $1 \%$ for the CDA fluence. The cobalt concentration increases by $67 \%$ (outboard) and $54 \%$ (inboard). The volatility data are uncertain for cobalt by at least a factor of two, so compositional changes can be ignored as relatively unimportant.

The reduction factors for individual key elements illustrates that the reduction factors for air or steam volatility will not differ much from the specific dose reduction factor. Depending on air versus steam, temperature, fluence, etc., one of these elements will dominate the volatility hazard.

\section{Summary of key steel reduction factors}

\begin{tabular}{|l||l|l|l|l|}
\hline & $\begin{array}{l}\text { Minimum } \\
\text { Physics }\end{array}$ & $\begin{array}{l}\text { Maximum } \\
\text { Physics }\end{array}$ & $\begin{array}{l}\text { Minimum } \\
\text { Technology }\end{array}$ & $\begin{array}{l}\text { Maximum } \\
\text { Technology }\end{array}$ \\
\hline \hline Manganese & 6.0 & 4.4 & 2.8 & 2.2 \\
\hline Cobalt & 6.3 & 4.7 & 4.1 & 2.1 \\
\hline Molybdenum & 5.0 & 4.8 & 3.2 & 1.0 \\
\hline \hline $\begin{array}{l}\text { Specific dose over } \\
\text { all elements }\end{array}$ & 6.2 & 4.7 & 3.7 & 2.1 \\
\hline
\end{tabular}




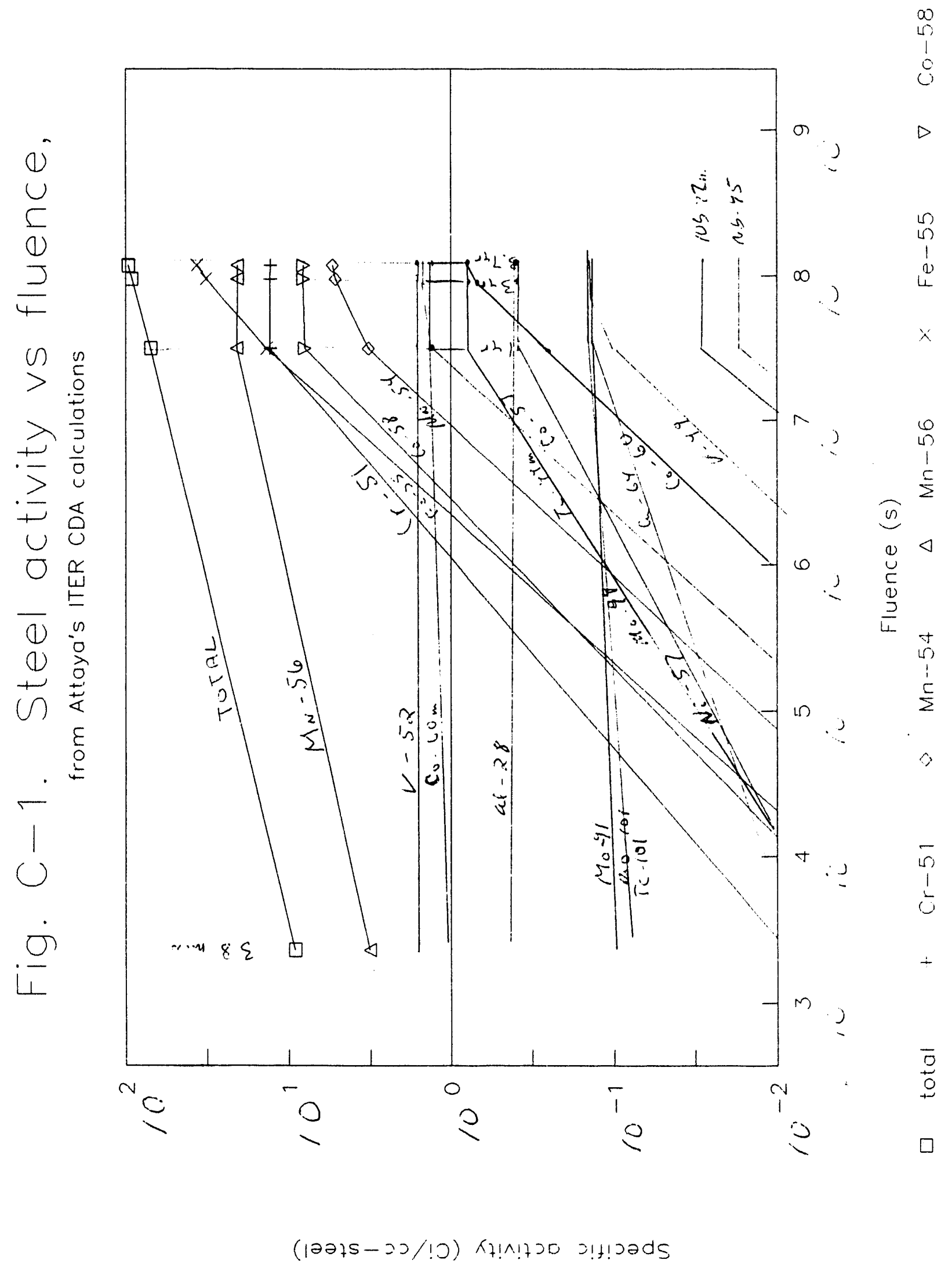

Page 32 


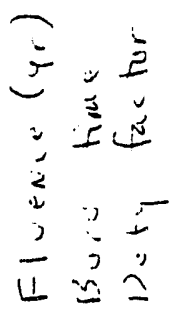

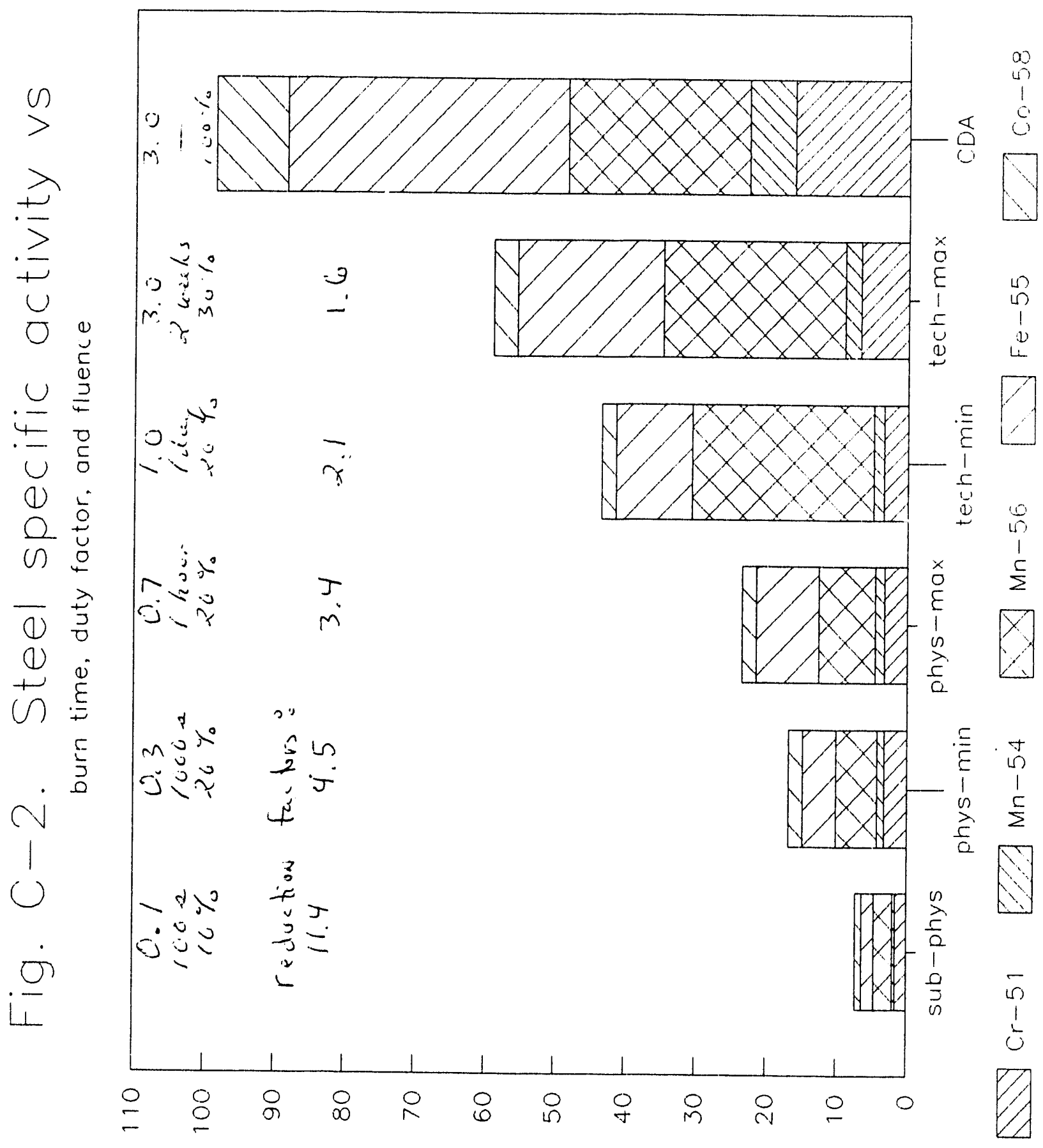

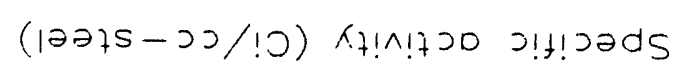




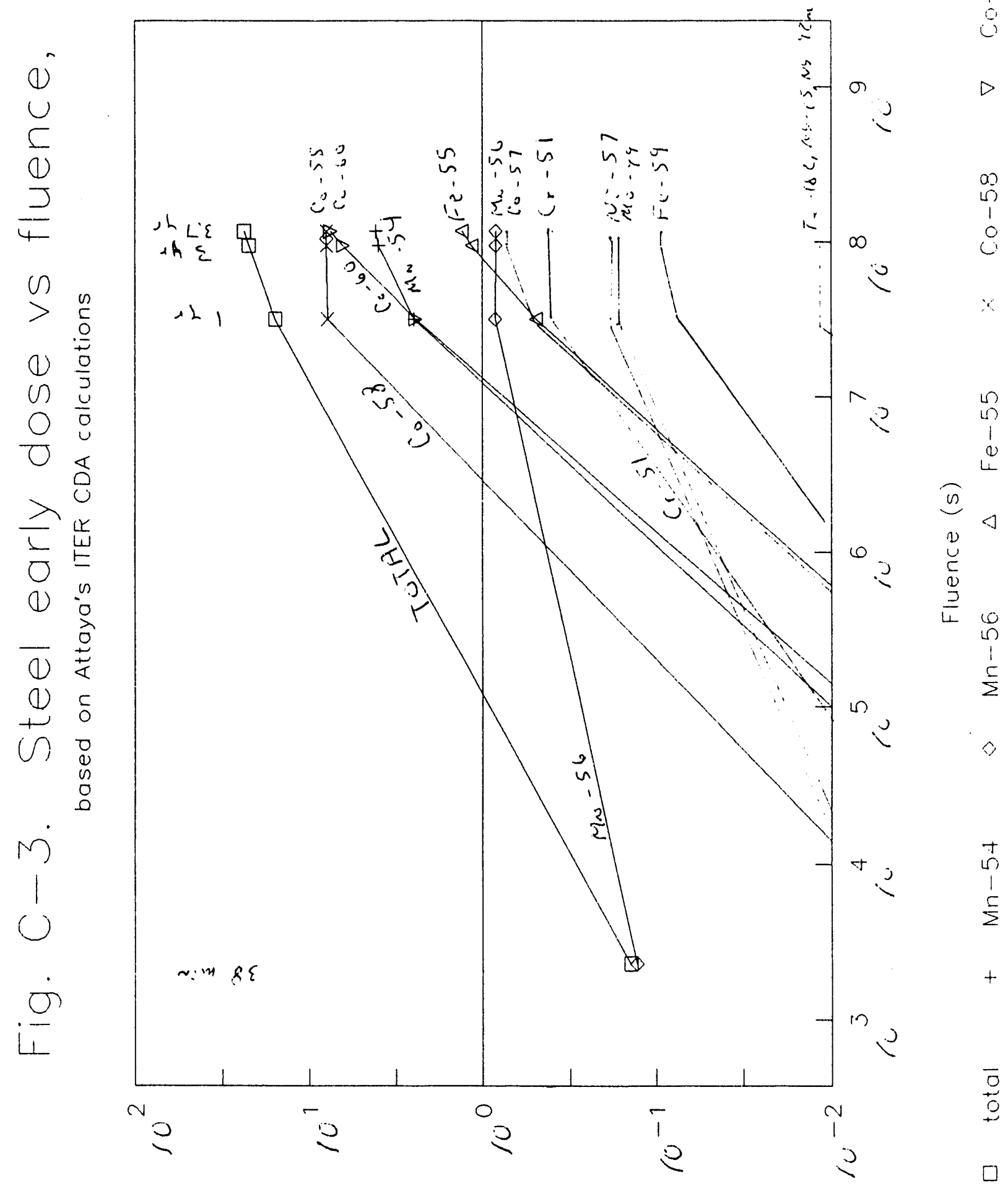

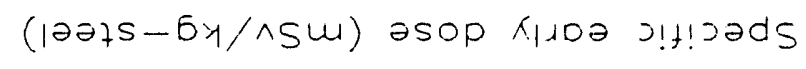

Page 34 


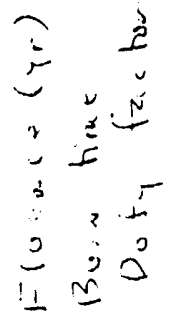

O

.

(

0

0

0

2

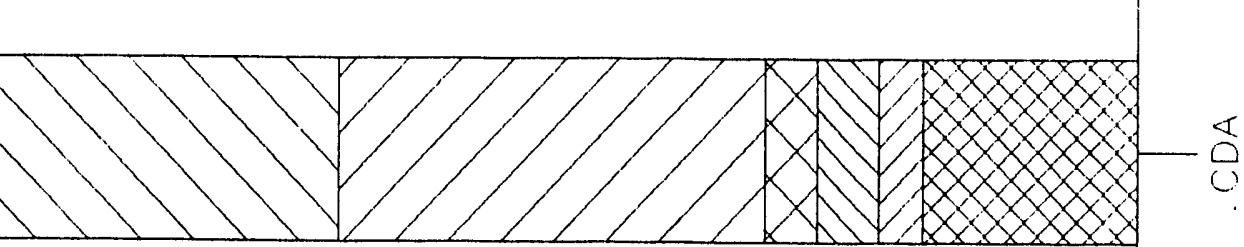

$\stackrel{\square}{6}$

0
0
0
0

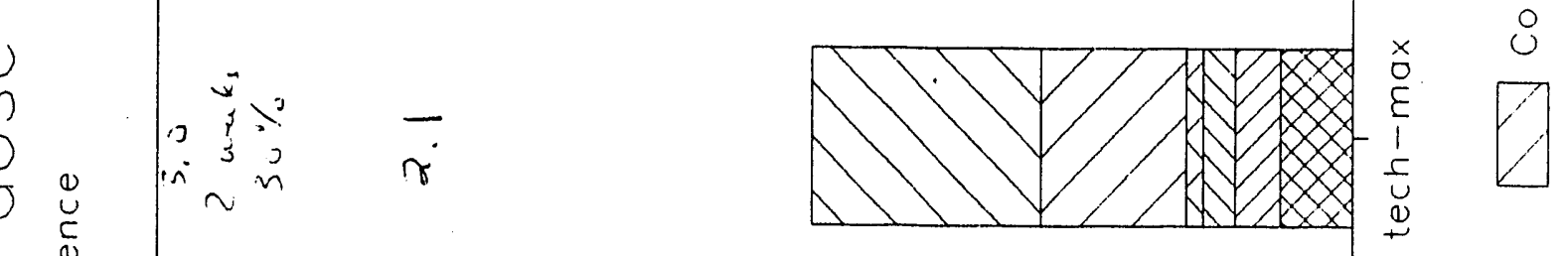

$\frac{3}{2}$

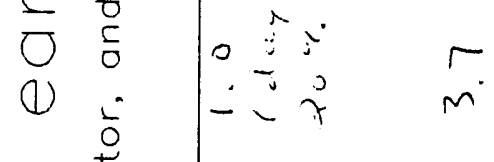

(1)

$+\frac{1}{0}$

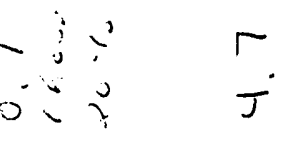

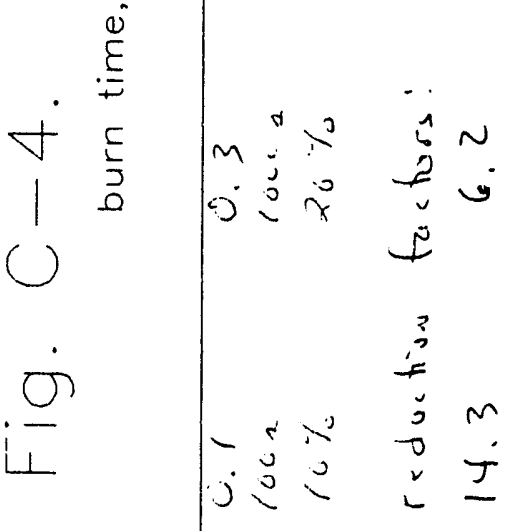

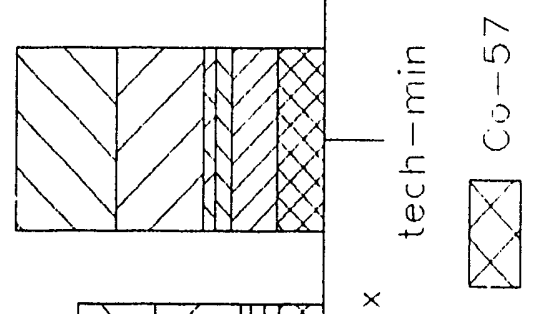

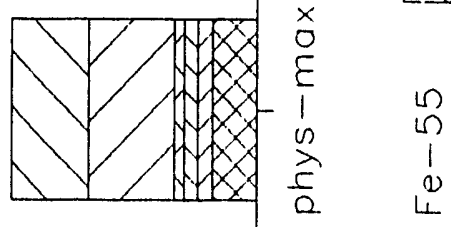

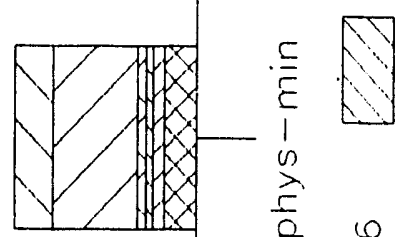

$\frac{5}{0}$

10

$\sqrt{\frac{1}{2}} \frac{1}{2}$

$\frac{1}{3}$

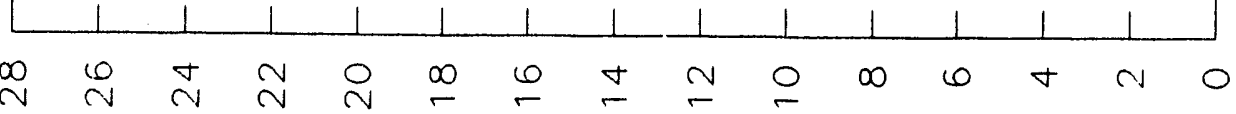

1
10
1
5
2
8
8
2

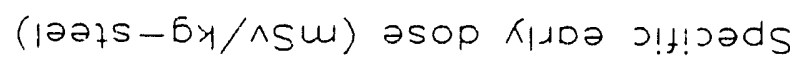

Page 35 


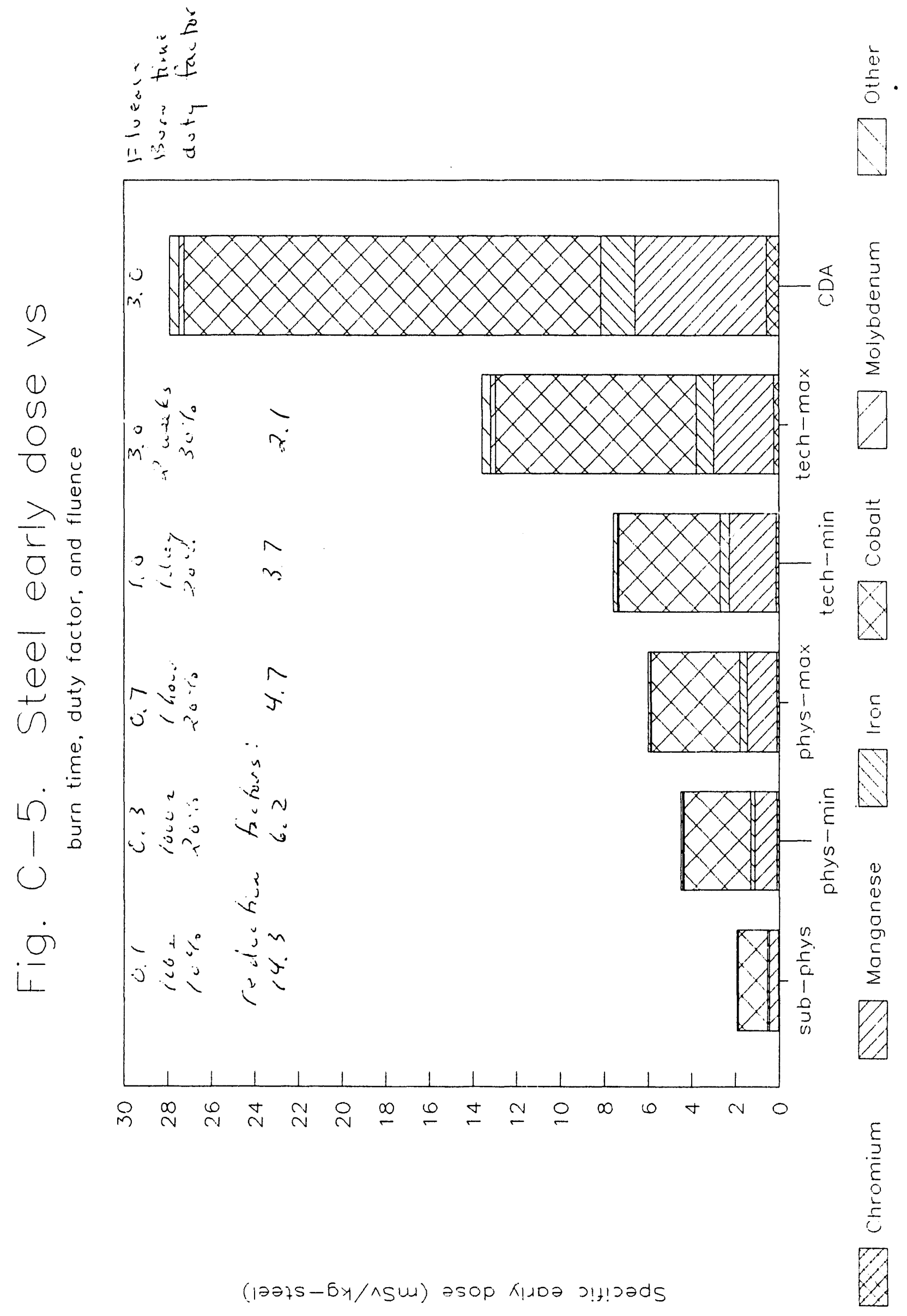

Page 36 


\section{APPENDIX D. COPPER DETAILS}

Figure $0-1$ shows the specific activity as a function of fluence, based on H. Attaya's CDA calculation. The copper is initially pure. The dominant isotopes all are well predicted by the parent/progeny assumptions. Figure D-2 shows the copper specific activity for various ITER "missions." The reduction factors are only 1.0 to 1.3 for technology missions.

Figure D-4 shows the specific dose as a function of fluence, based on Attaya's CDA calculation. The parent/progeny assumptions predict the inventory of Cu-64 and Co-60 very well. The other important isotope is $\mathrm{Zn-65}$, which is not well predicted. Still, for the specific dose over all elements, the error in Zn-65 should not matter much because $Z n-65$ contributes 1 ess than $10 \%$ to the total specific dose and contributes even less at lower fluence (where the approximations fail for $(n-65)$. Figure $D-4$ shows the copper specific activity for various ITER missions. The reduction factors are only 1.2 to 2.0 for technology missions. Figure D-5 is the same as D-4 except it is grouped by chemical element instead of individual isotopes. Copper and cobalt are clearly dominant.

I examined the impact on air and steam volatility. Like the CDA, I assumed the accident at the first wall/blanket/shield is sufficient to heat the copper to $600{ }^{\circ} \mathrm{C}$ for 7 days. The first issue is how does the composition change with irradiation. Unlike stee? (Appendix C), the composition changes dramatically. The copper is initially pure. At 3.0-yr fluence, the percent of cobalt, nickel, and zinc rise to $0.02 \%, 1.2 \%$, and $1.1 \%$. Because the composition changes so much the scaling of volatility (Sec. 3) is critical. Ignoring burn time and duty factor, Figures $0-6$ and $0-7$ show the dose from $\mathrm{Cu}-\mathrm{air}$ volatility as a function of fluence for two cases. One, assume a variable case where volatility scales as the elemental composition, $C_{j}$, to the $D$ power $(D=$ composition exponent). Assumed $D$ values range from 1.0 ( $\mathrm{Mn}, \mathrm{Fe})$ to $0.5(\mathrm{Co}, \mathrm{Ni}, \mathrm{Cu})$ to $0.0(\mathrm{Zn})$. Then, the volatility flux varies as $c_{i}$ and the release fraction varies as $c_{i}{ }^{0.1}$. The dose varies less than linearly with fluence because the increasing specific activity is partially offset by falling release fractions. Two, assume fixed release fractions. This is equivalent to setting $D=1$ for all elements. The volatility flux varies as $c_{i}$, release fractions are constant, and the dose varies approximately as fluence because the specific activity is increasing. Thus, the "fixed" case should show higher reduction factors than the "variable case" and it does. Depending on the assumptions, either cobalt, copper, or zinc dominates. The first case (variable release fractions, volatility flux) is probably the best assumption at the present time. See reference 5 .

Figures $D-8$ and $D-9$ show the same type of information, except for steam instead of air. Clearly, we need to better understand the impact of changing composition on volatility. The INEL Fusion Safety Program plans to look at this in 1993.

The reduction factors for individual key elements illustrates how the reduction factors for air or steam volatility may differ from the specific dose reduction factor. Depending on air versus steam, temperature, fluence, composition, and composition exponents, etc., one of these elements will dominate the volatility hazard. 
Finally, I approximated the Cu-air and Cu-steam reduction factors for the two cases noted above for the various ITER missions. (That is, Figures D- 6 through D-9 show volatility doses as a function of fluence for continuous irradiation. Now, I go further and look at duty factor and burn time effects on volatility reduction factors). Instead of always scaling from the highest fluence, I used whatever fluence in Attaya's calculations was the closest to one of the ITER "missions." This should reduce the errors caused by the parent/ progeny assumptions.

Summary of key copper reduction factors

\begin{tabular}{|l||l|l|l|l||}
\hline & $\begin{array}{l}\text { Minimum } \\
\text { Physics }\end{array}$ & $\begin{array}{l}\text { Maximum } \\
\text { Physics }\end{array}$ & $\begin{array}{l}\text { Minimum } \\
\text { Technology }\end{array}$ & $\begin{array}{l}\text { Maximum } \\
\text { Technology }\end{array}$ \\
\hline \hline Cobalt & 9.1 & 4.4 & 3.4 & 1.5 \\
\hline Copper & 4.8 & 4.5 & 1.3 & 1.0 \\
\hline Zinc & 6.1 & 4.9 & 4.8 & 3.1 \\
\hline $\begin{array}{l}\text { Specific dose over all } \\
\text { elements }\end{array}$ & 6.4 & 4.5 & 2.0 & 1.2 \\
\hline $\begin{array}{l}\text { Cu-air volatility, variable } \\
\text { flux and release fractions }\end{array}$ & 3.8 & 2.5 & 2.2 & 1.5 \\
\hline \begin{tabular}{l} 
fixed release fraction \\
\hline $\begin{array}{l}\text { Cu-steam volatility, variable } \\
\text { flux and release fractions }\end{array}$
\end{tabular} & 3.5 & 2.3 & 2.1 & 2.5 \\
\hline fixed release fraction & 15.2 & 6.7 & 5.3 & 1.5 \\
\hline
\end{tabular}




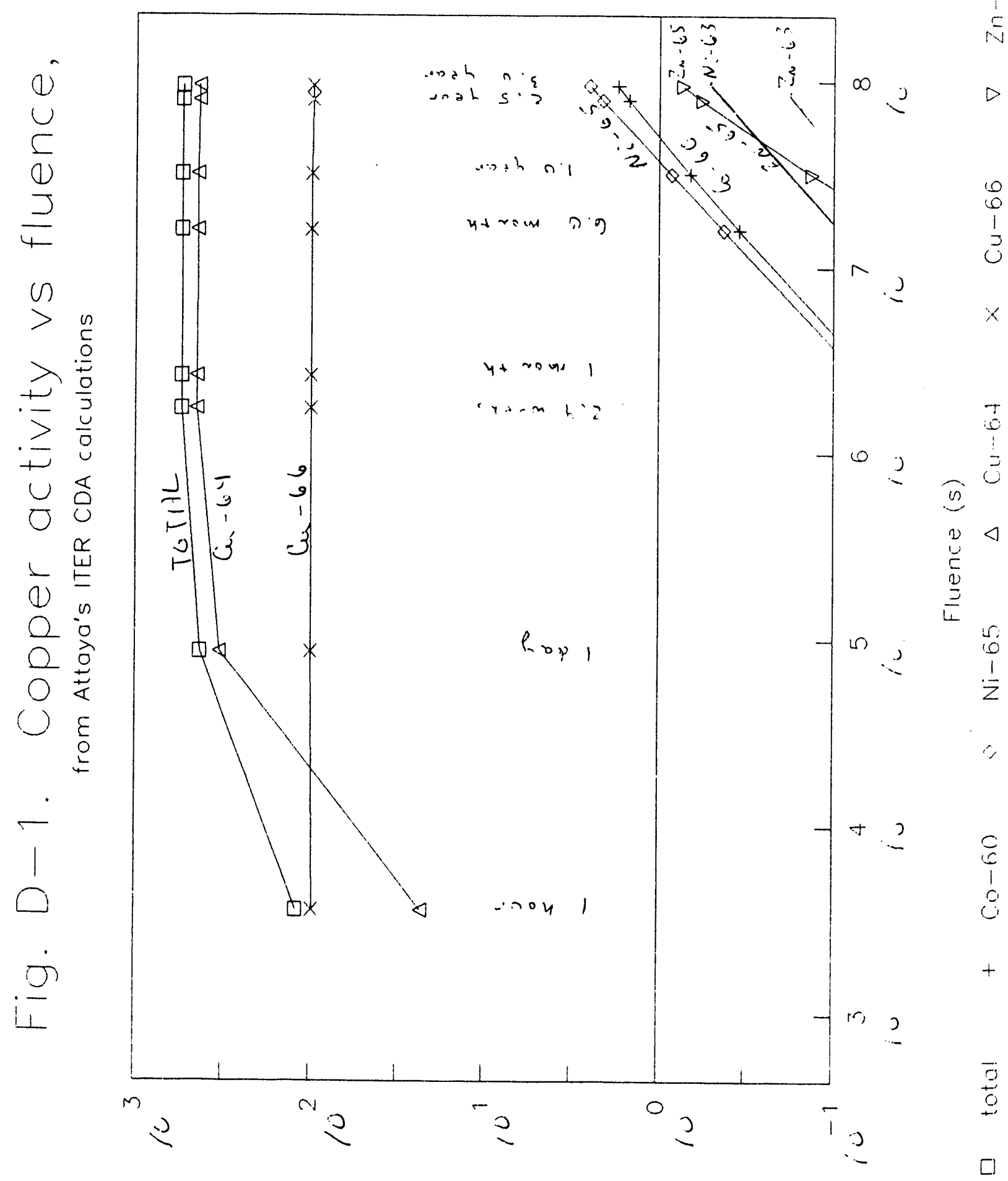

$$
(n 0-20 / 10) x_{7 ! 1 ! 700} 2 ! 1 ! j a d s
$$




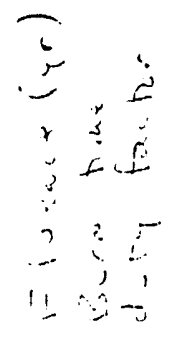

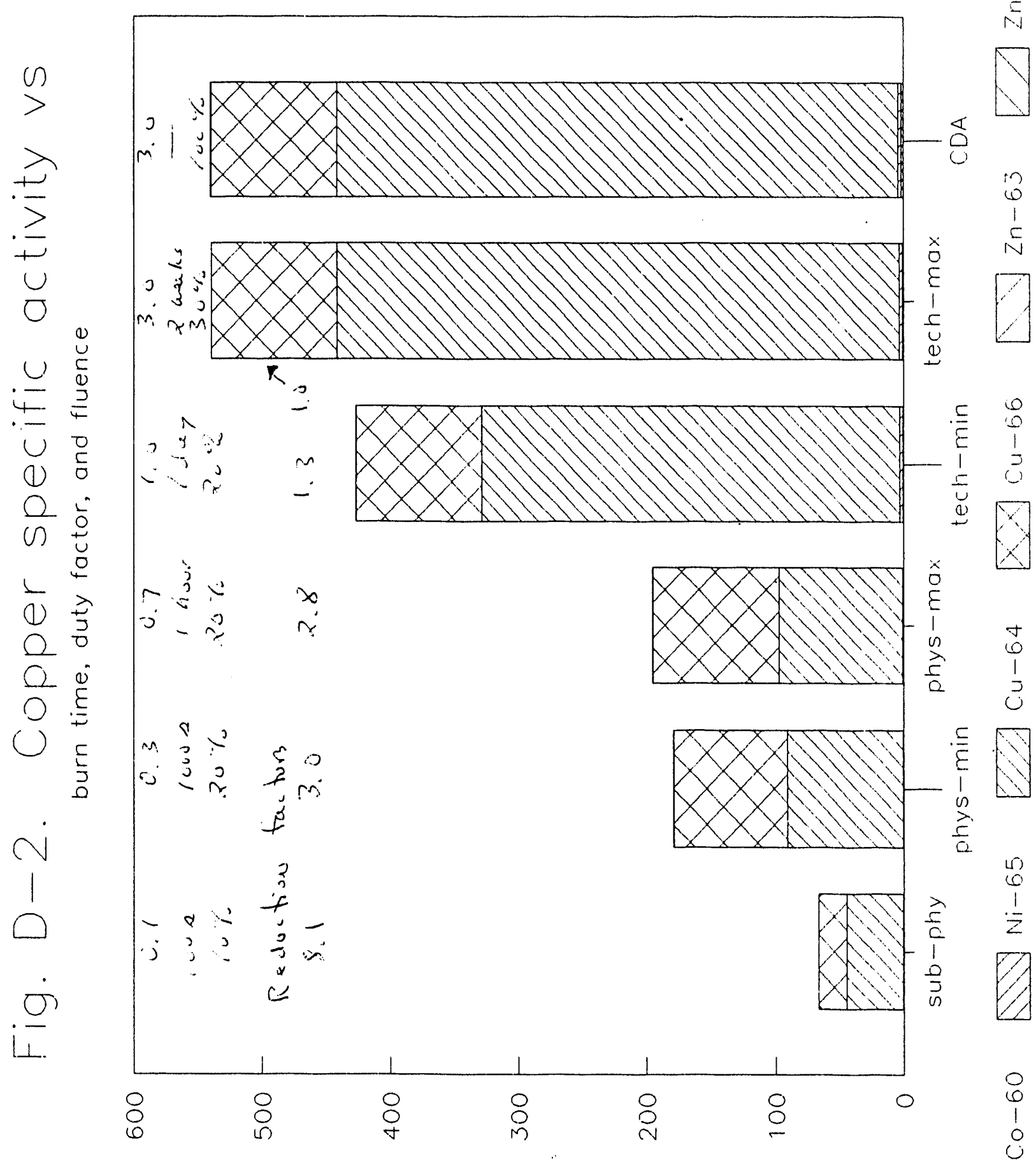

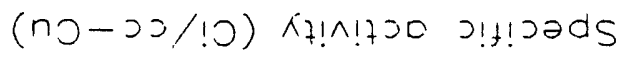




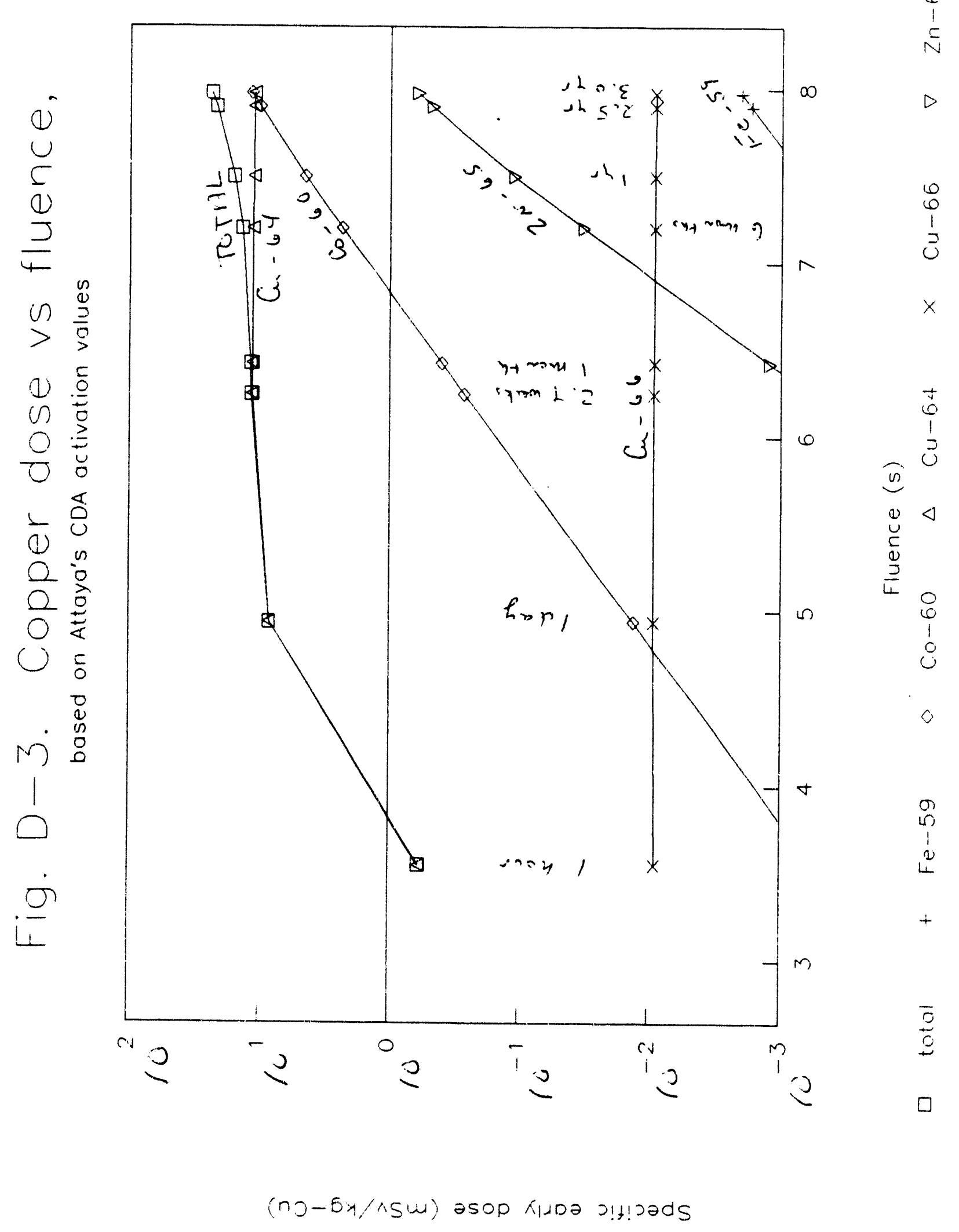

Page 41 

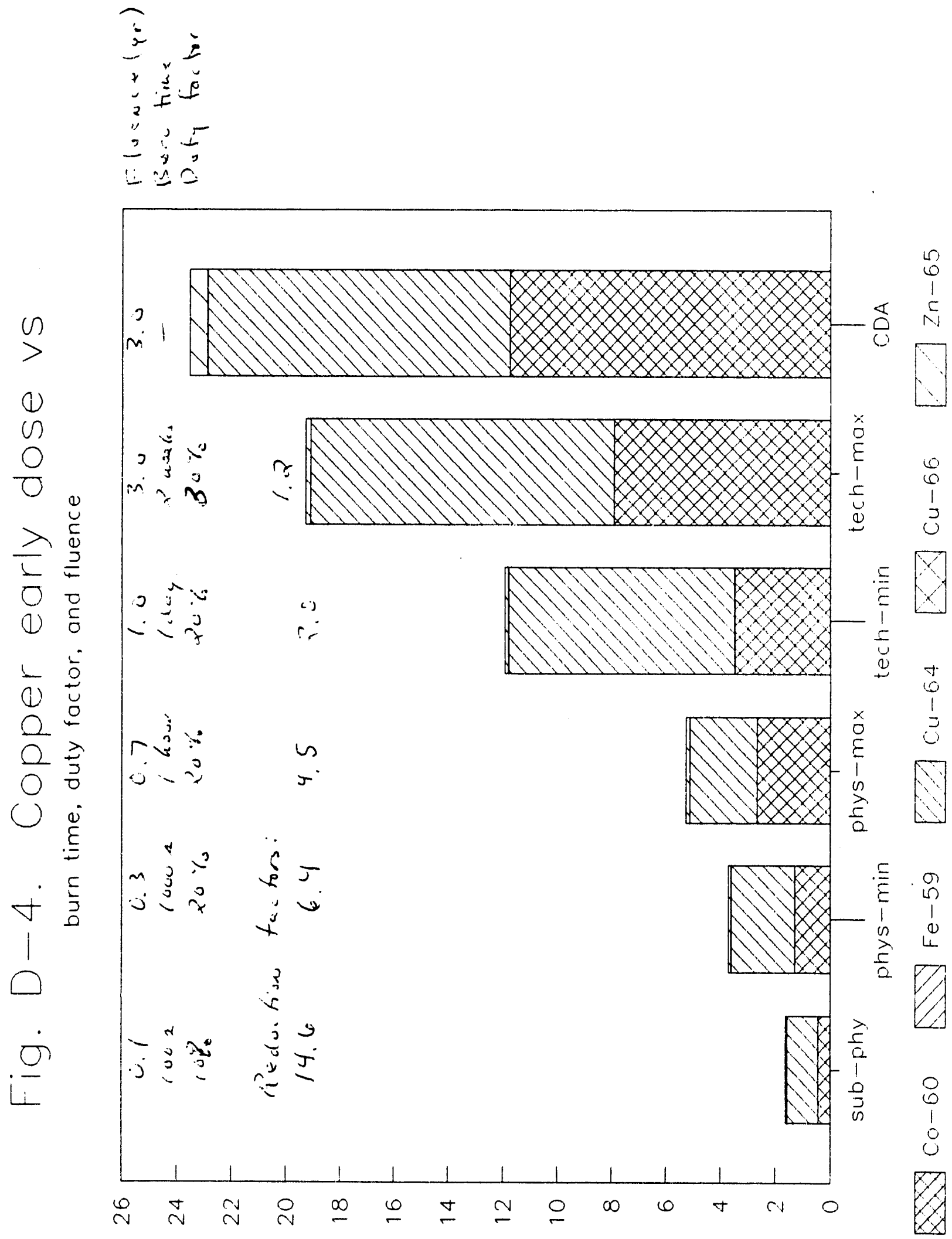

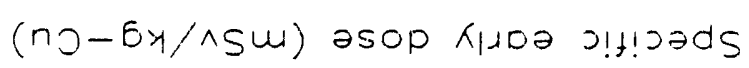

Page 42 


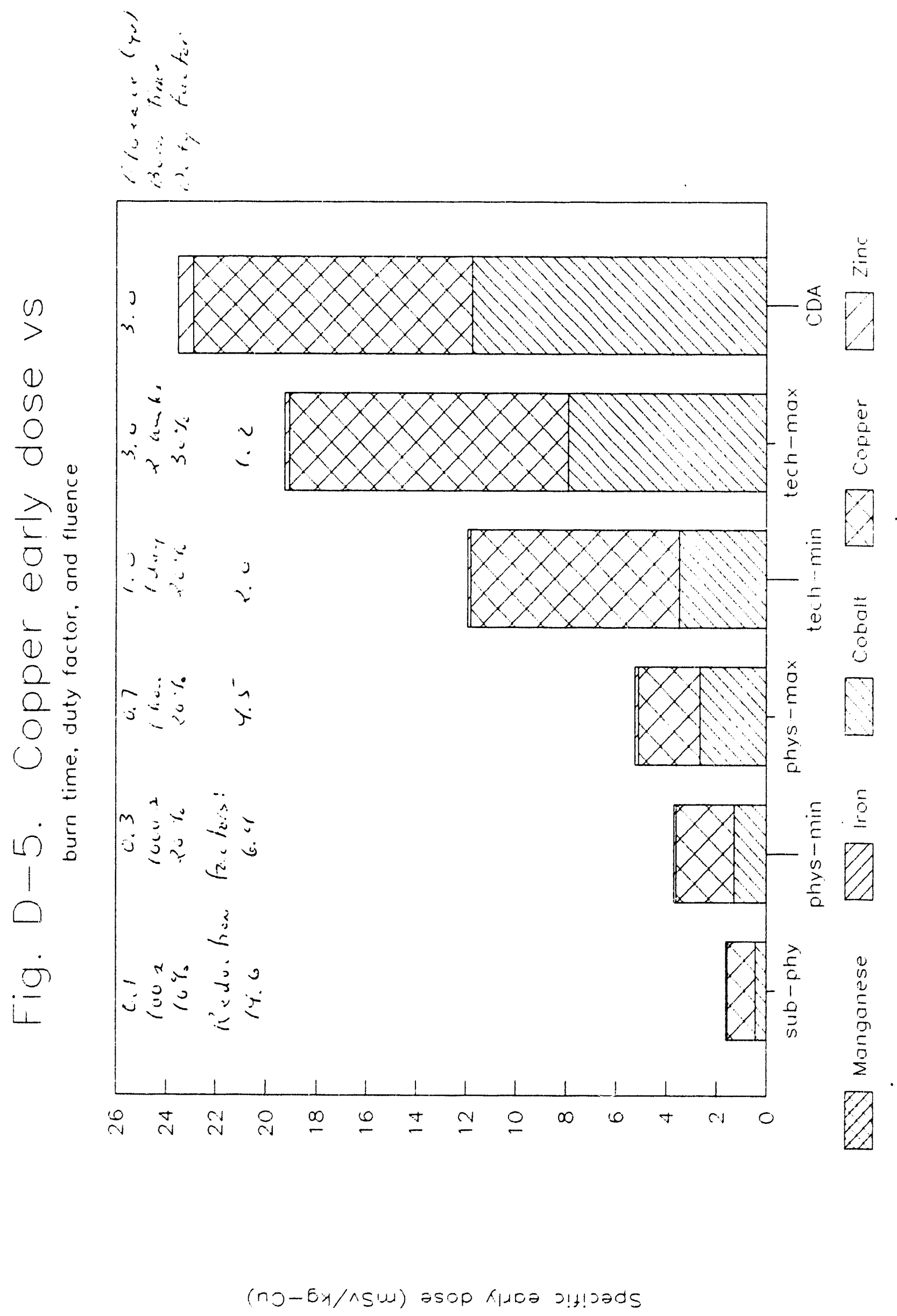

\section{Page 43}




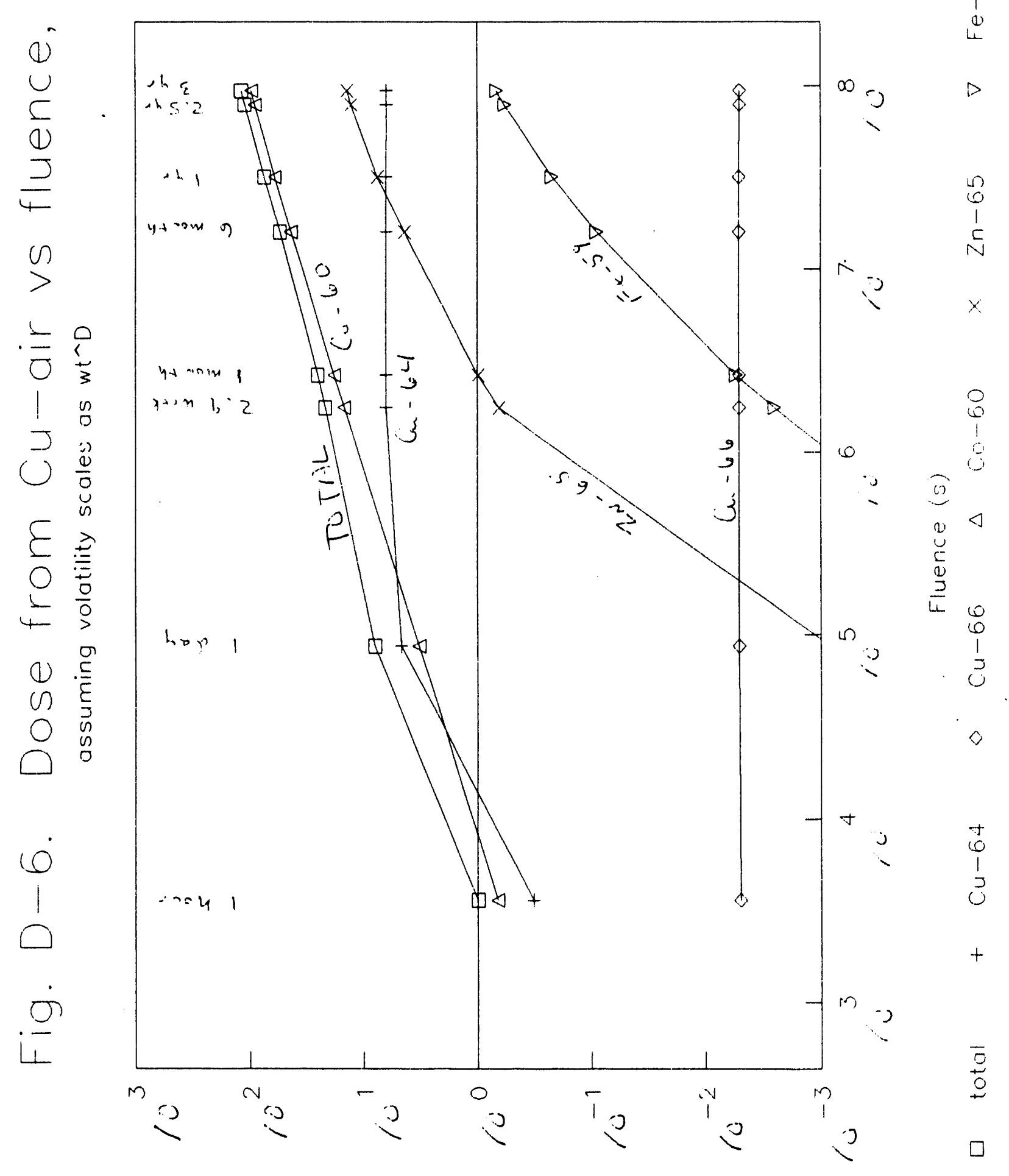

ג!o-no modt ( $\mathrm{sm}$ ) әsop s!land K/ג0 


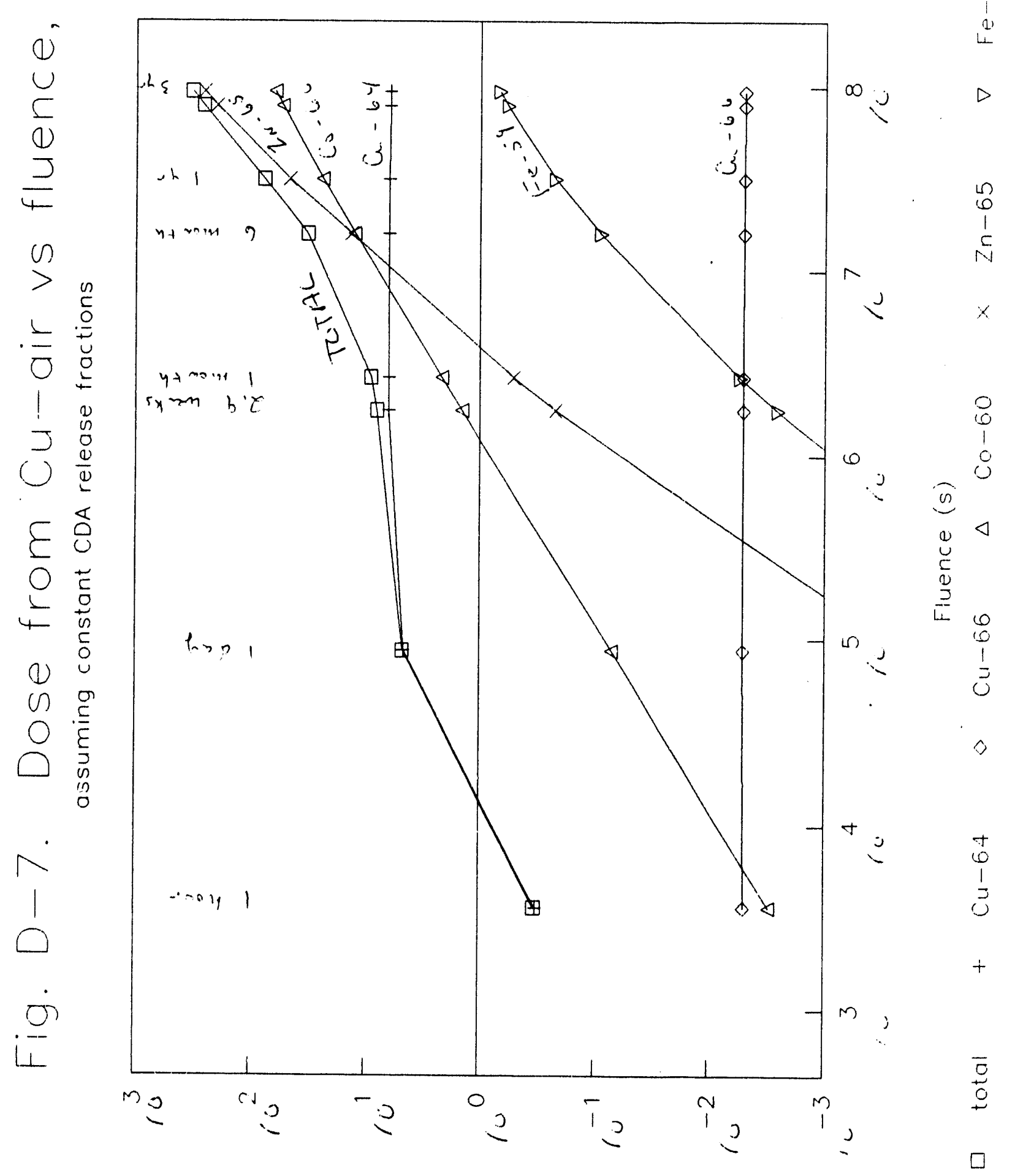

d!o-nj modf (Asm) asop s!land ridoz 


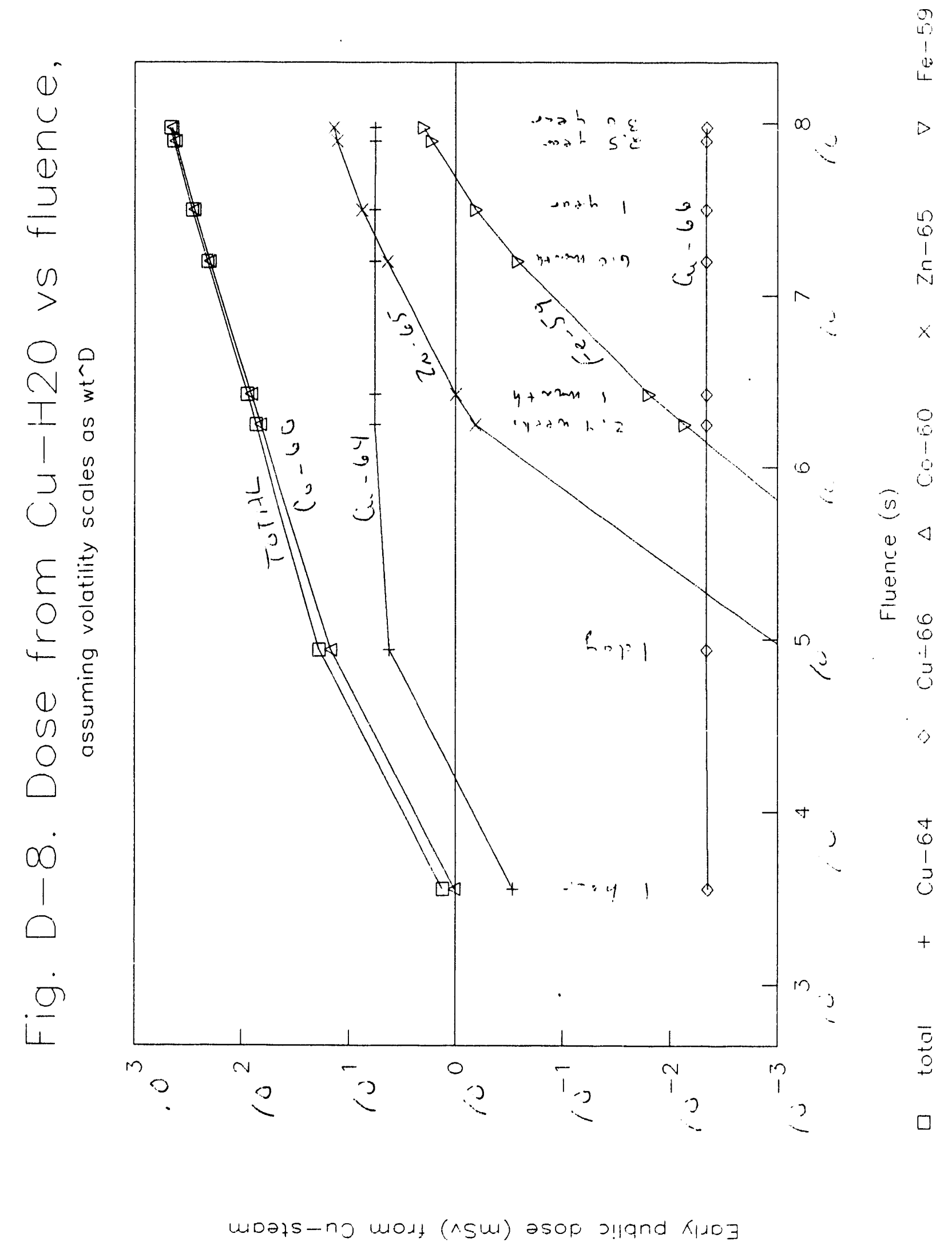

Page 46 


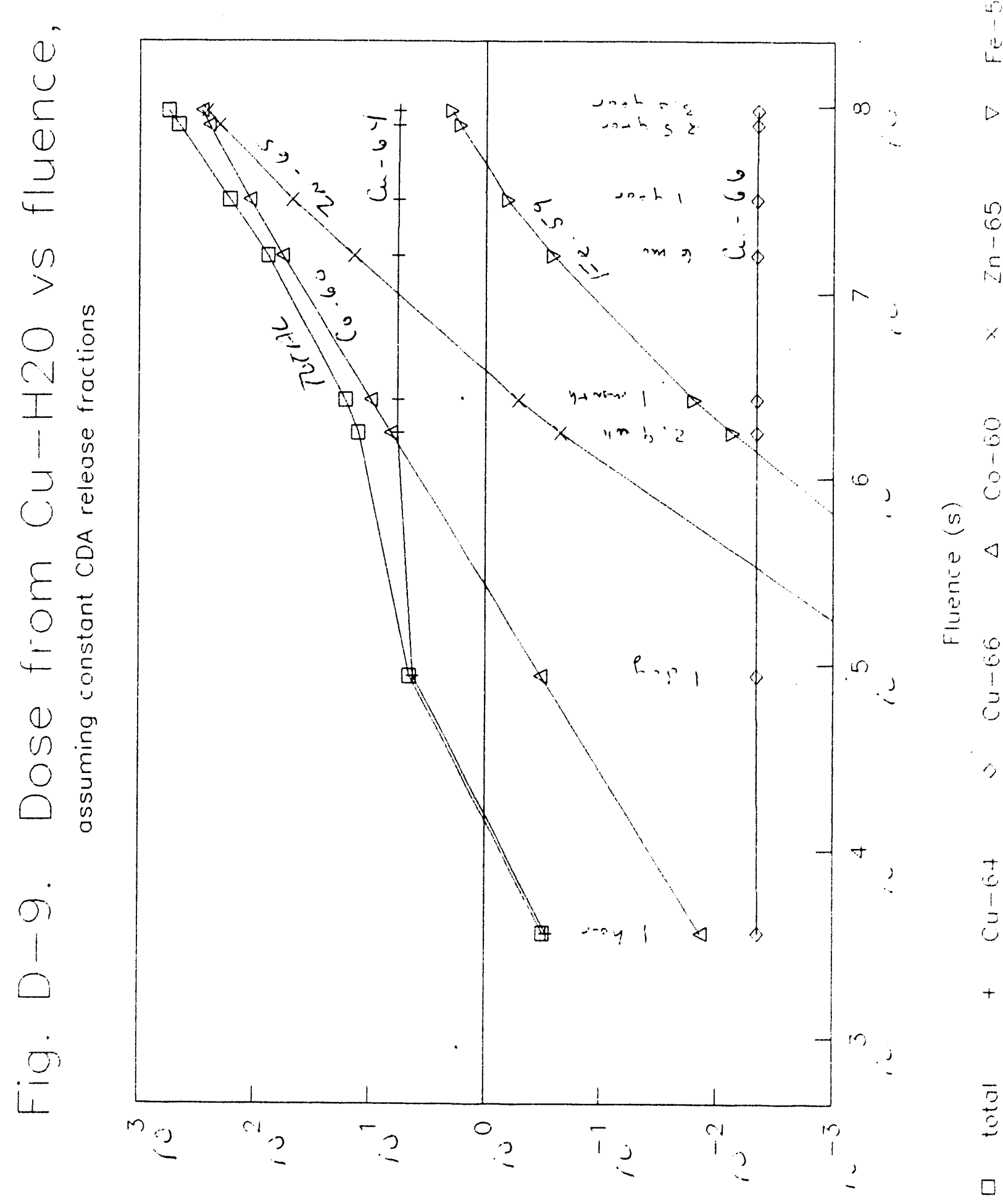

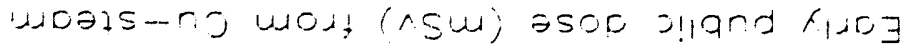




\section{APPENDIX E. TUNGSTEN - FIRST WALL DETAILS}

Figure E-1 shows the specific activity as a function of fluence, based on Attaya's CDA calculation. The tungsten is initially pure. The dominant isotopes all are well predicted by the parent/progeny assumptions. Figure E-2 shows the tungsten specific activity for various ITER "missions." The reduction factors are only 1.3 to 2.6 for technology missions.

Figure E-3 shows the specific dose as a function of fluence, based on Attaya's CDA calculation. The parent/progeny assumptions predict the inventory of W-187 and other tungsten isotopes very well. The other important isotopes are Re-186 and Ta-182, which are not well predicted. Thus, when examining ITER missions, I used the activation inventory from whatever Attaya fluence value was the closest, hopefully reducing the errors for Re-186 and Ta-182 from the parent/progeny assumption. Figure E-4 shows the fourth figure shows the tungsten specific dose for various ITER missions. The reduction factors are only 1.3 to 3.2 for technology missions.

I examined the impact on air and steam volatility. Consistent with the CDA, I assumed the accident was sufficient to heat the tungsten at the first wall to $600{ }^{\circ} \mathrm{C}$ for 7 days. The first issue is how does the composition change with irradiation. The composition changes dramatically. The tungsten is initially pure. At 3.0-yr fluence, the percent of tantalum and rhenium rise to $0.4 \%$ and $4.5 \%$. Because the composition changes so much, the scaling of volatility (Sec. 3.) is critical.

The reduction factors for individual key elements illustrate how the reduction factors for air or steam volatility may differ from the specific dose reduction factor. Depending on air versus steam, temperature, fluence, composition, and composition exponents, etc., one of these elements will dominate the volatility hazard. Mobilization of tungsten dust and W-steam volatility is dominated by tungsten isotopes; so those reduction factors apply. W-air is dominated by tungsten isotopes at low fluence and by rhenium isotopes at high fluence.

Summary of key tungsten (first wall) reduction factors

\begin{tabular}{||l||l|l|l|l||}
\hline & $\begin{array}{l}\text { Minimum } \\
\text { Physics }\end{array}$ & $\begin{array}{l}\text { Maximum } \\
\text { Physics }\end{array}$ & $\begin{array}{l}\text { Minimum } \\
\text { Technology }\end{array}$ & $\begin{array}{l}\text { Maximum } \\
\text { Technology }\end{array}$ \\
\hline \hline Tantalum & 29.1 & 28.0 & 27.7 & 3.1 \\
\hline Tungsten & 4.6 & 4.4 & 1.9 & 1.1 \\
\hline Rhenium & 18.8 & 18.6 & 13.9 & 1.1 \\
\hline \hline $\begin{array}{l}\text { Specific dose over all } \\
\text { elements }\end{array}$ & 7.1 & 6.9 & 3.2 & 1.3 \\
\hline
\end{tabular}


I did some specific calculations for $W$-air and $W$-steam volatility (at $600{ }^{\circ} \mathrm{C}$ ) assuming that the composition exponent for rnenium and tantalum is 1.0 , that is, they behave like dilute solutions in tungsten. (The composition exponent for tungsten is unimportant since the tungsten composition changes little.) Because Re-186 and Ta-182 do not follow the parent/progeny assumption, it was not possible to meaningfully calculate the $W$-air and $W$-steam reduction factors for various ITER missions (function of fluence, burn time, duty factor). But, using Attaya's activation values, I could at least calculate reduction factors as a function of fluence. The reduction factors as a function of fluence only are as follows:

$\begin{array}{lllll} & 38 \text { minutes } & 1 \text { year } & 3 \text { year } & 3.7 \text { year } \\ \text { W-air } & 3300 & 5.0 & 1.3 & 1.0 \\ \text { W-steam } & 115 & 1.7 & 1.1 & 1.0\end{array}$

The 1.0 values at 3.7 year merely state the obvious. All other $W / F W$ calculations used a maximum fluence of 3 years.

The $W$-air case is dominated by Re-186. Since Re-186 is more influenced by lower fluence, the $W$-air reduction factors are higher than $W$-steam, which is dominated by $W-187$. The 1-year reduction factors (5.0 for $W$-air, 1.7 for $W$ steam) are similar to the "minimum-technology" reduction factors noted above. Specifically, the 1.7 value for $W$-steam ( 1 -yr continuous irradiation) is similar to the 1.9 value for $W$ isotopes for $1-y r$ fluence, $20 \%$ duty factor, 1 day pulses. (Since $W$ isotopes dominate $W$-air, this is expected.) The 5.0 value for $W$-air (1yr continuous irradiation) is between the 1.9 value for $W$ isotopes and 13.9 for rhenium isotopes. At higher fluence, $W$-air is dominated by rhenium; as the fluence and Re-186 inventory drop, $W$ isotopes contribute more. 


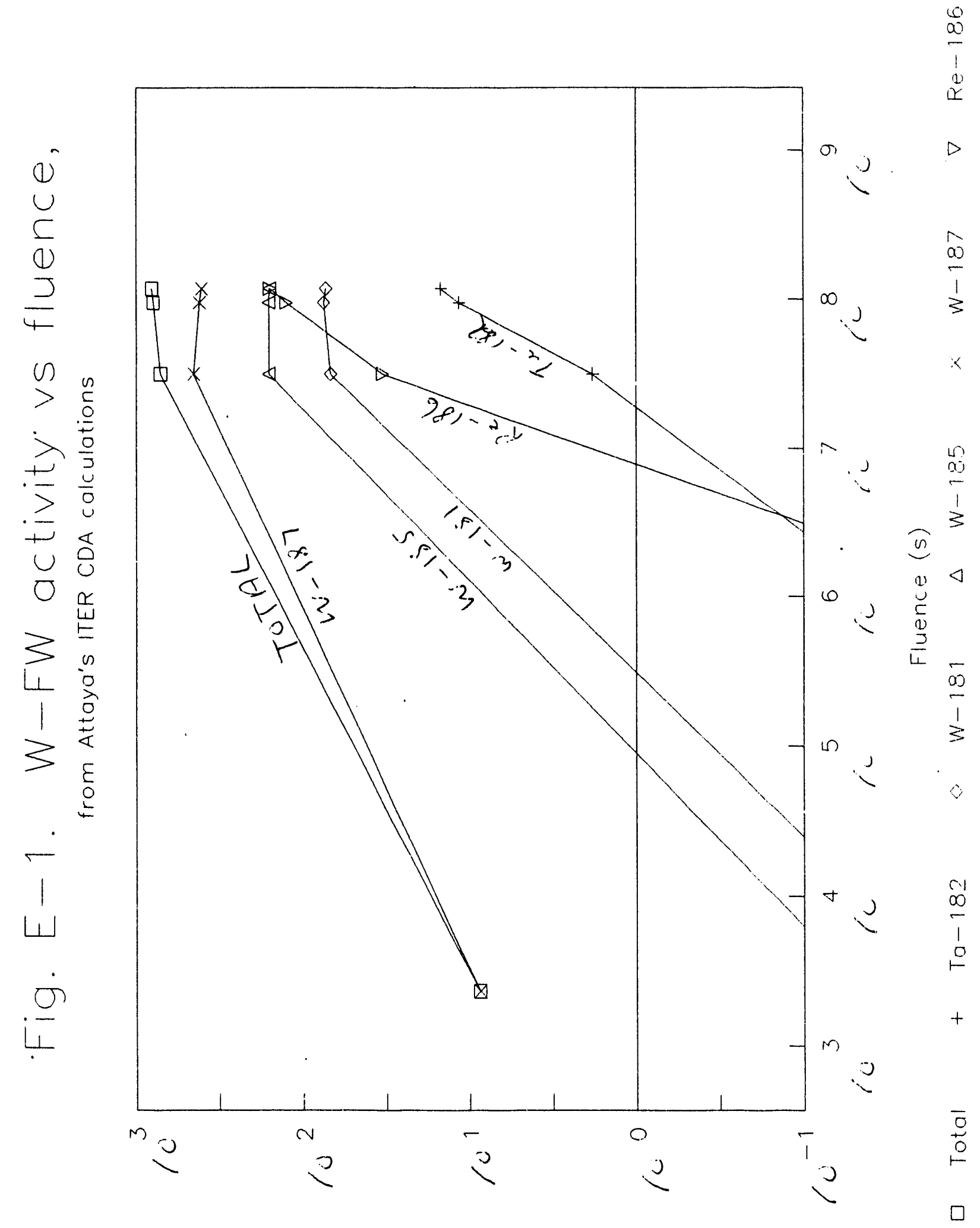

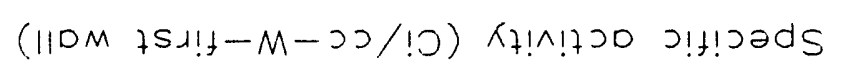

Page 50 


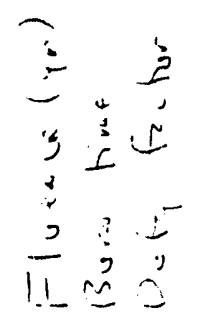

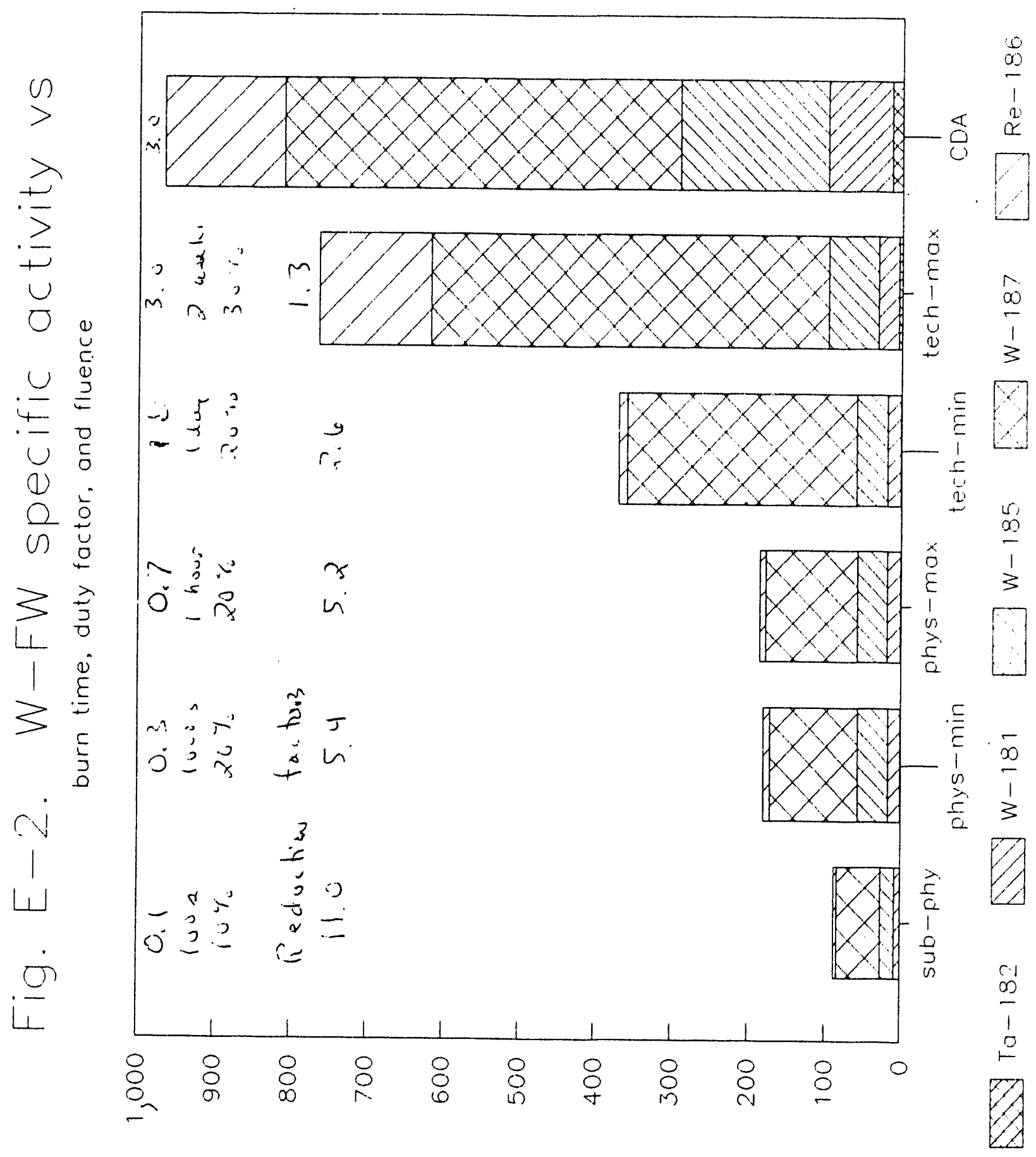

$(110 M+75 \mu ! f-M-20 / 10) K+! \wedge ! 720 \quad 2 ! f ! 32 d S$ 


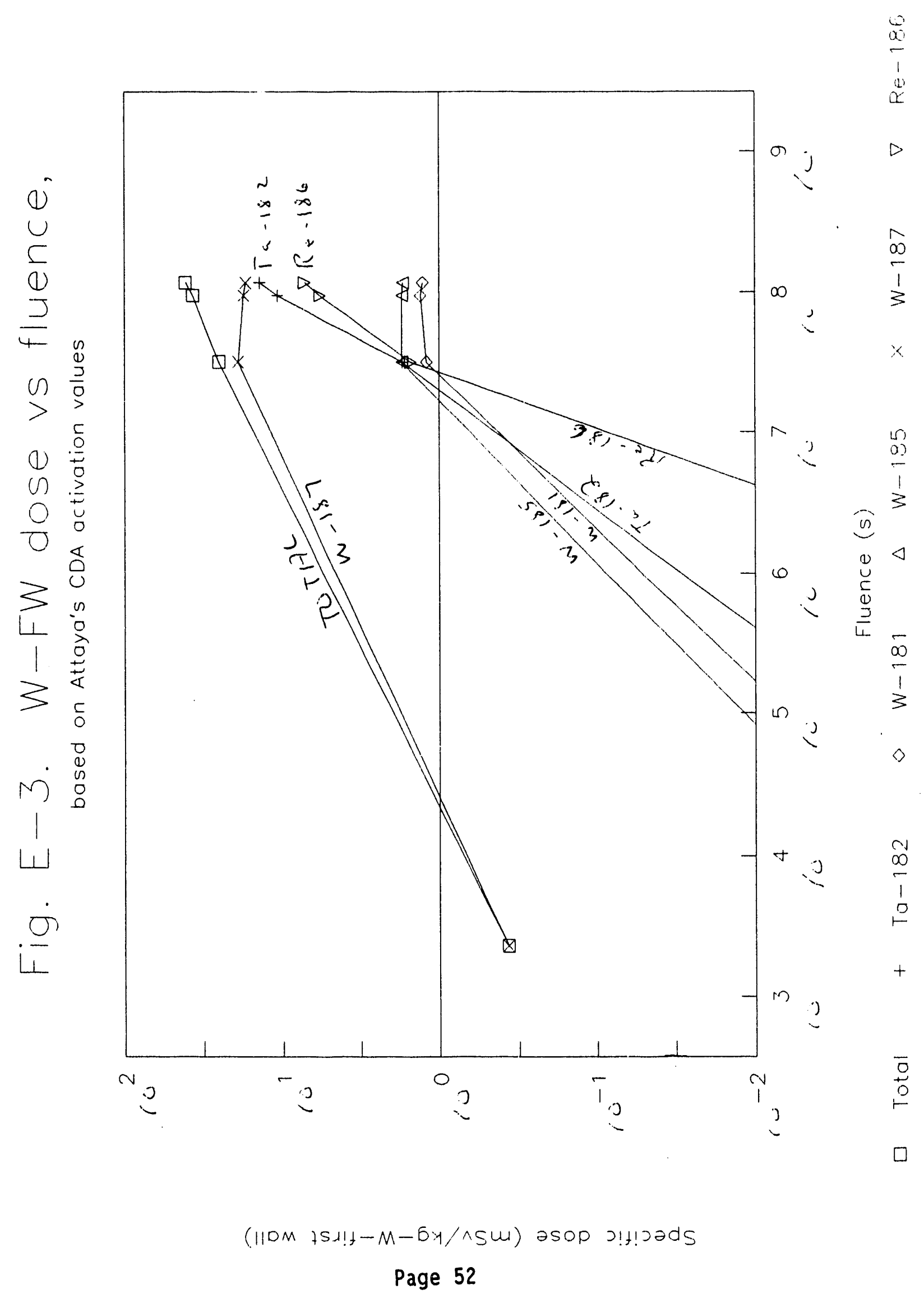




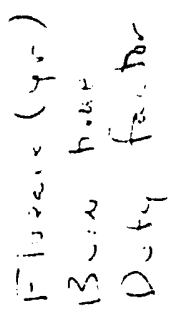

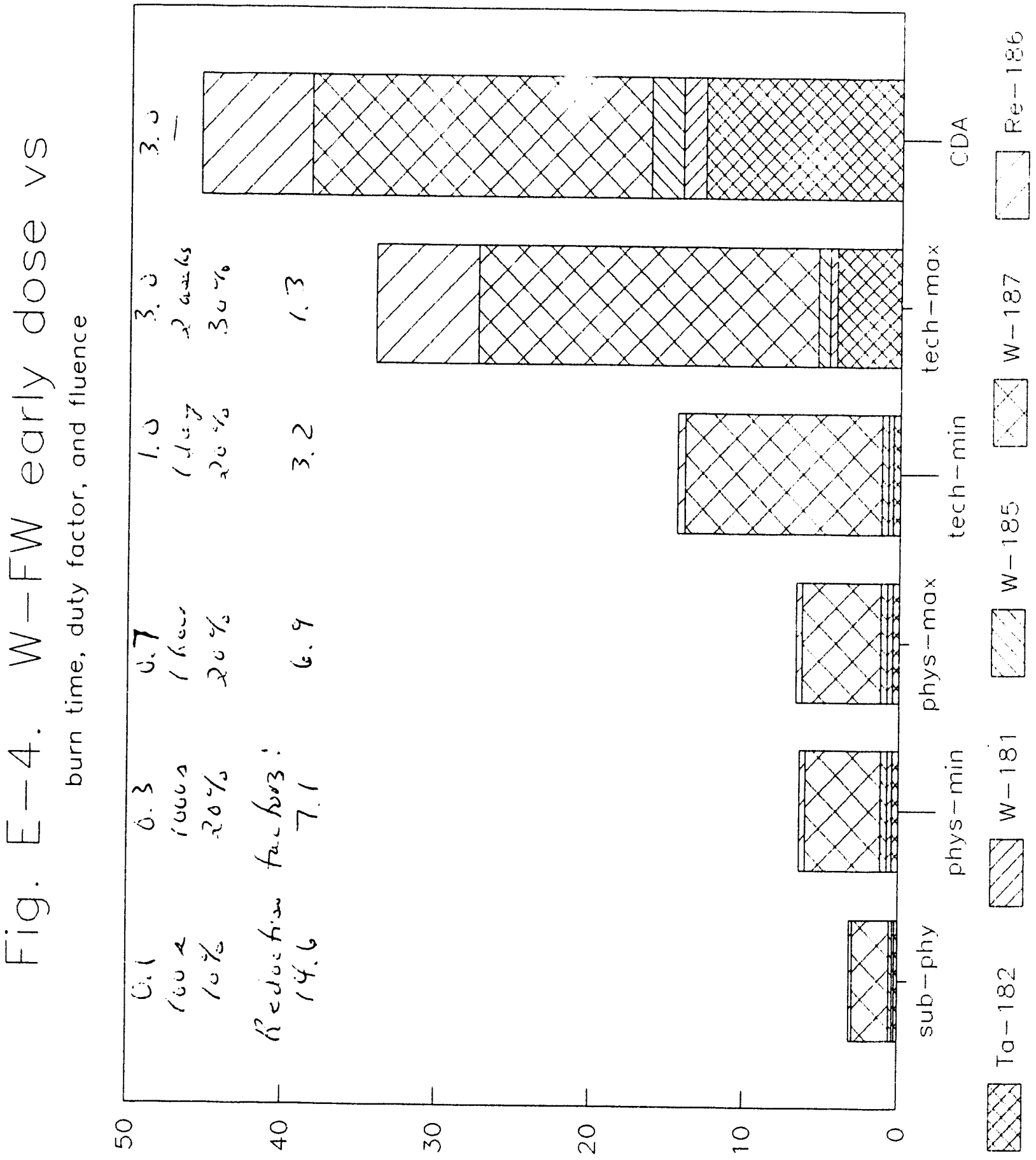

(110M 7Sג!t-M-EY/ASM) әSOP 2!!!ว2dS

Page 53 


\section{APPENDIX F. TUNGSTEN - DIVERTOR DETAILS}

This case is the basically same as the tungsten-first wall case, except the total fluence is lower. There are also some neutron spectrum differences, since the niobium substrate is behind the tungsten divertor coating and steel is behind the tungsten first wall coating.

Figure F-1 shows the specific activity as a function of fluence, based on $H$. Attaya's CDA calculation. Note that there are more time-edit points before shutdown than for the $W / F W$ case. The tungsten is initially pure. The dominant isotopes all are well predicted by the parent/progeny assumptions. Figure F-2 shows the tungsten specific activity for various ITER "missions." The reduction factors are only 1.5 to 2.7 for technology missions.

Figure F-3 shows the specific dose as a function of fluence, based on Attaya's CDA calculation. The parent/progeny assumptions predict the inventory of W-187 and other tungsten isotopes very well. The other important isotopes are Re-186 and Ta-182, which are not well predicted. Thus, when examining ITER missions, I used the activation inventory from whatever Attaya fluence value was the closest, hopefully reducing the errors for $\mathrm{Re}-186$ and Ta-182 from the parent/progeny assumption. (Because there are more time-edit points than in the W/FW case, this approaches works better here.) Figure F-4 shows the fourth figure shows the tungsten specific dose for various ITER missions. The reduction factors are only 1.2 to 2.3 for technology missions.

I examined the impact on air and steam volatility. Consistent with the CDA, I assumed the worst case accident raises the temperature to $700{ }^{\circ} \mathrm{C}$ for the divertor (versus $600^{\circ} \mathrm{C}$ for the first wall/blanket/shield) for 7 days. The first issue is how does the composition change with irradiation. The composition changes dramatically. The tungsten is initially pure. At 1.0-yr fluence, the percent of tantalum and rhenium rise to $0.03 \%$ and $0.21 \%$. Because the composition changes so much, the scaling of volatility (Sec. 3.) is critical.

I did some specific calculations for $W$-air and $W$-steam volatility (at $600{ }^{\circ} \mathrm{C}$ ) assuming that the composition exponent for rhenium and tantalum is 1.0 , that is, they behave like dilute solutions in tungsten. (The composition exponent for tungsten is unimportant since the tungsten composition changes little.) Because Re-186 and Ta-182 do not follow the parent/progeny assumption, it was not possible to meaningfully calculate the li-air and $W$-steam reduction factors for various ITER missions (function of fluence, burn time, duty factor). But, using Attaya's activation values, I could at least calculate reduction factors as a function of fluence.

Ignoring burn time and duty factor, Figures F-5 and F-6 show the dose from $W$-air volatility as a function of fluence for two cases. One, assume a variable case where volatility scales as the elemental composition, $c_{i}$, to the $D$ power (D = composition exponent). Then, the volatility flux varies as $c_{i}{ }^{D}$ and the release fraction varies as $c_{i}{ }^{D} \cdot$. The dose varies less than linearly with fluence because the increasing specific activity is partially offset by falling release fractions. Two, assume fixed release fractions. This is roughly equivalent to setting $D=1$ for all elements. The volatility flux varies as $c_{i}$, release 
fractions are constant, and the dose varies approximately as fluence because the specific activity is increasing. The first case (variable release fractions, volatility flux) is probably the best assumption at the present time. See reference 5 .

Figures F-7 and F-8 show the same type of information, except for W-steam instead of W-air. Clearly, we need to better understand the impact of changing composition on volatility.

The reduction factors for individual key elements illustrates how the reduction factors for air or steam volatility may differ from the specific dose reduction factor. Depending on air versus steam, temperature, fluence, composition, and composition exporients, etc., one of these elements will dominate the volatility hazard. Mobilization of tungsten dust and W-steam volatility is dominated by tungsten isotopes; so those reduction factors apply. W-air is dominated by tungsten isotopes at low fluence and by rhenium isotopes at high fluence.

Summary of key tungsten (divertor) reduction factors

\begin{tabular}{||l|l|l|l|l||}
\hline & $\begin{array}{l}\text { Minimum } \\
\text { Physics }\end{array}$ & $\begin{array}{l}\text { Maximum } \\
\text { Physics }\end{array}$ & $\begin{array}{l}\text { Minimum } \\
\text { Technology }\end{array}$ & $\begin{array}{l}\text { Maximum } \\
\text { Technology }\end{array}$ \\
\hline \hline Tantalum & 11.6 & 4.5 & 4.4 & 2.7 \\
\hline Tungsten & 4.9 & 4.7 & 2.2 & 1.2 \\
\hline Rhenium & 20.5 & 4.9 & 3.7 & 1.1 \\
\hline $\begin{array}{l}\text { Specific dose over all } \\
\text { elements }\end{array}$ & 5.1 & 4.7 & 2.3 & 1.2 \\
\hline
\end{tabular}




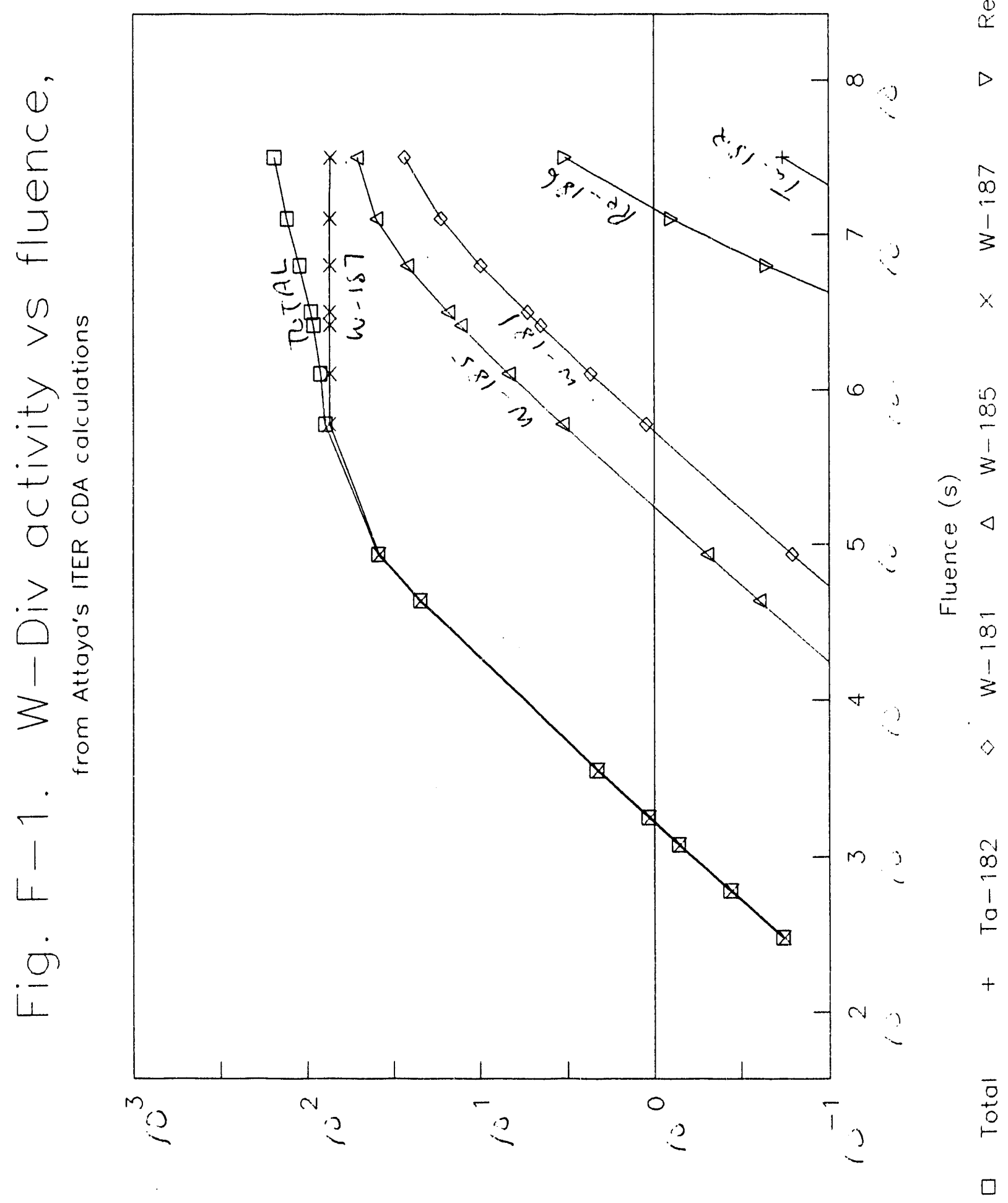

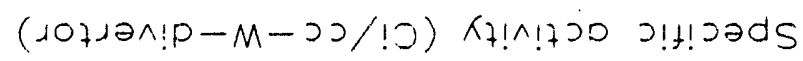

Page 56 


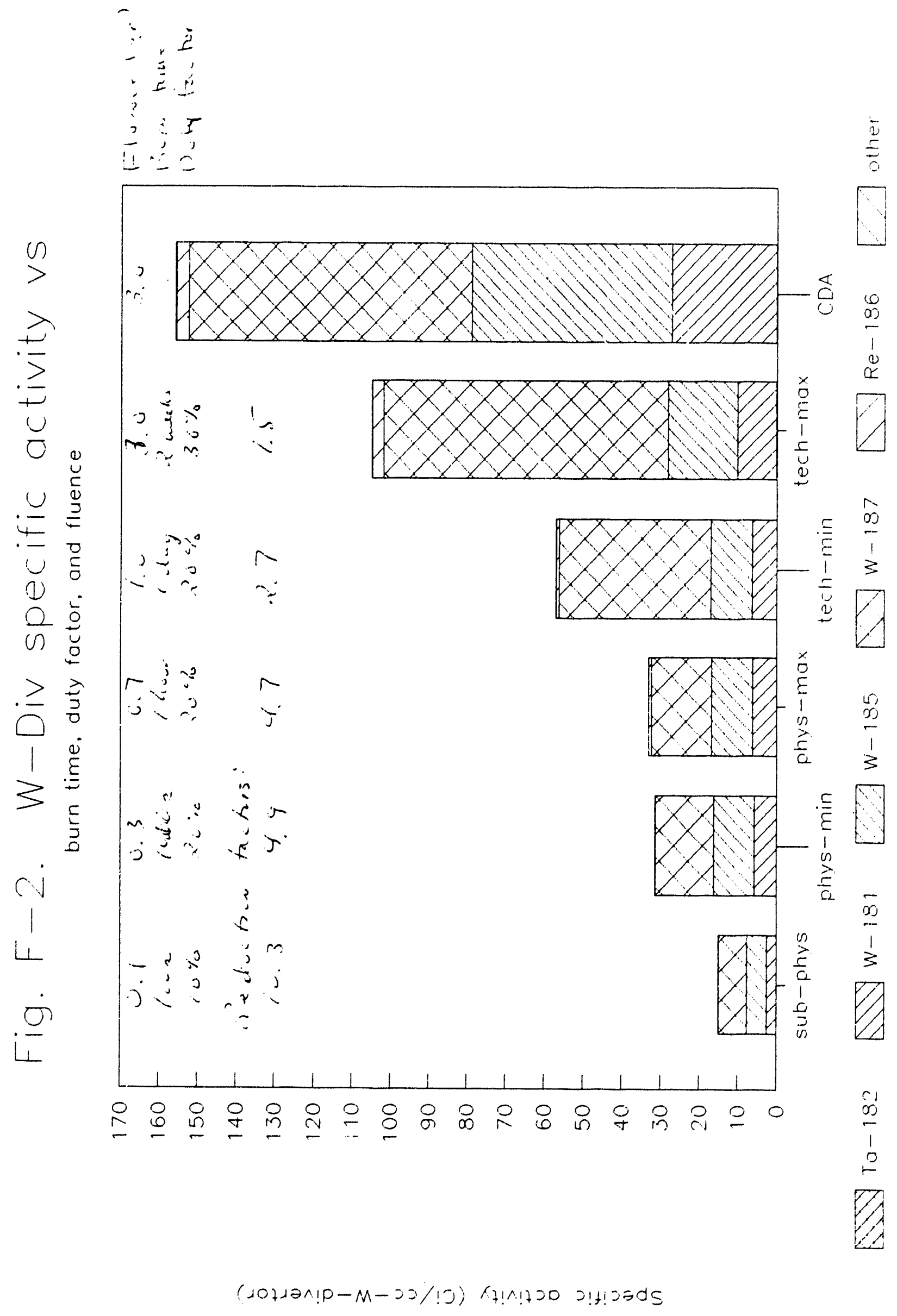

Page 57 


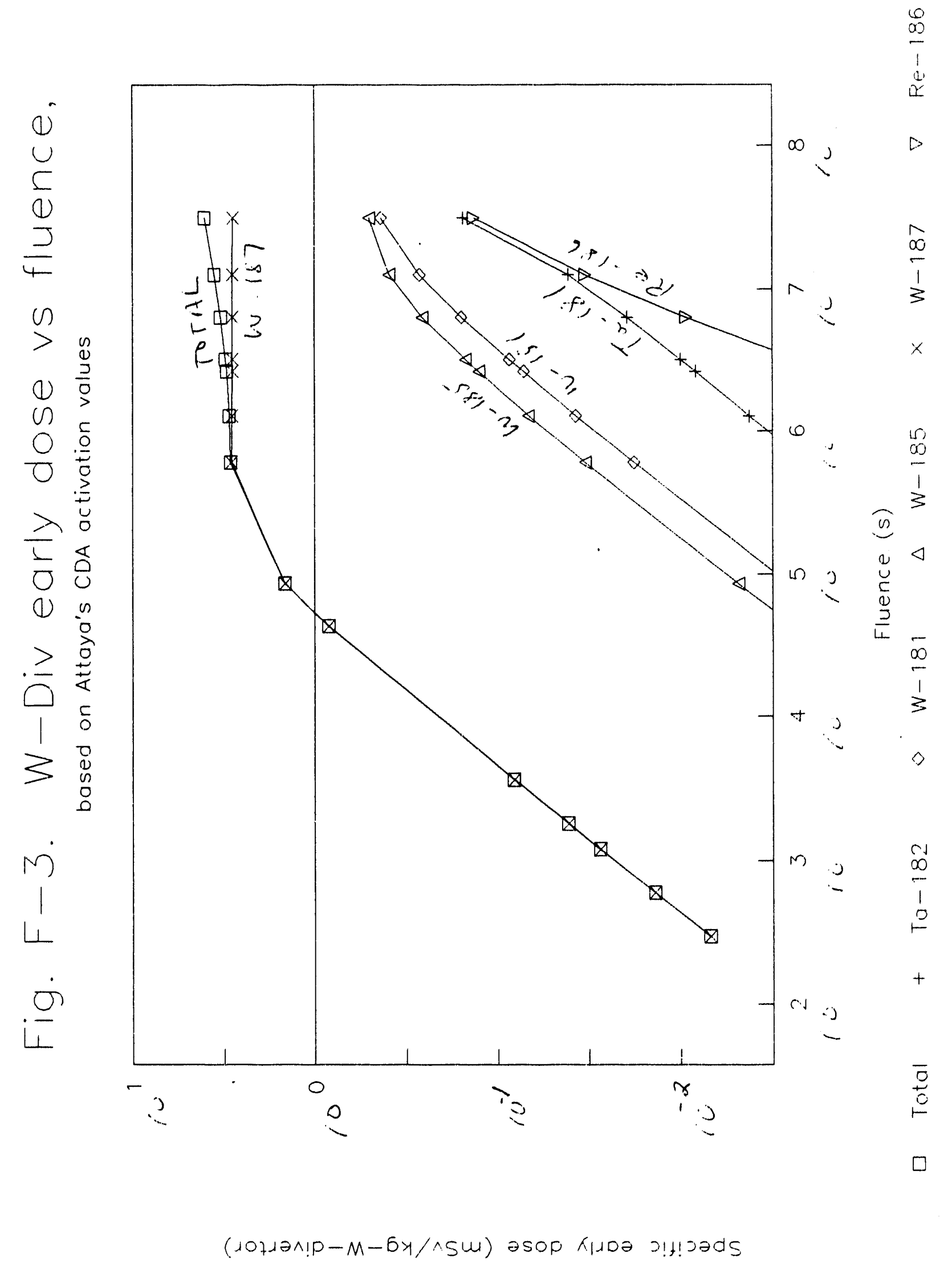




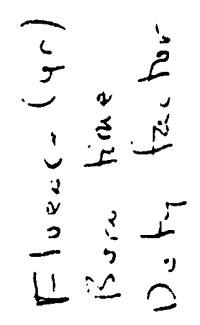

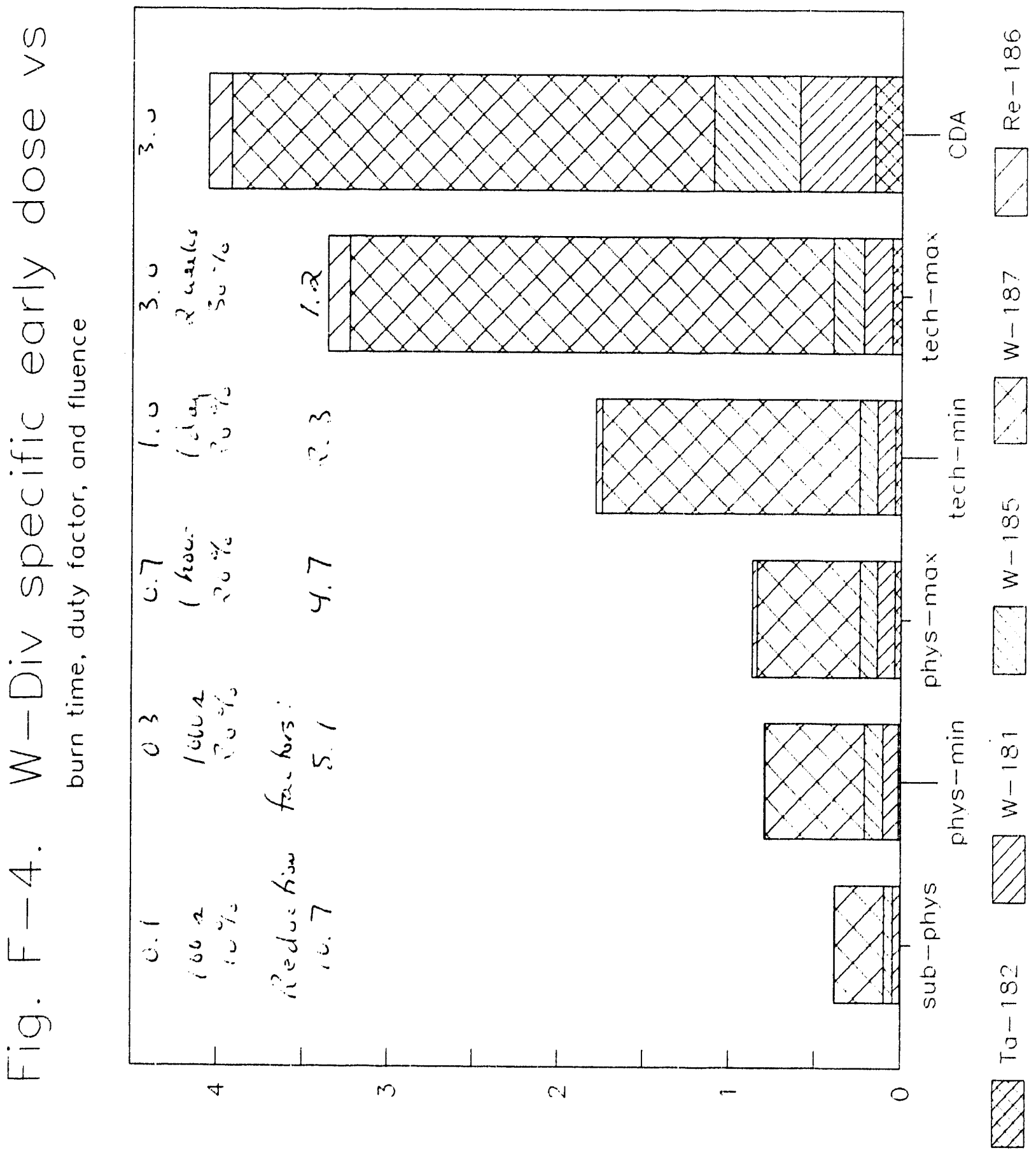

$(10+12 \mu ! p-M-6 \lambda / \wedge s \mu)$ әSCp K1100 J!f!jads 


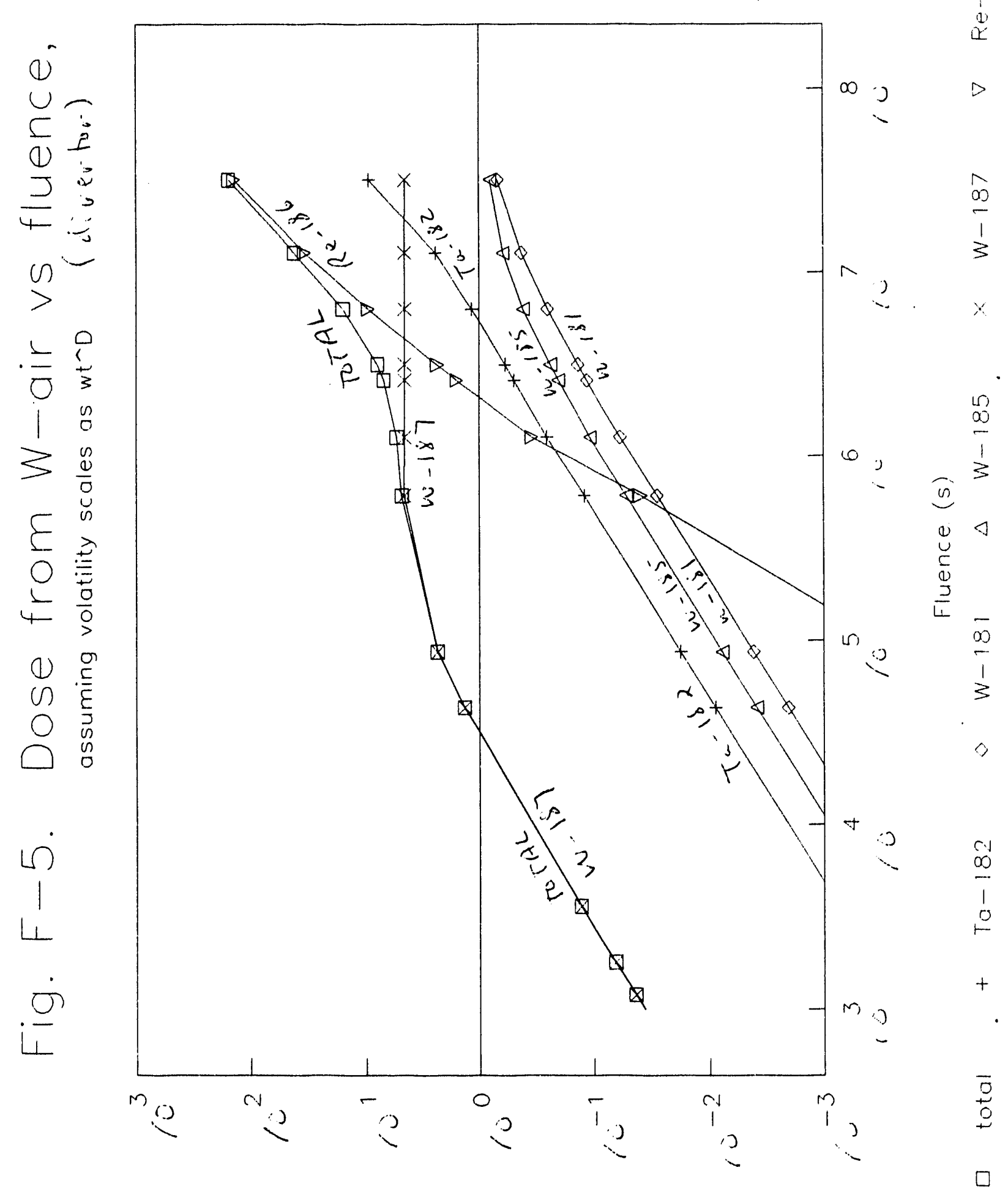

1!O-M wodf ( 


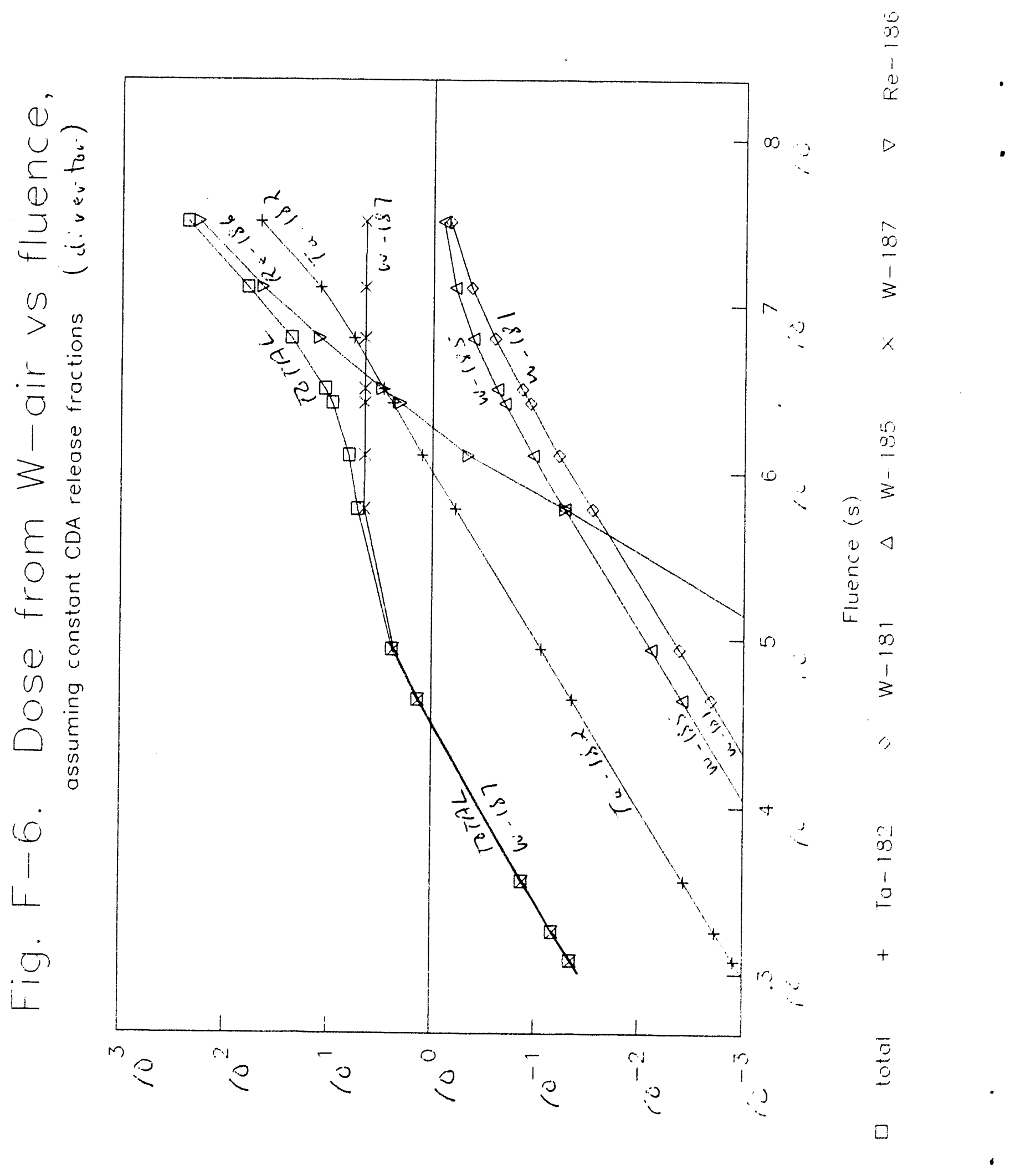

1!O-N Wodt (ASU) asop s!land K1doz 


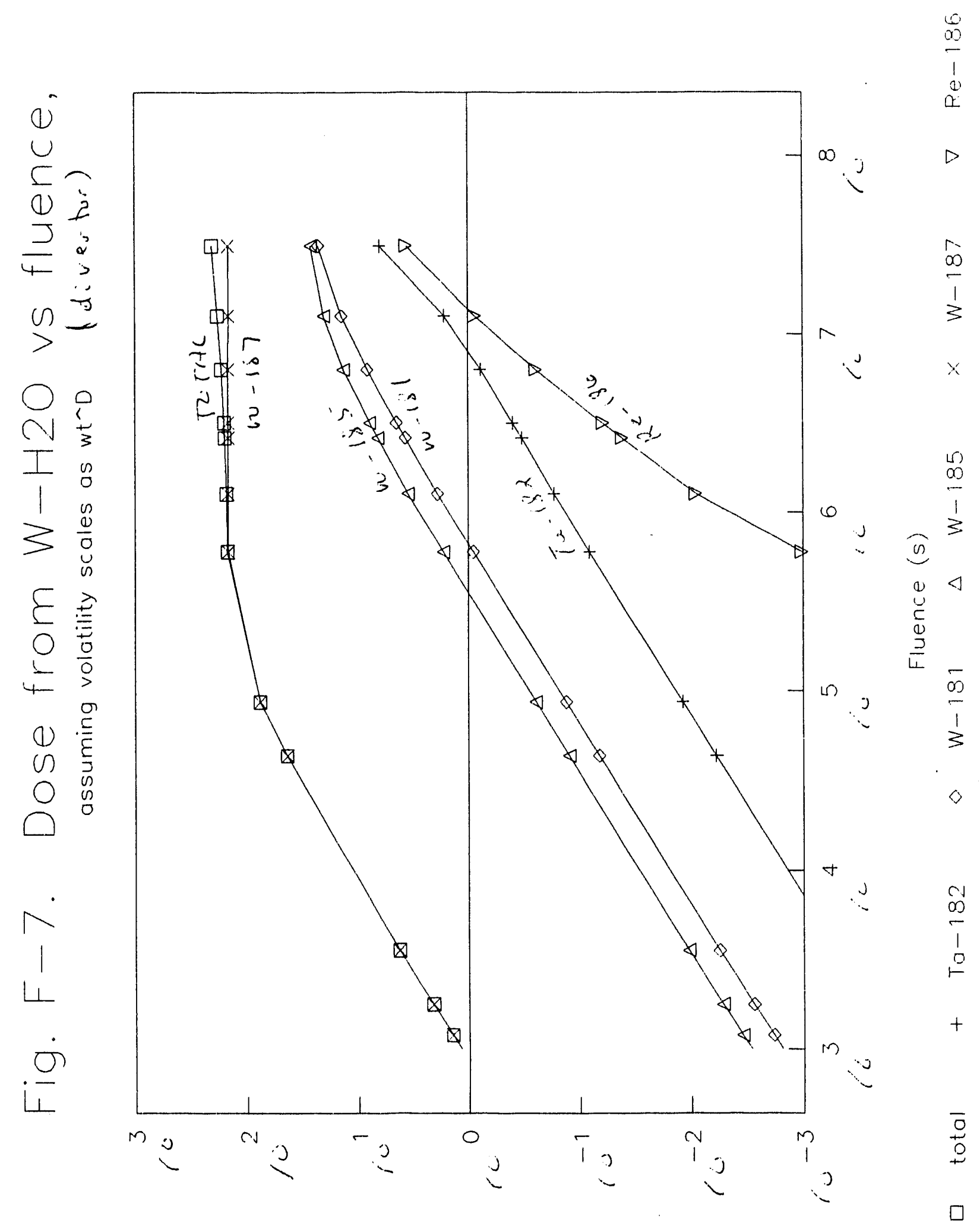

morts-M Uiodf (ASM) rsop s!land K.10

Page 62 


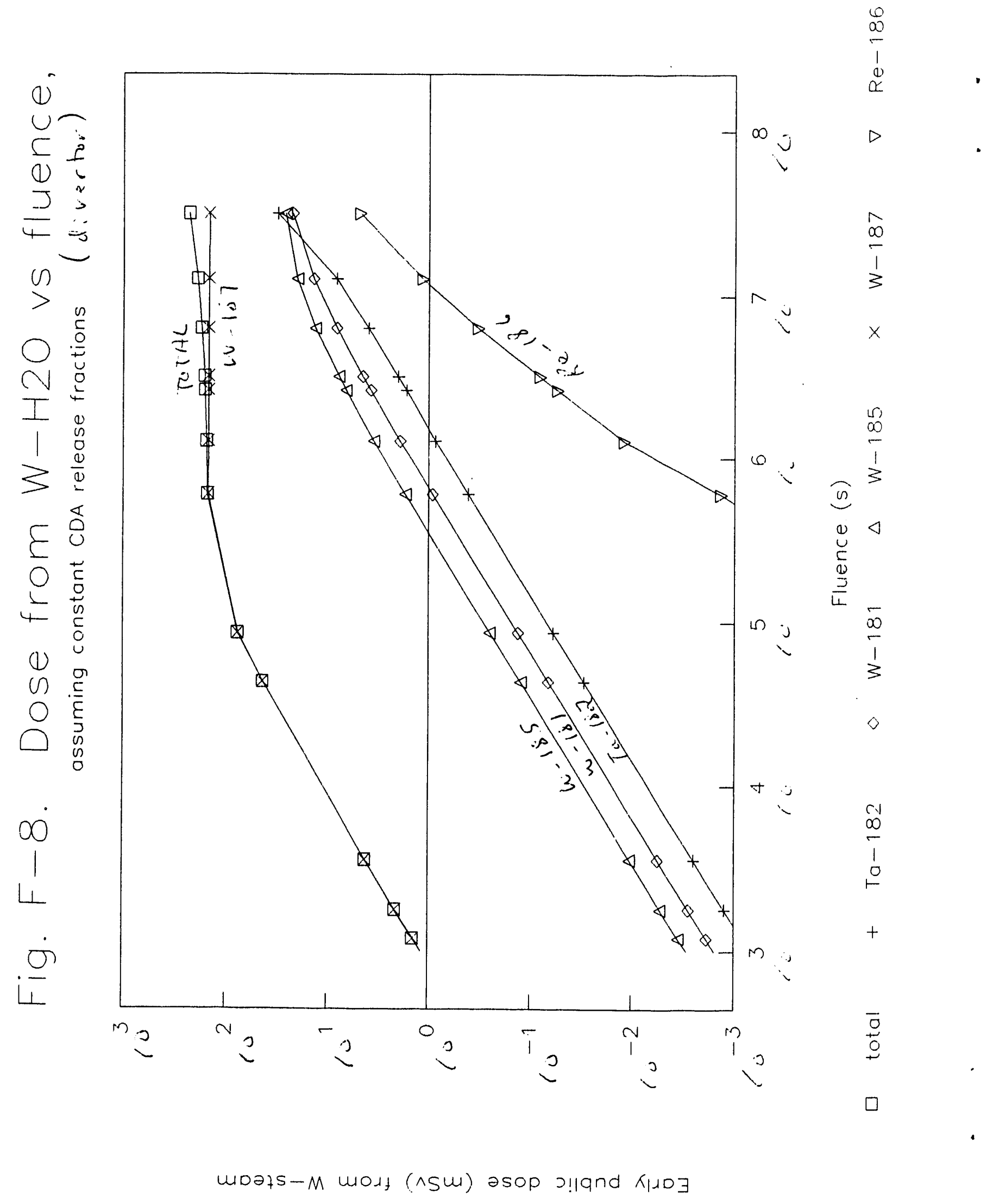

Page 63 


\section{APPENDIX G. NIOBIUM - DIVERTOR DETAILS}

Figure G-1 the specific activity as a function of fluence, based on $H$. Attaya's CDA calculation. The dominant isotopes all are well predicted by the parent/progeny assumptions. Figure G-2 shows the tungsten specific activity for various ITER "missions." The reduction factors are only 1.2 to 1.6 for technology missions.

Figure G-3 shows the specific dose as a function of fluence, based on $H$. Attaya's CDA calculation. The parent/progeny assumptions predict the important isotopes adequately we11. Figure G-4 shows the fourth figure shows the niobium specific dose for various ITER missions. The reduction factors are only 1.6 to 4.4 for technology missions. Figure $G-5$ is the same as G-4, except the contributions are grouped by chemical element instead of individual isotopes. Clearly, niobium isotopes dominate.

I examined the impact on air and steam volatility. Consistent with the CDA, I assumed the accident was capable of raising the divertor temperature to $700{ }^{\circ} \mathrm{C}$ for 7 days. The first issue is how does the composition change with irradiation. The composition changes dramatically. The initial composition of nominal $\mathrm{Nb}-1 \mathrm{Zr}$ includes $\mathrm{Zr}(0.95 \%), \mathrm{Nb}(98.82 \%), \mathrm{Ta}(0.06 \%)$, and $\mathrm{W}(0.03 \%)$. At $1.0-y r$ fluence, the percent of these elements does not change much, but $Y$ grows to $0.0006 \%$ and $\operatorname{Re}$ to $0.0002 \%$.

The reduction factors for individual elements illustrates how the reduction factors for air or steam volatility may differ from the specific dose reduction factor. Depending on air versus steam, temperature, fluence, composition, and composition exponents, etc., one of these elements will dominate the volatility hazard.

Summary of key niobium (divertor) reduction factors

\begin{tabular}{||l|l|l|l|l||}
\hline & $\begin{array}{l}\text { Minimum } \\
\text { Physics }\end{array}$ & $\begin{array}{l}\text { Maximum } \\
\text { Physics }\end{array}$ & $\begin{array}{l}\text { Minimum } \\
\text { Technology }\end{array}$ & $\begin{array}{l}\text { Maximum } \\
\text { Technology }\end{array}$ \\
\hline \hline Yttrium & 5.0 & 4.9 & 3.2 & 1.0 \\
\hline Zirconium & 5.0 & 4.9 & 3.7 & 1.2 \\
\hline Niobium & 5.0 & 5.0 & 4.6 & 1.5 \\
\hline Tantalum & 4.6 & 4.5 & 4.4 & 2.7 \\
\hline Tungsten & 4.9 & 4.7 & 1.9 & 1.0 \\
\hline \hline $\begin{array}{l}\text { Specific dose over al1 } \\
\text { elements }\end{array}$ & 5.0 & 4.9 & 4.4 & 1.6 \\
\hline
\end{tabular}




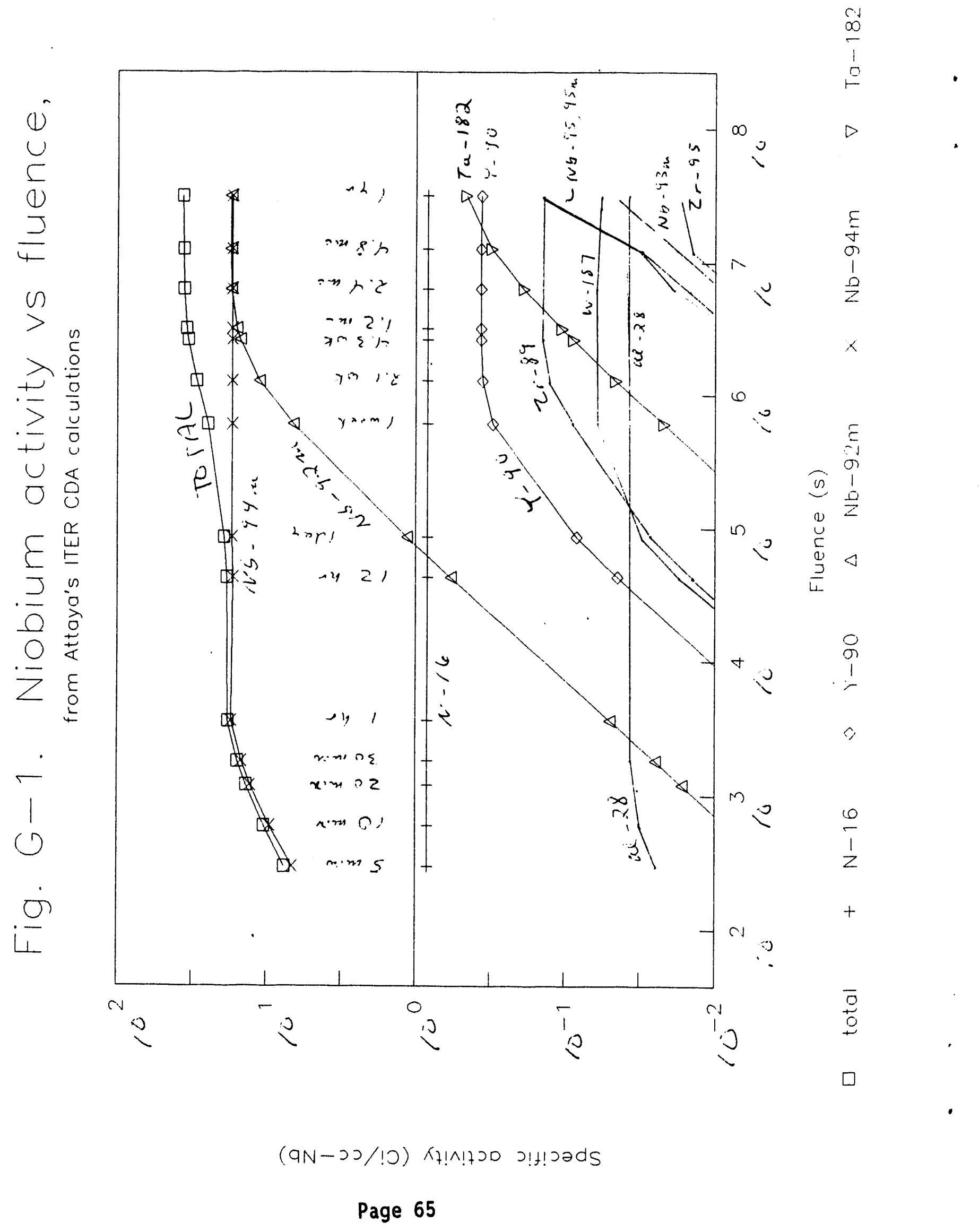




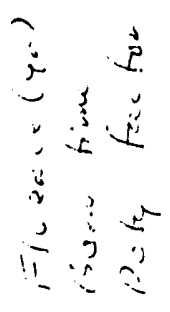

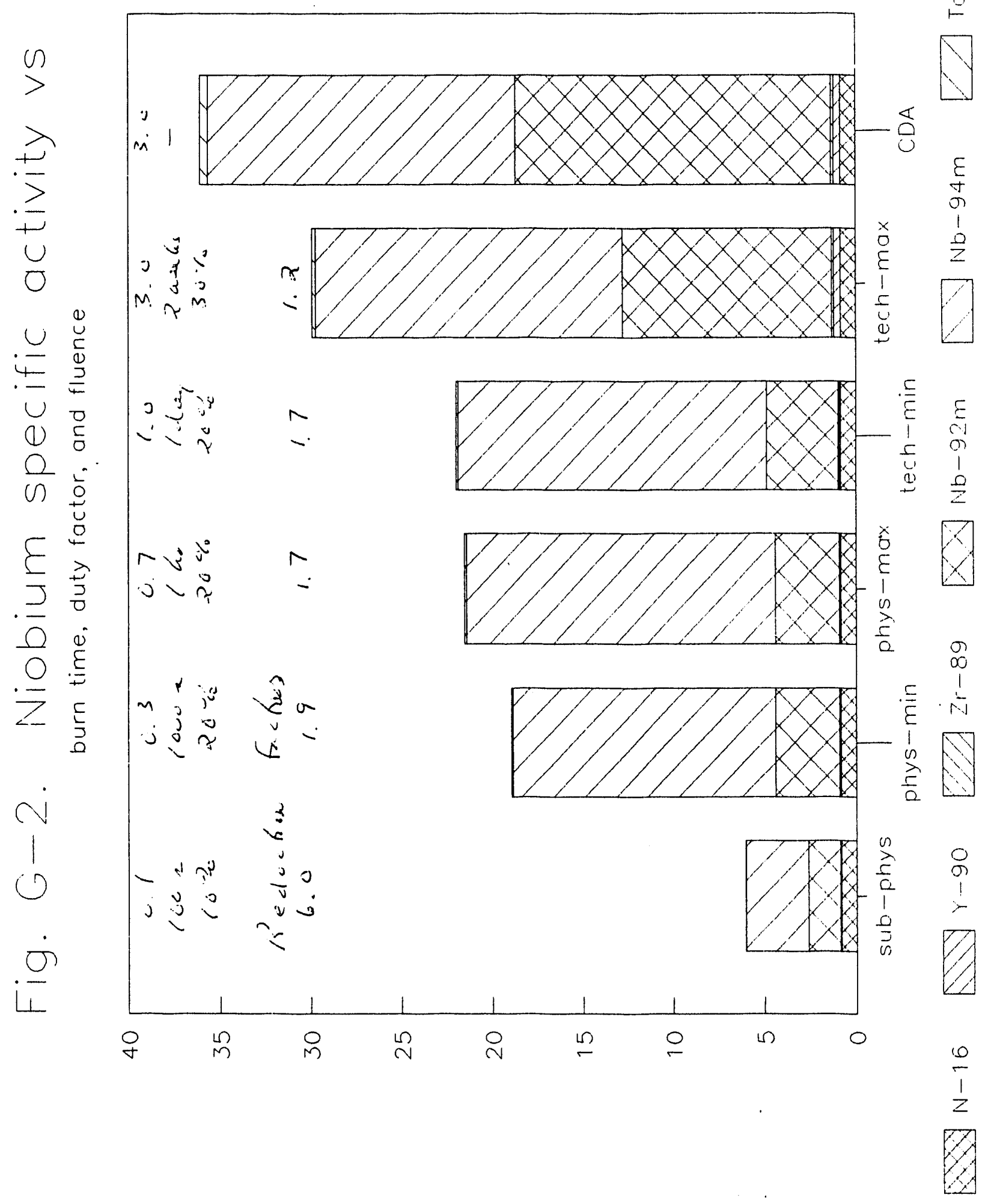

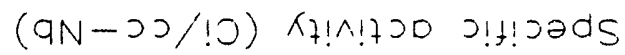




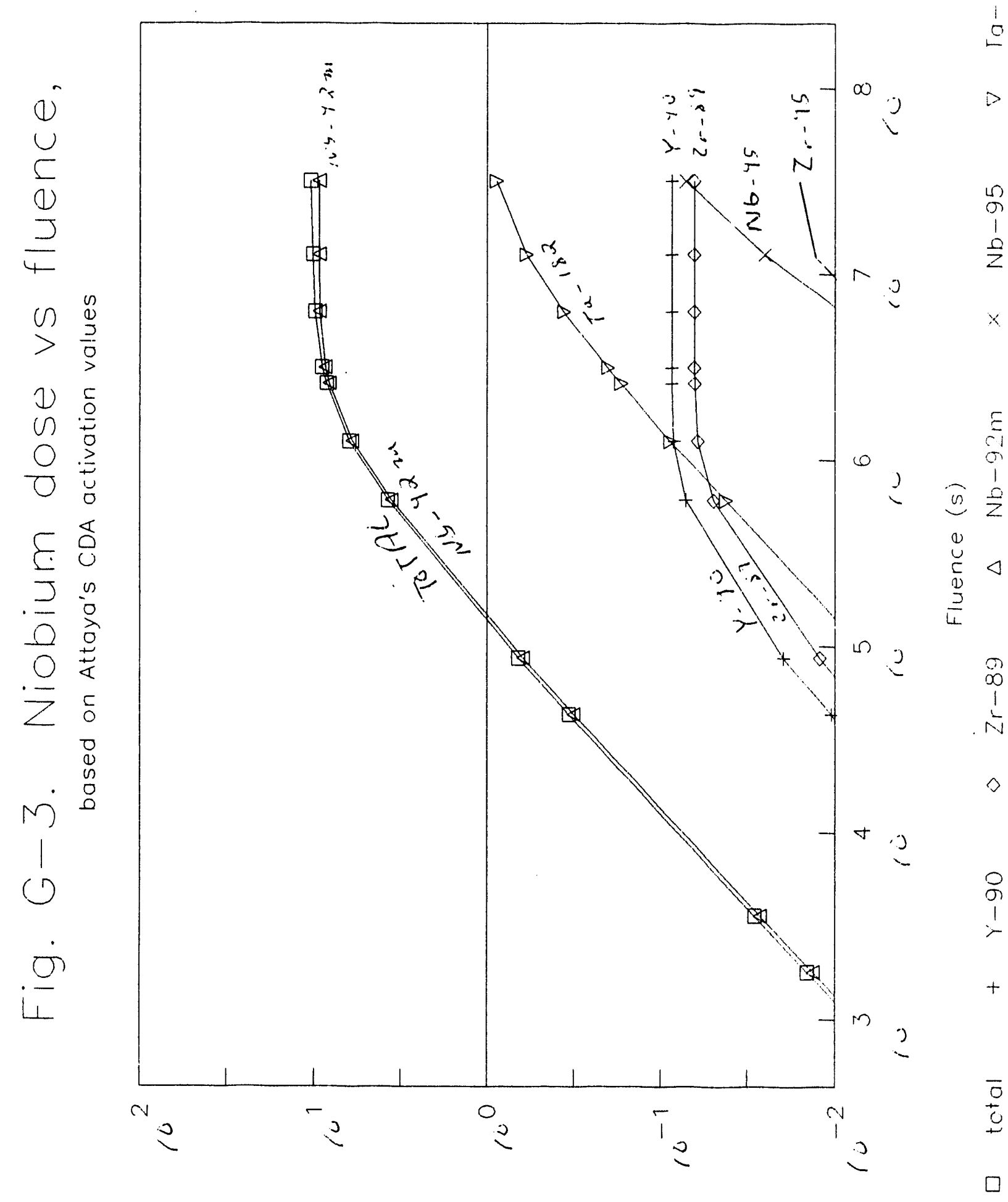

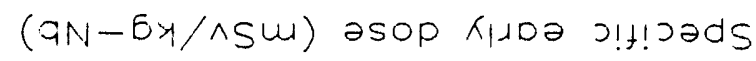




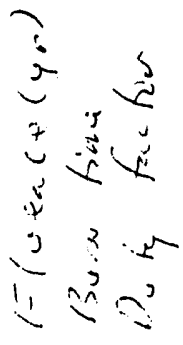

$>$

(1)

0

$\frac{\pi}{0}$

(1) $\frac{0}{0}$

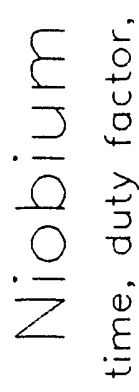

$+\frac{5}{3}$

1

$\dot{\square}$

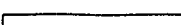
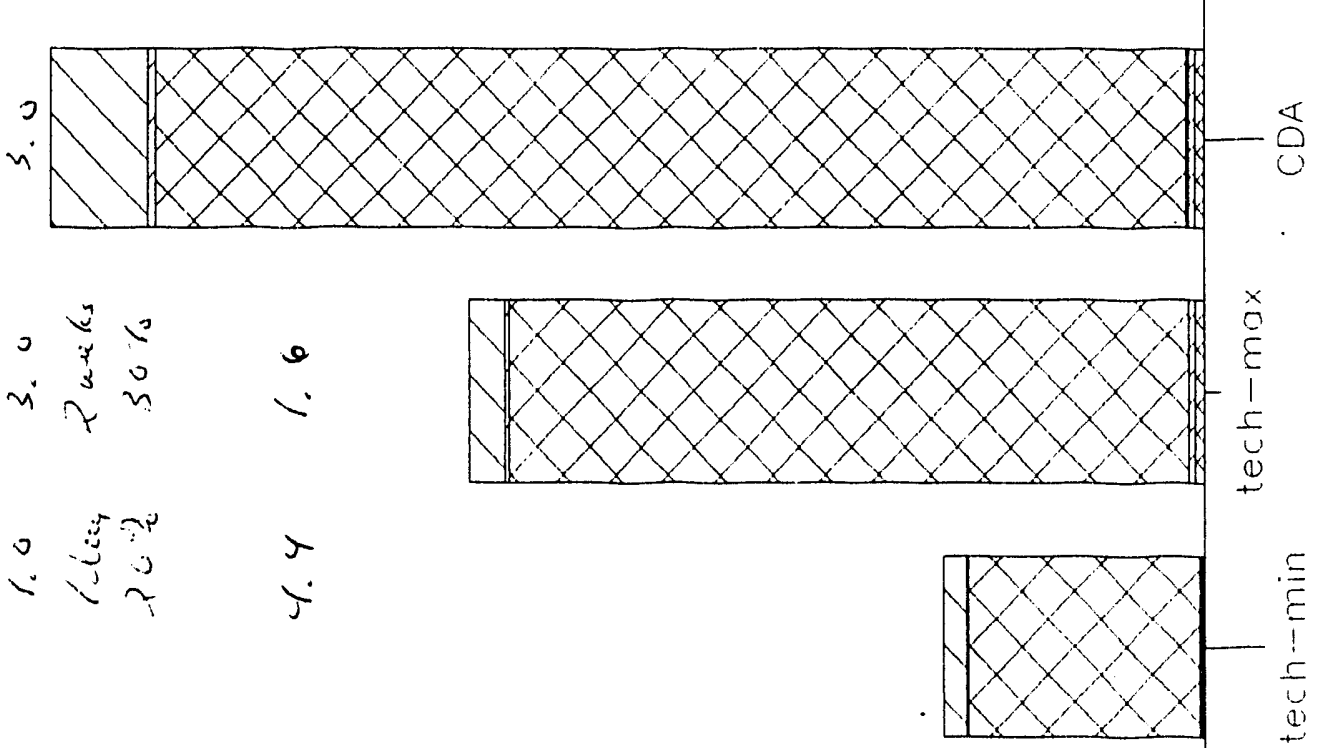

$\begin{array}{cc}\Xi & E \\ E & 0 \\ \frac{1}{ \pm} & 1 \\ 0 & 0\end{array}$

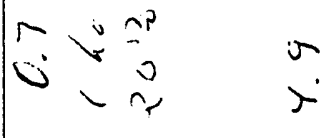

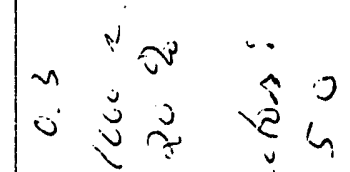

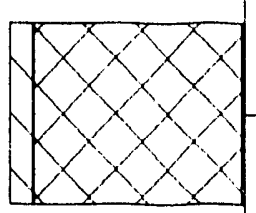

$\begin{array}{ll}x & \cdots \\ 0 & \cdots\end{array}$

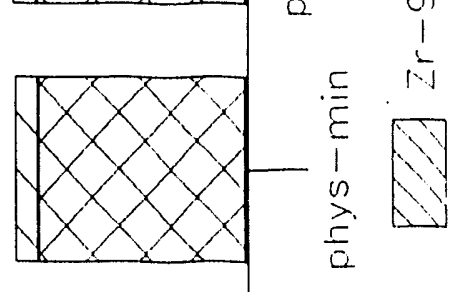

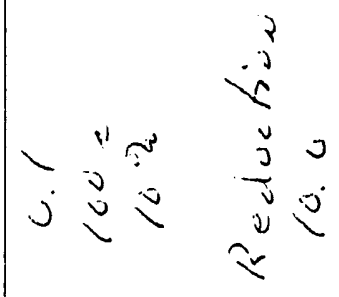

Xxy

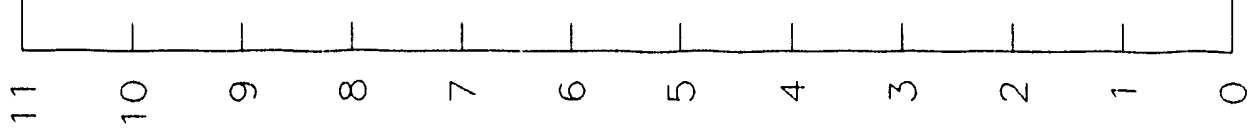

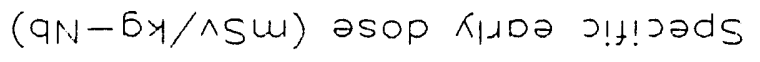




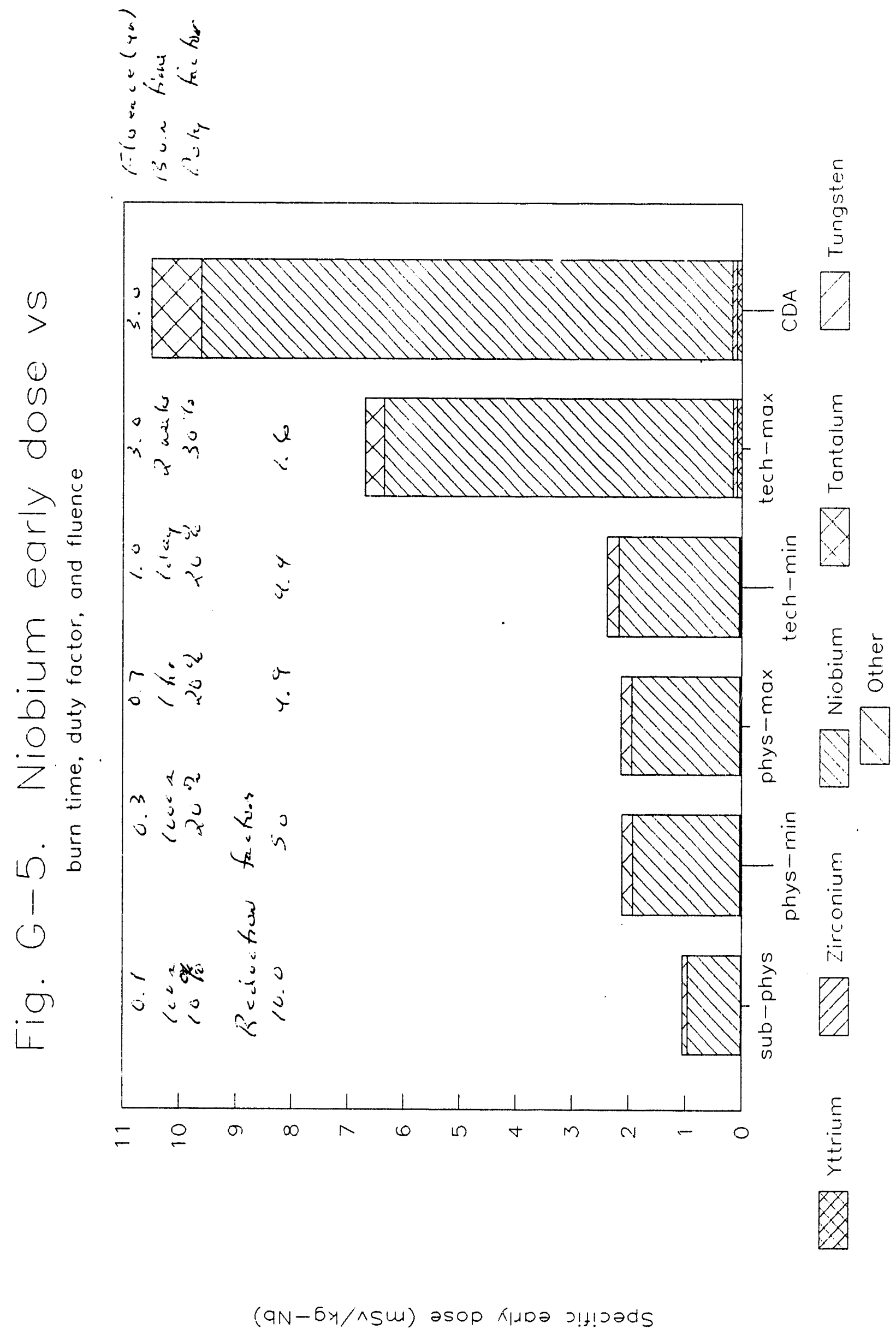




\section{DISTRIBUTION LIST}

H. M. Attaya (ANL)

C. C. Baker (ORNL)

S. J. Brereton (LLNL)

E. T. Cheng (TSI)

V. Chuyanov (KIAE/ITER)

I. Cook (Cutham)

M. L. Corradini (UW)

J. N. Doggett (LLNL)

T. J. Dolan (INEL)

T. J. Erickson (INEL), 4 copies publications processing

R. A. Forrest (Harwe11)

Y. Gohar (ANL)

D. L. Henderson (UW)

J. S. Herring (INEL)

S. K. Ho (UCB)

J. P. Holdren (UCB)

D. F. Holl and (INEL)

M. S. Kazimi (MIT)

B. N. Kolbasov (KIAE)

J. H. Nadler (DOE-ID)

G. R. Nardella (DOE-HQ)

R. F. Mattas (ANL)

K. A. McCarthy (INEL)

R. Parker (MIT/ITER)

J. M. Perlado (Instito de Fusion Nuclear)

L. J. Perkins (LLNL)

S. J. Piet (INEL)

Y. G. Prokofiev (Efremov)

J. Raeder (NET)

G. Saji (JAERI/ITER)

M. E. Sawan (UW)

Y. Seki (JAERI)

J. Selles (LLNL), I copy for U.S. ITER file

Y. S. Strebkov (RDIPE)

M. T. Tobin (LLNL)

Fusion Safety Program library, 15 copies 

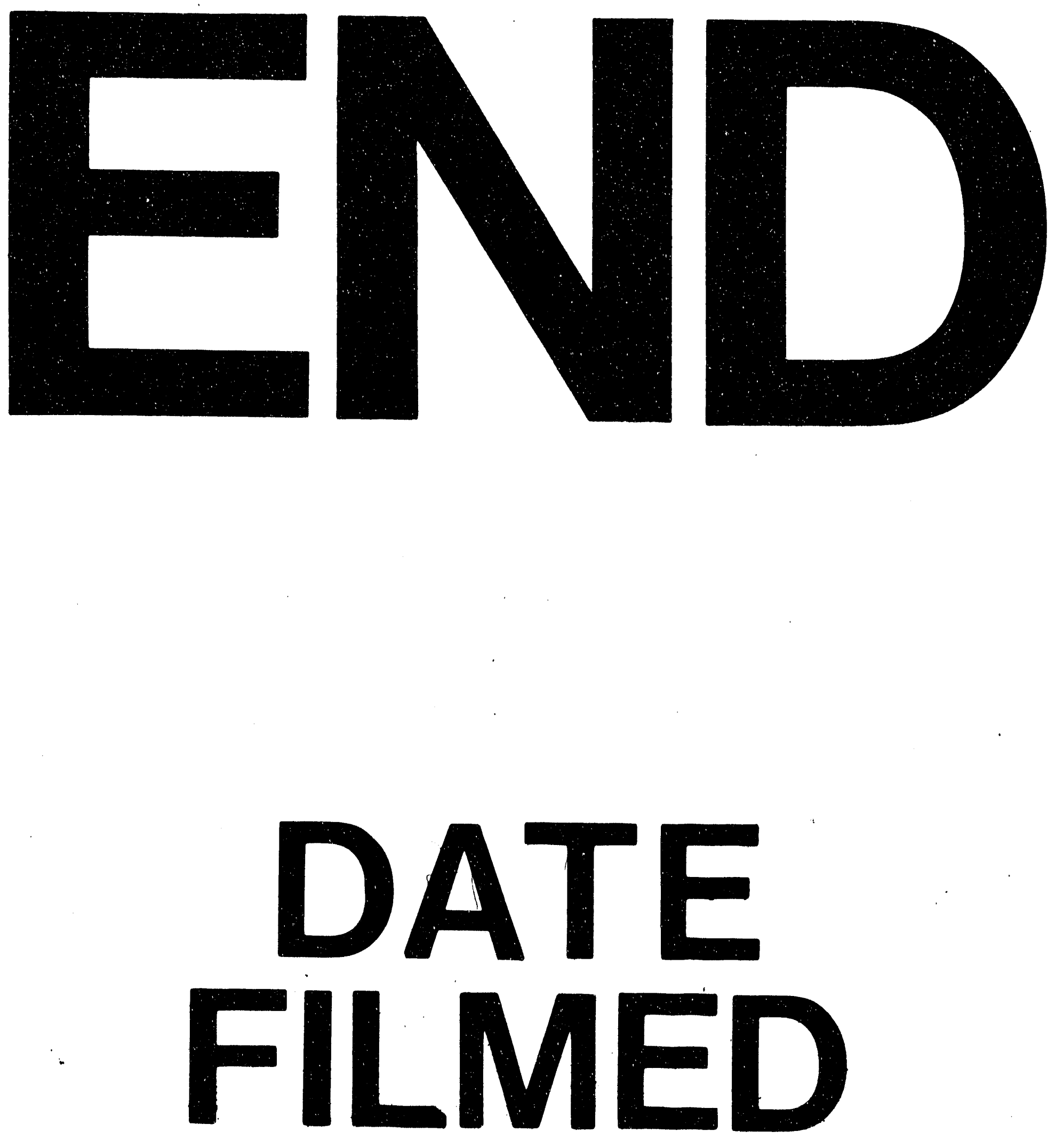

1

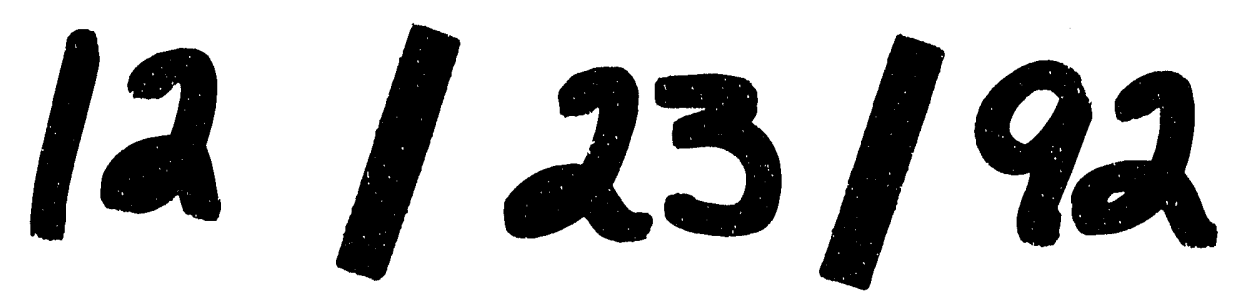


